\title{
Clearing the Air: The Impacts of Ambient Air Pollution on Environmental Equity
}

\author{
By \\ Robyn Chatwin-Davies
}

\begin{abstract}
A thesis submitted to the Faculty of Graduate and Postdoctoral Affairs in partial fulfillment of the requirements for the degree of
\end{abstract}

Masters of Applied Science

In

Environmental Engineering

Carleton University

Ottawa, Ontario

(C) 2018

Robyn Chatwin-Davies 


\begin{abstract}
The field of environmental equity investigates how environmental risk factors such as air pollution are associated with socioeconomic status (SES). This thesis examines current levels of inequity across income groups of the health risk caused by fine particulate matter $\left(\mathrm{PM}_{2.5}\right)$ air pollution, in New York City (NYC) and surrounding areas, and identifies emission control measures that can improve equity in this region.

Results show that inequity persists in NYC, with low-income populations facing greater health risk than their higher-income counterparts. Adjoint sensitivity analysis was used to identify emission control measures that carry the greatest influence on the current levels of environmental inequity. It was found that emission reductions have positive impacts on public health, but the impact on environmental equity depends on the average income where the reduction occurs. By considering the impacts on public health and environmental equity together, major improvements can be yielded through one air quality management strategy.
\end{abstract}




\section{Acknowledgements}

This thesis is here thanks to the hard work and support of countless people. First, l'd like to thank my supervisor Dr. Amir Hakami. Thank-you for taking a risk, by allowing me to explore a topic of which neither of us were familiar. Many thanks to the rest of my thesis examination committee: Dr. Colin Rennie and Dr. Thomas Walker. I truly appreciate the time and effort that goes into examining a thesis, and I know this work has benefitted from your consideration.

Thank-you to lyad Kheirbek and Kazuhiko Ito from the New York City Department of Health and Mental Hygiene, as well as Jay Haney and Sharon Douglas from ICF International, for so generously sharing your data set with me.

My work would not have been possible without the patient contribution of my colleagues. Endless thanks are owed to Shunliu Zhao, Burak Oztaner, Melanie Fillingham, Angèle Généreux, Marjan Soltanzadeh, Sina Voshtani, Amanda Pappin, Rabab Mashayekhi, Pedram Falsafi, Sahar Saeednooran, Natalie Linklater, and Shabnam Mizani. I would like to thank all those that helped with editing this document, especially Tim Kitz, Filzah Nasir, and Meagan Zettler. I now have a large collection of unemployed semi-colons ready for my next project.

Finally, I wouldn't be here without the love and support of my family and friends. I am a better person for you all. Thank-you from the bottom of my heart. 


\section{Table of Contents}

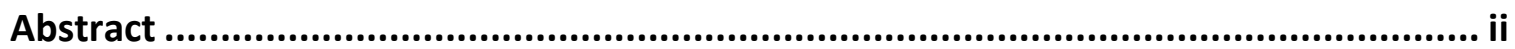

Acknowledgements ..................................................................................................... iii

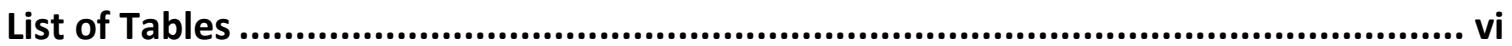

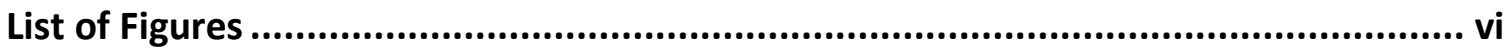

List of Abbreviations....................................................................................................iii

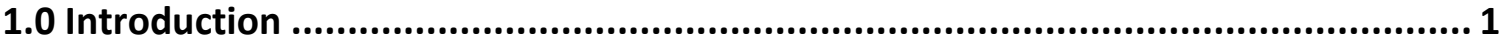

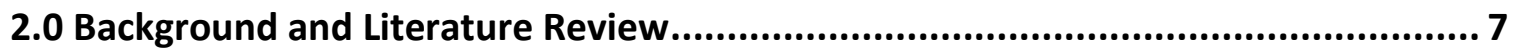

2.1 Justice, Equity, and Equality: A Note on Terminology....................................................

2.2 History of Environmental Justice....................................................................................

2.3 Air Pollution and Environmental Equity....................................................................11

2.3.1 Different Kinds of Air Pollution .........................................................................12

2.3.2 Methodologies for Assessing Air Pollution ............................................................. 14

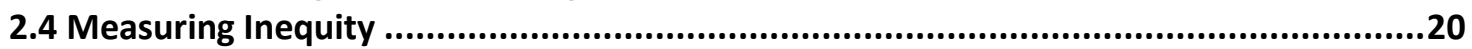

2.4.1 Lorenz Curve and Gini Coefficient......................................................................20

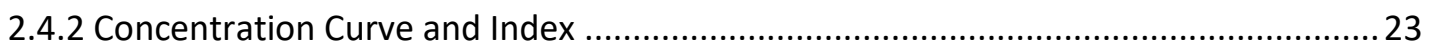

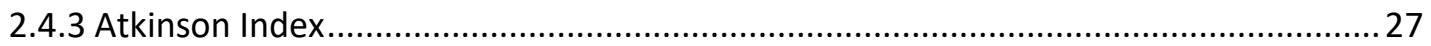

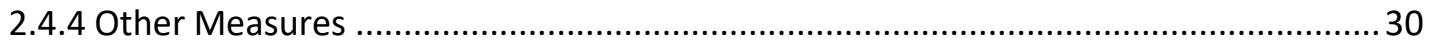

2.5 Health Impacts of Air Pollution ...............................................................................33

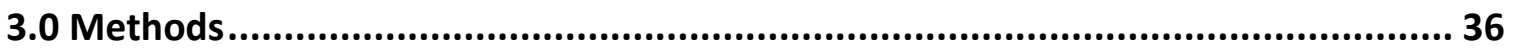

3.1 Atmospheric Chemical Transport Models ......................................................................36

3.2 The CMAQ Modelling system ...................................................................................39

3.3 Sensitivity Analysis .................................................................................................40

3.3.1 Forward Sensitivity Analysis .......................................................................... 41

3.3.2 Adjoint Sensitivity Analysis...............................................................................

3.4 Adjoint Cost Function ..............................................................................................44

3.4.1 Health Impacts Forcing Term ............................................................................. 45

3.4.2 Inequity Impacts Forcing Term............................................................................... 47

4.0 High-Resolution Air Quality Modelling in Support of Environmental Justice Studies

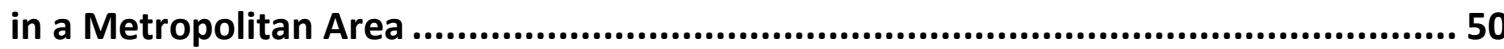

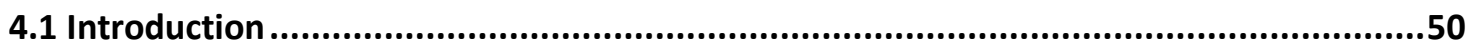

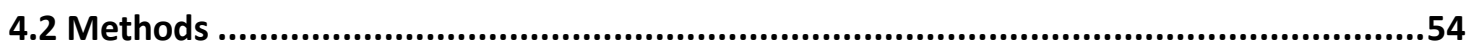

4.2.1 Health Impacts from Air Pollution Exposure...........................................................54

4.2.2 Measures of Environmental Inequality and Inequity..............................................55

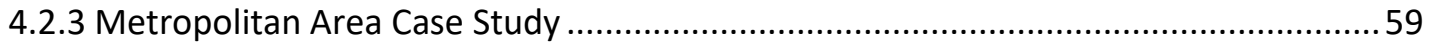

4.3 Results and Discussion.............................................................................................63

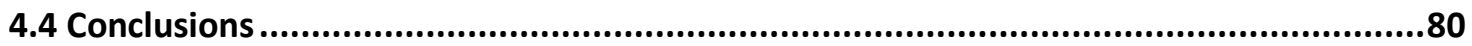


5.0 Quantifying Impacts of Emission Reductions on Environmental Justice and Human Health in New York City.................................................................................. 83

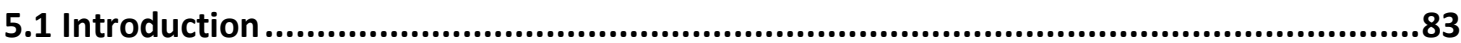

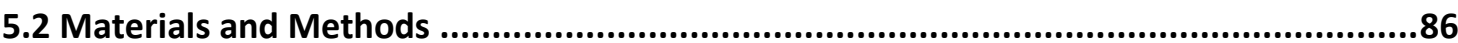

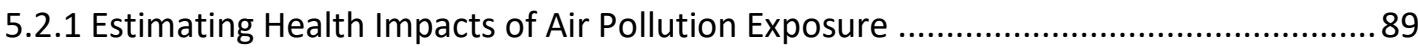

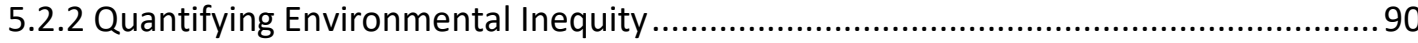

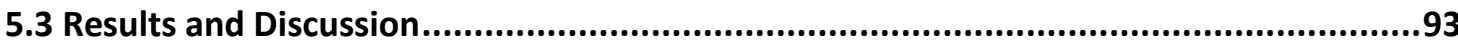

5.3.1 Coordinating Emission Reductions across Policy Endpoints ..................................... 101

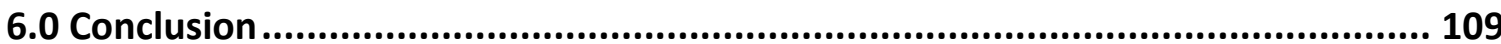

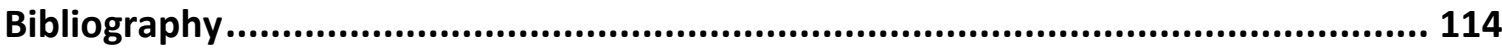

Appendix 1: Lorenz Curves for 8-Year LUR Dataset.......................................... 142

Appendix 2: Concentration Curves for 8-Year LUR Dataset .................................... 146

Appendix 3: Summary Tables for LUR Environmental Equity ............................... 150

Appendix 4: Marginal Health Benefits for Secondary PM2.5 Concentrations ............. 157 


\section{List of Tables}

Table 1. Income Distribution Categories Provided by the U.S. Census ........................... 62

Table 2. Environmental Justice Results for $\mathrm{PM}_{2.5}$ Health Risk ........................................ 68

Table 3. One-Sample t-test Results for Environmental Justice Analysis of LUR and CMAQ Results, 2008-2016. 69

Table 4. Share of Total Income and Total $\mathrm{PM}_{2.5}$ Health Risk by Income Group, for LUR year 2009 and CMAQ July 2008 ................................................................ 76

Table 5. Share of total income and total $\mathrm{PM}_{2.5}$ health burden by income group ........... 97

Table 6. Case Study Results, prioritizing different policy endpoints ............................. 107

Table 7. Share of Total Income and Total PM 2.5 Health Burden, for LUR Year 2010..... 150

Table 8. Share of Total Income and Total PM 2.5 Health Burden, for LUR Year 2011..... 151

Table 9. Share of Total Income and Total PM 2.5 Health Burden, for LUR Year 2012..... 152

Table 10. Share of Total Income and Total PM 2.5 Health Burden, for LUR Year 2013... 153

Table 11. Share of Total Income and Total PM 2.5 Health Burden, for LUR Year 2014 ... 154

Table 12. Share of Total Income and Total $\mathrm{PM}_{2.5}$ Health Burden, for LUR Year 2015... 155

Table 13. Share of Total Income and Total PM 2.5 Health Burden, for LUR Year 2016... 156

\section{List of Figures}

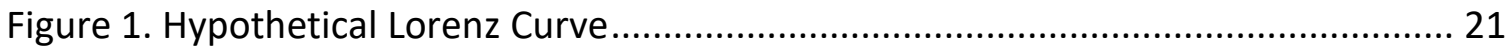

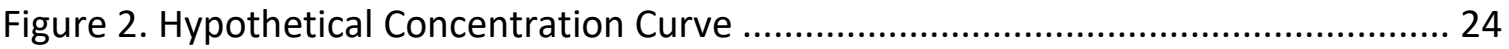

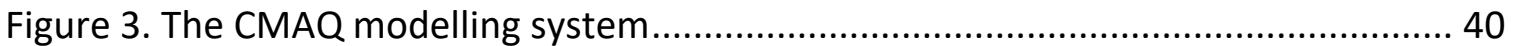

Figure 4. Map of domain used for LUR and CTM air pollution concentrations............... 60

Figure 5. NYC Households, as a percent of the total number of households ................. 63

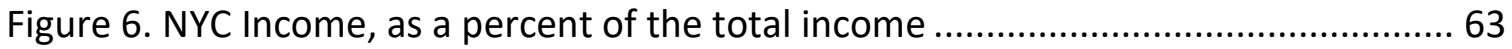

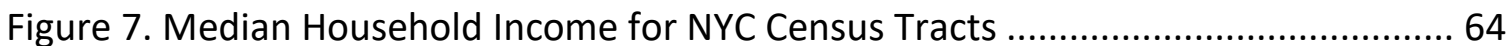

Figure 8. Average Annual PM2.5 Concentrations over 8 Years, from Land-Use

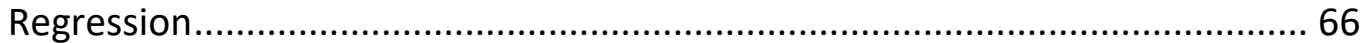

Figure 9. Average 2-week PM 2.5 Concentrations Generated by CMAQ ......................... 67

Figure 10. Lorenz Curve (A) and Concentration Curve (B) for Land-Use Regression

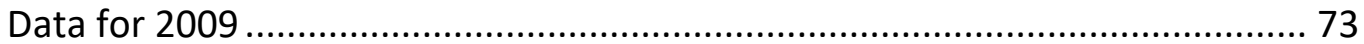

Figure 11. Lorenz Curve (A) and Concentration Curve (B) for CMAQ data

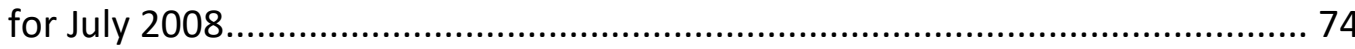

Figure 12. Temporal Trend in Inequality and Inequity of $\mathrm{PM}_{2.5}$ Health Risk for 8-years

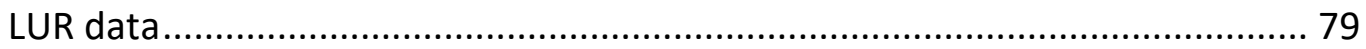

Figure 13. Modelling domain of New York City and surrounding areas......................... 87

Figure 14. Marginal Health Benefits from individual locations for a 1 tonne/year reduction in primary PM emissions ................................................................ 94

Figure 15. Concentration Curve for $\mathrm{PM}_{2.5}$ Health Burden Inequity ............................... 96 
Figure 16. Percent reduction in environmental inequity of $\mathrm{PM}_{2.5}$ health burden for a 1 tonne/year reduction in primary PM emissions.

Figure 17. Monetary equivalent of change in $\mathrm{PM}_{2.5}$ health burden inequity achieved by reducing 1 tonne/year primary PM emissions 100

Figure 18. Scatter plot showing the impact of reducing 1 tonne/year of primary PM emissions at each location in the modelling domain 102

Figure 19. Ranking of effectiveness of primary PM emission reductions on health and equity endpoints 103

Figure 20. Monetized benefit of reducing 1 tonne/year primary PM emissions, when considering combined benefits of reduced $\mathrm{PM}_{2.5}$ mortality, as well as improved equity of $\mathrm{PM}_{2.5}$ health burden across income groups ................... 105

Figure 21. Lorenz Curve for Land-Use Regression Data for 2009 ................................. 142

Figure 22. Lorenz Curve for Land-Use Regression Data for 2010 ............................... 142

Figure 23. Lorenz Curve for Land-Use Regression Data for 2011 ............................... 143

Figure 24. Lorenz Curve for Land-Use Regression Data for 2012 ................................ 143

Figure 25. Lorenz Curve for Land-Use Regression Data for 2013 ............................... 144

Figure 26. Lorenz Curve for Land-Use Regression Data for 2014 ................................ 144

Figure 27. Lorenz Curve for Land-Use Regression Data for 2015 ............................... 145

Figure 28. Lorenz Curve for Land-Use Regression Data for 2016 ............................... 145

Figure 29. Concentration Curve for Land Use Regression Data for 2009...................... 146

Figure 30. Concentration Curve for Land Use Regression Data for 2010 ...................... 146

Figure 31. Concentration Curve for Land Use Regression Data for 2011 .................... 147

Figure 32. Concentration Curve for Land Use Regression Data for 2012 ..................... 147

Figure 33. Concentration Curve for Land Use Regression Data for 2013 ...................... 148

Figure 34. Concentration Curve for Land Use Regression Data for 2014 ..................... 148

Figure 35. Concentration Curve for Land Use Regression Data for 2015 ..................... 149

Figure 36. Concentration Curve for Land Use Regression Data for 2016 ...................... 149

Figure 37 Marginal Health Benefits from individual locations for a 1 tonne/year reduction in $\mathrm{SO}_{2}$ emissions 


\section{List of Abbreviations}

- ADE: Atmospheric Diffusion Equation

- AQM: Air Quality Model

- BCON: Boundary Conditions Processor

- BENMAP: Environmental Benefits Mapping and Analysis Program

- BMR: Baseline Mortality Rate

- CAMx: Comprehensive Air Quality Model with Extensions

- CMAQ: Community Multiscale Air Quality modelling system

- CTM: Chemical Transport Model

- EPA: Environmental Protection Agency

- HIW: High-income whites

- ICON: Initial Conditions Processor

- JPROC: Photolysis Rate Processor

- LGBTQ: Lesbian, gay, bisexual, transgender, and queer

- LIN: Low-income non-whites

- LUR: Land-use regression

- MCIP: Meteorology Chemistry Interface Processor

- NATA: National-scale Air Toxics Assessment

- NPRI: National Pollutant Release Inventory

- NYC: New York City

- PCB: Polychlorinated biphenyl

- PM: Particulate matter

- $\mathrm{PM}_{2.5}$ : Fine Particulate Matter (having a size of $<2.5 \mu \mathrm{m}$ )

- RSEI: Risk-Screening Environmental Indicators model

- SES: Socio-economic status

- SMOKE: Sparse Matrix Operator Kernel Emissions model

- TRI: Toxics Release Inventory

- UCC: United Church of Christ

- U.S.: United States of America

- WRF: Weather Research and Forecasting 


\subsection{Introduction}

The central tenet of environmental justice is that all people have an equal right to be protected from environmental hazards and to participate in the decision-making process to developing environmental laws, regulations, or policies regardless of background or socio-economic status (SES) (U.S. Environmental Protection Agency, 2017b). Society places intrinsic value on environmental justice, and many fundamental legal documents uphold the principle that every person has a right to a clean and safe environment (Boyce, Zwickl, \& Ash, 2015). Within environmental justice literature, there is a primary concern with environmental equity, which refers to the distribution of environmental risks across various segments of a population. Studies in environmental equity are concerned with the relationship between the environment, demographics, and SES. SES can include a variety of indicators, such as income, education, employment, or wealth. The fundamental question addressed in environmental equity research is whether environmental hazards impact the population differently, and whether these impacts are concentrated within lower-SES communities.

Ambient air pollution is a significant global health concern and is associated with many adverse health effects on human populations. In a recent global burden of disease study by Forouzanfar et al. (Forouzanfar et al., 2016), it was estimated that ambient air pollution accounts for nearly 4.5 million premature deaths every year, with 4.2 million deaths attributable to ambient particulate matter (PM) pollution, and 250,000 deaths 
attributable to ambient ozone $\left(\mathrm{O}_{3}\right)$ pollution alone. With a growing global awareness of air pollution as a primary health concern, there is a strong imperative to reduce ambient air pollution and its impacts on human health.

Air pollution is unique as an environmental risk since exposure varies highly in space, and is not subject to geopolitical borders. Furthermore, population centres and urban areas are particularly affected by air pollution (Miranda, Edwards, Keating, \& Paul, 2011), resulting in impacts across a wide demographic of people, with varying SES. As a result, the serious adverse health effects of air pollution exposure are not distributed evenly across the population.

Previous environmental equity studies find that lower-SES populations tend to be exposed to worse ambient air pollution, which is compounded with their vulnerability and greater susceptibility to environmental hazards (Clark, Millet, \& Marshall, 2014). As researchers and policy makers, it is important that we can assess the current levels of environmental equity across a domain, as related to a variety of air pollutants.

Once current levels of ambient air pollution and inequity are quantified, it is also of interest to assess how the situation might be improved. Air pollution and its distributed impacts on human health and environmental equity come from emissions, as well as processes out of our control such as atmospheric transport and chemistry. In order to 
have an impact on ambient air pollution, and on human health and equity, our best option is to control emissions.

However, not all emission controls are of equal impact. Depending on the timing and location of various pollutant emissions, the downwind concentrations and impacts can change considerably. Sensitivity analysis is a tool that can be used to better understand the relationship between emission sources and receptor impacts. In this thesis, sensitivity analysis is used to estimate how concentrations of ambient air pollution, and subsequent public health impacts, are influenced by changes in emissions. By including information on epidemiology, economics, and SES into air quality models, we can assess how reducing emissions at various locations and times might impact the landscape of environmental equity and human health across a domain.

Sensitivity analysis provides information on the effectiveness of various emissions reductions that are targeted at a desired policy endpoint. Typical policy endpoints include meeting attainment of air quality standards, and prioritize the most costeffective emission reductions to meet these goals. Less common are policy endpoints that target human health, or the distribution of air pollution impacts across a population (i.e. environmental equity). By providing an analysis centred on human health and environmental equity, emission reductions can be targeted to better meet these goals. 
Furthermore, this information can be used to target emission reductions that will have synergistic benefits across multiple policy items.

At the intersection of air quality modelling, human health, and environmental equity, this thesis attempts to answer the following questions:

1. How can atmospheric chemical transport models be used to assess the current levels of environmental equity in a metropolitan area?

2. How does the assessment of environmental equity change depending on the inequity metric and air pollution data selected?

3. What are the spatial and temporal patterns of effective emission reductions that can be used to improve human health and environmental equity?

4. How can air quality management strategies be designed to meet both health and equity goals?

This thesis is structured around two manuscripts that address these research questions. In order to establish the context for this work in greater detail, Chapter 2 provides a review of the major literature that informs this thesis. This literature review focusses on the major bodies of literature surrounding air pollution and its impacts on human health and environmental equity. Chapter 3 discusses the methods used to address the research questions. While these methods are expanded upon in the manuscripts presented later, this chapter provides a more in-depth description of the modelling 
system, and the data that is used to inform the model. The results of the research are presented in the form of draft manuscripts in Chapters 4 and 5.

The draft manuscript in chapter 4 seeks to address the use of atmospheric chemical transport models in environmental equity analyses. Using a refined 1-km resolution model of New York City (NYC) and the surrounding areas, current levels of environmental equity are assessed. This paper looks at the relationship between household income (as an indicator of SES), and air pollution in the form of $\mathrm{PM}_{2.5}$ concentrations. Multiple different environmental equity indicators are also used, and analysis is provided as to the challenges of assessing current levels of environmental equity in a metropolitan area.

Chapter 5 is a draft manuscript that addresses how emission reductions might be used to tackle the impacts of air pollution on human health and environmental equity. Using the same 1-km modelling domain over NYC, adjoint sensitivity analysis is used to calculate the influence of emission reductions on health and equity endpoints. In this manuscript, analysis is focussed around the impacts of $\mathrm{PM}_{2.5}$ concentrations, and SES is measured through household income. Furthermore, this paper examines how sensitivity information can be used to coordinate air quality management strategies to address multiple goals, including a case study of emission reductions in NYC. 
Chapter 6 summarizes the main conclusions of the research presented in the thesis, and addresses limitations and future work. Overall, this thesis contributes original research at the intersection of air quality modelling, human health, and environmental equity, toward ensuring that all people have access to improved air quality. 


\subsection{Background and Literature Review}

\subsection{Justice, Equity, and Equality: A Note on Terminology}

Within the literature in the field of environmental justice, terminology is not always standardized. As a result, terms such as "environmental justice", "environmental equity", and "environmental equality" are used interchangeably, or the distinguishing features are unclear. This section explains the terminology as it will be used in this thesis.

In general, "environmental justice" refers to the social movement concerned with ensuring that all people are equally and fairly protected from environmental hazards and can participate in the development of environmental regulations and policies. The U.S. EPA defines environmental justice as follows:

Environmental justice is the fair treatment and meaningful involvement of all people regardless of race, color, national origin, or income, with respect to the development, implementation, and enforcement of environmental laws, regulations, and policies.

EPA has this goal for all communities and persons across this nation. It will be achieved when everyone enjoys:

- the same degree of protection from environmental and health hazards, and

- equal access to the decision-making process to have a healthy environment in which to live, learn, and work.

(U.S. Environmental Protection Agency, 2017b)

When referring to this social movement, or the field as a whole, the term "environmental justice" is used. However, within the field of environmental justice, there is a set of literature particularly concerned with the distribution of environmental 
hazards across a population, and how this is correlated with SES. This is known as "environmental equity", and is the primary term used in this thesis.

Within the literature, "environmental equality" is often used interchangeably with "environmental equity", however this thesis distinguishes the two terms. Environmental equality does not consider SES, and is only concerned with having environmental hazards distributed exactly equally across a population. On the other hand, environmental equity is concerned with SES, and is primarily interested in minimizing the environmental hazards of low-SES communities (University of Washington, 2018). In this thesis, any reference made to research that focusses on the relationship between environmental hazards and SES will use the term "environmental equity", while research that does not consider SES will use the term "environmental equality".

\subsection{History of Environmental Justice}

Dr. Robert Bullard, often called the "father of environmental justice", wrote that "whether by conscious design or institutional neglect, communities of color in urban ghettos, in rural 'poverty pockets', or on economically impoverished Native-American reservations face some of the worst environmental devastation in the nation" (Bullard, 1993). The history of environmental justice as a movement began with these communities. The movement was started by individuals, primarily people of colour, who were concerned about the environmental risks being faced by their communities. 
Some of the first reports of environmental injustice appeared in the 1960s and 1970s. For example, in the second annual report of the Council on Environmental Quality (1971), an entire chapter is dedicated to examining environmental problems in "The Inner city Environment". The report explained the existence of the chapter by noting that "special attention this year should be given to the inner city where many of our most severe environmental problems interact with social and economic conditions which the Nation is also seeking to improve" (ibid, p. 189).

The catalyst for the broader social movement of environmental justice is widely recognized as the activism against the polychlorinated biphenyl (PCB) landfill in Warren County, North Carolina. As described in Agyeman's review on environmental justice (Agyeman, Schlosberg, Craven, \& Matthews, 2016), over 400 activists were arrested for a peaceful sit-in demonstration against the siting of a PCB landfill in a predominantly low-SES neighbourhood. Prompted by the sit-ins, the United States General Accounting Office conducted a study called "Siting of Hazardous Waste Landfills and Their Correlation with Racial and Economic Status of Surrounding Communities" (United States General Accounting Office, 1983), to examine whether the claims made by activists at Warren County were true. Using the 1980 census data, the study found that $75 \%$ of the hazardous waste landfills examined were found in predominantly low-SES neighbourhoods, disproportionately affecting African American populations. 
The terms "environmental justice" and "environmental racism" first appeared in a study published by the United Church of Christ (UCC) Commission for Racial Justice (1987). Again, while examining hazardous waste sites and the communities surrounding them, the study found that there was a strong correlation between low-SES communities and environmental risks. The study found that 14 million African Americans and 8 million Hispanics, as well as $50 \%$ of all Native Americans, lived near a toxic waste site.

These two reports gave considerable weight to the claims that lower-SES populations were being exposed to greater environmental risks. Many of the recommendations from the 1987 UCC report were adopted following its publication. In November 1992, the U.S. Environmental Protection Agency (EPA) created the Office of Environmental Equity (now named the "Office of Environmental Justice"). In 1993, the National Environmental Justice Advisory Council was established, and began to hold public meetings on environmental justice across the United States (U.S. Environmental Protection Agency, 2017b). In 1994, President Clinton signed Executive Order 12898, which stated that "each Federal agency shall make achieving environmental justice part of its mission by identifying and addressing, as appropriate, disproportionately high and adverse human health or environmental effects... on minority populations and low income populations" (Agyeman et al., 2016). 
With a growing political interest in environmental justice, researchers turned their attention to the quantification of environmental justice across the United States. Early studies focussed on the correlation between SES and the proximity to hazardous waste sites (United Church of Christ Commission for Racial Justice, 1987; United States General Accounting Office, 1983). With technological advancement and growth in this research area, findings continued to show that low-SES communities were disproportionately affected by environmental hazards (Bullard, Mohai, Saha, \& Wright, 2008; Mohai \& Saha, 2006). Within this growing body of research, this thesis will focus on studies related specifically to ambient air pollution.

\subsection{Air Pollution and Environmental Equity}

The distribution of air pollution across varying SES groups has been a concern since the beginning of the environmental justice movement. When the Council on Environmental Quality report examined environmental risks faced by urban low income communities, they explicitly identified that "Air pollution, a problem for nearly all of the Nation, lays its pall most heavily over the inner city in many metropolitan areas" (Council on Environmental Quality, 1971, p. 189).

There are many different overlapping themes that can be used to distinguish the vast amount of literature on air pollution and environmental equity. The types of pollutants 
examined, and how these pollutants are apportioned on to the population are two key distinguishing features in the literature.

\subsubsection{Different Kinds of Air Pollution}

Within the environmental equity and air pollution literature, studies differ significantly on how to characterize air pollution. Many of the earlier environmental justice studies looked at the populations that live in proximity to industrial sources of air pollution. In U.S. studies, this is most often approximated using the U.S. EPA Toxics Release Inventory (TRI) (Abel, 2008; Chakraborty \& Zandbergen, 2007; Fisher, Kelly, \& Romm, 2006;

Grineski \& Collins, 2010; Maantay, 2007; Pastor, Sadd, \& Morello-Frosch, 2002, 2004b, 2004a; Perlin, Wong, \& Sexton, 2001; Stuart, Mudhasakul, \& Sriwatanapongse, 2009), or the EPA's Risk-Screening Environmental Indicators (RSEI) model (Abel \& White, 2011; Ash \& Boyce, 2011; Ash \& Fetter, 2004; Conley, 2011; Downey, Dubois, Hawkins, \& Walker, 2008; Downey \& Hawkins, 2008; Grant, Trautner, Downey, \& Thiebaud, 2010; Mohai, Kweon, Lee, \& Ard, 2011; Sicotte \& Swanson, 2007), which is based off the Toxics Release Inventory. In Canada this is usually approximated with the National Pollutant Release Inventory (NPRI) (Premji, Bertrand, Smargiassi, \& Daniel, 2007), and similar studies exist internationally as well (Grineski \& Collins, 2008; Grineski, Collins, Aguilar, \& Aldouri, 2010; Laurian, 2008). 
A typical study using point source data would be Fisher, Kelly, and Romm's study in West Oakland, California (Fisher et al., 2006). In this study they examined the spatial pattern of facilities identified in the U.S. EPA's Toxics Release Inventory. The authors integrated a basic dispersion model with the TRI to estimate the number of people that could be potentially impacted by the emissions from the point sources. The authors found that the disproportionately polluted areas had demographics that were predominantly low-income and high-minority.

A significant number of U.S. studies draw on the EPA's National-scale Air Toxics Assessment (NATA) (Apelberg, Buckley, \& White, 2005; Chakraborty, 2009, 2012; Chakraborty, Collins, Grineski, Montgomery, \& Hernandez, 2014; Collins, Grineski, \& Chakraborty, 2015; Collins, Grineski, Chakraborty, \& McDonald, 2011; Gilbert \& Chakraborty, 2011; Grineski \& Collins, 2010; Grineski, Collins, \& Chakraborty, 2013; Grineski, Collins, Chakraborty, \& McDonald, 2013; Grineski, Collins, Chakraborty, \& Montgomery, 2014; Grineski \& McDonald, 2011; James, Jia, \& Kedia, 2012; Linder, Marko, \& Sexton, 2008; Pastor, Morello-Frosch, \& Sadd, 2005, 2006; Young et al., 2012). The U.S. EPA NATA model "provides estimates of the risk of cancer and other serious health effects from breathing (inhaling) air toxics" (U.S. Environmental Protection Agency, 2017c). NATA is classically used for case studies in a single metropolitan area. A typical example of NATA's usage is Chakraborty's study on the cancer risk from hazardous air pollution exposure in Tampa Bay, Florida (Chakraborty, 2012). In this 
work, estimates of lifetime cancer risk were drawn from the 1999 NATA model, and were compared with U.S. census data. Multiple regression and spatial regression models were used to analyze the relationship between cancer risk and SES. The study found that race, ethnicity, and home ownership were correlated with cancer risk from a variety of sources of hazardous air pollution.

As the field of environmental equity has progressed, many studies have moved toward quantifying ambient concentrations of various air pollutants. This allows for more direct estimates of the concentrations across the entire population, regardless of proximity to particular sources. How these concentrations are quantified also provides a significant division in the literature.

\subsubsection{Methodologies for Assessing Air Pollution}

In order to obtain a spatial distribution of concentrations across an area of interest, researchers must use one of several methodologies. Many studies relied on interpolating between monitoring sites. Many studies in the Los Angeles area interpolated between monitors to generate a surface of concentrations of $\mathrm{PM}_{2.5}$ (Anderson et al., 1978; Brajer \& Hall, 2005; Molitor et al., 2011; Su et al., 2009; Su, Jerrett, Morello-Frosch, Jesdale, \& Kyle, 2012) and ozone (Brajer \& Hall, 2005). This was done, in part, due to a small number of government monitoring sites, and because $\mathrm{PM}_{2.5}$ varied over a larger area than other pollutants (such as $\mathrm{NO}_{2}$, for which land-use 
regression is generally preferred). A similar geostatistical interpolation was used for several state and national studies to generate concentrations of $\mathrm{PM}_{2.5}$ (Bell \& Ebisu, 2012; Miranda et al., 2011), $\mathrm{NO}_{2}$ (Clougherty et al., 2007), and ozone (Hackbarth, Romley, \& Goldman, 2011). Interpolation was used similarly in Canadian metropolitan areas for $\mathrm{PM}_{2.5}$ (Buzzelli \& Jerrett, 2003, 2004), or other pollutants including $\mathrm{CO}, \mathrm{SO}_{2}$, and $\mathrm{NO}_{\mathrm{x}}$ (Adams, DeLuca, Corr, \& Kanaroglou, 2012); this method has been used in China (Brajer, Mead, \& Xiao, 2010) and Europe as well (Brainard, Jones, Bateman, Lovett, \& Fallon, 2002; Branis \& Linhartova, 2012).

One of the earliest examples of this is a study by Anderson et al. (1978), which examined whether there was any correlation between socio-economic status and air pollution in the Los Angeles area. Researchers took census data from the 1970 census, as well as pollution information from 11 air pollution monitors across the Los Angeles area. They did not find a strong correlation with SES. Their findings indicated that air quality improved slightly with a combined metric of education, income, rental level, and housing value. Perplexingly, they also found that black people breathed slightly better air quality than white people. However, their research was severely limited by only having 11 data points for air pollution across the entirety of Los Angeles. This work built off similar work by Van Arsdol (1966), which examined earlier census data sets for the 1950s and 1960s. 
Land-use regression (LUR) is another popular method of deriving concentration surfaces. For the same studies that used geostatistical interpolation of $\mathrm{PM}_{2.5}$ monitors in Los Angeles, LUR was preferred to generate $\mathrm{NO}_{2}$ concentration surfaces in the same area (Molitor et al., 2011; Su et al., 2009, 2012). This was done because $\mathrm{NO}_{2}$ has a high spatial variation, especially in and around roadways. Similar LUR procedures were used to generate concentrations of $\mathrm{NO}_{2}$ in Ottawa (Parenteau \& Sawada, 2012), Montreal (Carrier, Apparicio, Séguin, \& Crouse, 2014a, 2014b, 2016; Crouse, Ross, \& Goldberg, 2009), Toronto (Buzzelli \& Jerrett, 2007), Vancouver (Pinault, Crouse, Jerrett, Brauer, \& Tjepkema, 2016), Seattle (Su, Larson, Gould, Cohen, \& Buzzelli, 2010), London (Goodman, Wilkinson, Stafford, \& Tonne, 2011), and Northern Spain (FernándezSomoano, Hoek, \& Tardon, 2013).

Satellite data can also be used with LUR to generate concentrations surfaces over a larger geographical area. This was done for $\mathrm{PM}_{2.5}$ and $\mathrm{NO}_{2}$ in Massachusetts (Rosofsky, Levy, Zanobetti, Janulewicz, \& Fabian, 2018); $\mathrm{NO}_{2}$ across Western Europe (Temam et al., 2017); $\mathrm{NO}_{2}, \mathrm{PM}_{10}$, and $\mathrm{PM}_{2.5}$ in Wales (Brunt et al., 2016); $\mathrm{PM}_{2.5}$ across Canada (Pinault, van Donkelaar, \& Martin, 2017), and for $\mathrm{NO}_{2}$ across the United States (Clark et al., 2014; Clark, Millet, \& Marshall, 2017).

The dataset generated by Clark, Millet, and Marshall $(2014,2017)$ has been of great significance to environmental justice literature. In these publications, the authors 
analyzed a LUR dataset for the continental United States, which gave concentrations of $\mathrm{NO}_{2}$ at a $1 \mathrm{~km}$ resolution. This high-resolution dataset across the entire country was unprecedented, and allowed for an important analysis on country-wide levels of inequality, where previous studies could only focus on specific metropolitan areas. In their 2014 study, the authors found that $\mathrm{NO}_{2}$ concentrations were $4.6 \mathrm{ppb}$ (38\% relative difference) higher for non-whites than whites across the U.S., and that low-income nonwhite young and elderly people were disproportionately exposed to high concentrations of $\mathrm{NO}_{2}$. In their 2017 study, the authors examined changes in $\mathrm{NO}_{2}$ air pollution across the U.S. from 2000 to 2010. They found that $\mathrm{NO}_{2}$ concentrations decreased for the entire U.S. population, but that inequality persisted both by race and income. For example, the authors found that $\mathrm{NO}_{2}$ concentrations remained $2.9 \mathrm{ppb}$ (31\% relative difference) greater for non-whites when compared to whites in 2010.

Fewer studies use air quality models to generate a surface of concentrations. The most common use of air quality models is the use of atmospheric dispersion models. Some studies have used AERMOD (Chaix et al., 2017; Cohan, Wu, \& Dabdub, 2011; Maroko, 2012; Martenies, Milando, Williams, \& Batterman, 2017; Poorfakhraei, Tayarani, \& Rowangould, 2017; Pratt, Vadali, Kvale, \& Ellickson, 2015; Tayarani, Poorfakhraei, Nadafianshahamabadi, \& Rowangould, 2016), and some other less common dispersion models are used as well (Fan, Lam, \& Yu, 2012; Havard, Deguen, Zmirou-Navier, Schillinger, \& Bard, 2009; Levy, Greco, Melly, \& Mukhi, 2009). Even fewer studies have 
used Chemical Transport Models (CTMs). The literature review to date has found only three studies that used the Comprehensive Air Quality Model with Extensions (CAMx) (Marshall, Swor, \& Nguyen, 2014; Nguyen \& Marshall, 2018), and the Community Multiscale Air Quality (CMAQ) modelling system (Fann et al., 2011). These studies examined how changes in emissions will change environmental inequity, and two are discussed in more detail.

Fann et al. (2011) examined two different air quality management policies for the City of Detroit. They examined a "status-quo" (SQ) policy based on a pollutant-by-pollutant approach to meet air quality targets, as well as a "multipollutant risk-based" (MP/RB) strategy, using multipollutant emission reductions that maximize overall health benefits from reduced air pollution. Previous studies showed that the MP/RB strategy is much more cost-effective than the SQ strategy, giving nearly double the benefits for only a slightly higher cost. In this work, they examined the environmental justice consequences of prioritizing cost-efficiency in an air quality management strategy. They modelled changing levels of $\mathrm{PM}_{2.5}$ across Detroit using $\mathrm{CMAQ}$, and applied a measure of inequality (the Atkinson Index) to examine environmental equality for $\mathrm{PM}_{2.5}$ mortality and asthma risk across the population. Results showed that the MP/RB strategy delivers a $0.191 \%$ reduction in mortality risk inequality, and a $2.241 \%$ reduction in asthma risk inequality. The status quo (SQ) strategy gave a $0.026 \%$ reduction in morality risk inequality, and a 0.053\% increase in asthma risk inequality. Thus, for the case of Detroit, the authors 
found that there are synergistic benefits to reducing air quality using a multi-pollutant risk-based (MP/RB) strategy, since environmental inequality is also effectively reduced through this approach.

Marshall, Swor, and Nguyen's study (2014) also examined the potential trade-offs between efficiency and equity when reducing emissions, with a focus on the South Coast Air Basin in Southern California. Their case study examined the impact of a 10\% emission reduction in five different source categories: on-road mobile, off-road mobile, ships, trains, and stationary. Each scenario was modelled in CAMx, generating a surface of diesel PM concentrations. For each emission reduction scenario, the authors evaluated four different impacts, considering public health burden, emission reduction efficiency, equality of exposure among all people, and the difference between average exposure for high-income whites (HIW) and low-income non-whites (LIN). Each of these goals was given a shorthand name: "impact", "efficiency", "equality", and "justice", respectively. The authors found that there are some trade-offs depending on the policy goal that is being pursued. For example, a $10 \%$ emission reduction from ship emissions would improve public health, but cause an increase in the levels of inequality. Alternatively, a $10 \%$ emission reduction from trains carried the highest benefits for efficiency, equality, and justice. This paper is significant since it explored the complexity of multiple policy goals, and how air quality management strategies can have unexpected impacts on one or more of these goals. 


\subsection{Measuring Inequity}

There are several competing indices that can be used to quantify environmental inequity. This section describes several of the popular indices that are used in significant works in the environmental justice literature.

\subsubsection{Lorenz Curve and Gini Coefficient}

The most commonly used measure of environmental inequality is the Gini Coefficient (Gastwirth, 1972; Levy, Chemerynski, \& Tuchmann, 2006). The Gini Coefficient measures deviation from a scenario of perfect equality, and is a summary statistic based on the Lorenz curve. The Lorenz curve plots the percentage of the total measure of interest (such as income, or pollution exposure) earned by the cumulative percentage of the population (Gastwirth, 1972). The Lorenz curve shows the proportion of the overall unit of interest assumed by the bottom fraction of the population. Figure 1 shows a hypothetical Lorenz Curve. 


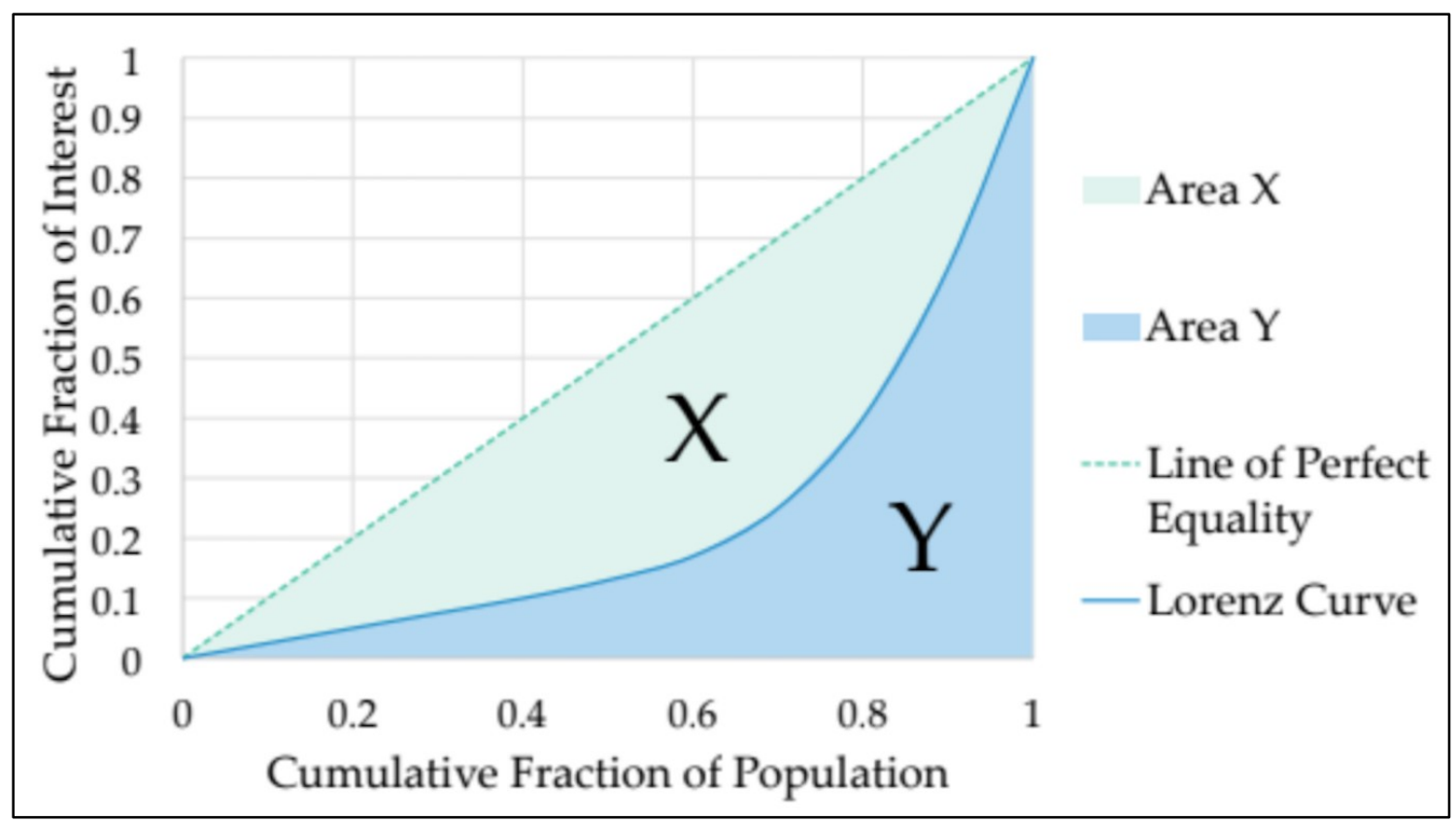

Figure 1. Hypothetical Lorenz Curve

Consider the example of income inequality. In a scenario of perfect equality, the poorest $10 \%$ should hold $10 \%$ of the income, or the poorest $50 \%$ to hold $50 \%$ of the income, and so on. The "Line of Perfect Equality" in Figure 1 represents this. The Lorenz curve then plots the true levels of income inequality seen in a population, where Figure $1 \mathrm{might}$ show that the poorest $40 \%$ of households hold $10 \%$ of the overall income.

The Gini Coefficient $(G)$ is a summary statistic based on the Lorenz curve, and is equivalent to the area between the Lorenz Curve and line of perfect equality (marked X on Figure 1), divided by the total area under the line of perfect equality (or the sum of $X$ $+Y$ on Figure 1). The Gini Coefficient will range from 0 to 1 , where a value of 0 represents maximum equality, and a value 1 represents maximum inequality. 
In environmental justice literature, the Gini Coefficient is commonly used as a representation of income inequality, which is then layered into a broader environmental equity analysis. For example, a large body of research examines whether there is a relationship between income inequality and environmental risks (Brajer et al., 2010; Chakraborty et al., 2014; Charafeddine \& Boden, 2008; Kawachi \& Kennedy, 1997; Lynch et al., 1998; Mellor \& Milyo, 2001). A classic example of this kind of work is Chakraborty et al. (2014), which analyzed the relationship between social inequities and exposure to air pollution risks in Houston, Texas. The Gini Coefficient was used to represent levels of income inequality in Houston neighbourhoods, and their work found a significant correlation between high levels of income inequality and a greater exposure to chronic and acute pollution risks.

The Gini Coefficient has also been modified to measure other forms of inequality outside of income, such as inequality in health outcomes (Castillo-Salgado et al., 2001; Lee, 1997; Turrell \& Mathers, 2001). More recently, the Gini Coefficient has been integrated more fully in to environmental justice analysis, where it has been used to measure inequality in emissions and exposures across a population (Boyce et al., 2015; Millimet \& Slottje, 2002b, 2002a). Its most sophisticated applications measure environmental inequality, and are then used to characterize changes in inequality based on various proposed policy measures (Fann et al., 2011; Levy, Greco, et al., 2009; Levy, Wilson, \& Zwack, 2007). Boyce et al. (2015) computed a Gini coefficient for inequality in 
exposure to industrial air pollution in each of the 50 U.S. states. They found a high level of exposure inequality across census tracts in each of the 50 states ( $\mathrm{Gini}=0.76$ ), higher than levels of income inequality in the United States (Gini $=0.47)$.

The Lorenz Curve and Gini Coefficient are popular because of the graph that allows a visual representation of inequality (Maguire \& Sheriff, 2011), and because the measure is well understood in environmental justice literature (De Maio, 2007). There are some limitations to the use of these measures; most significantly, that they can only measure inequality across one dimension, and fail to provide information about two dimensions of inequity, such as the relationship between income and air pollution (Boyce et al., 2015). In Levy et al.'s evaluation of population inequality and inequity indices, they conclude that "the Gini index may not be interpretable for many combined environmental justice/ health benefits analyses" (Levy et al., 2006, p. 9).

\subsubsection{Concentration Curve and Index}

The Concentration Curve is an adaptation of the Lorenz Curve that can be used to measure environmental inequity across two dimensions. A Concentration Curve plots the cumulative fraction of the population, sorted by a chosen SES metric, by the fraction of environmental risk held by that fraction of the population. A hypothetical Concentration Curve is given in Figure 2 below. In a situation of equity, the $20 \%$ most deprived (lowest SES) or $20 \%$ least deprived (highest SES) should be exposed each to 
$20 \%$ of the environmental risk. In this scenario, the Concentration Curve would match the Line of Equity. When the Concentration Curve falls above the Line of Equity, this represents a scenario where the lowest SES populations are exposed to a higher proportion of the environmental risk. For example, in Figure 2, the $20 \%$ most deprived in the population are exposed to $40 \%$ of the environmental risk, while the $20 \%$ least deprived (from $80-100 \%$ ) are exposed to just less than $10 \%$ of the environmental risk. In a situation where the Concentration Curve falls below the Line of Equity, this represents a scenario where those with a higher SES are exposed to a greater proportion of the environmental risk.

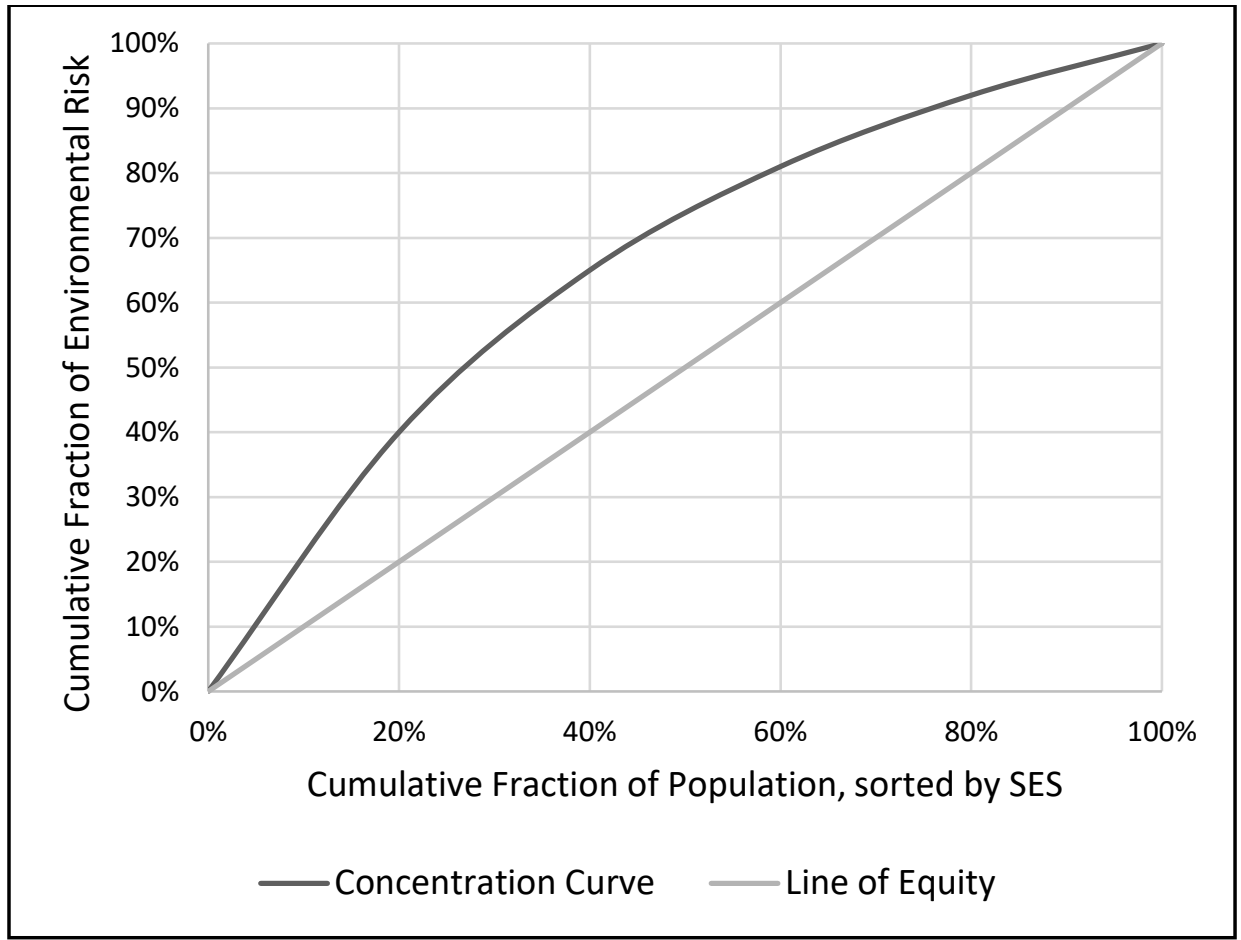

Figure 2. Hypothetical Concentration Curve 
The Concentration Curve was first introduced in 1989 to examine equity in the delivery of health care (Wagstaff, van Doorslaer, \& Paci, 1989). In this work, the researchers proposed using the Concentration Curve to examine whether health care is being delivered equitably across all income groups. They generated two Concentration Curves: one plotted the population sorted by income against the number of people reporting ill health in that income group, while the second plotted population sorted by income against health care expenditures. The researchers noted that "the concentration curve would seem to be more suited to measuring inequalities in health than the Lorenz curve. The latter is open to the objection that it measures inequalities per se rather than inequalities associated with income [...]. The same criticism cannot, of course, be levelled at the concentration curve" (Wagstaff et al., 1989, p. 100).

While it has mostly been applied to examining inequalities in health care delivery across income groups (Arokiasamy \& Pradhan, 2011; Costa Font, Hernandez-Quevedo, \& McGuire, 2011; Kakwani, Wagstaff, \& van Doorslaer, 1997; Wagstaff, 2002), the concentration curve was recently applied in environmental justice literature as well (Koolman \& van Doorslaer, 2004; Martenies et al., 2017; Sarabia \& Jorda, 2013; Su et al., 2009; Walker, Mitchell, Fairburn, \& Smith, 2005). One of the first applications by Walker et al. (2005) used the Concentration Curve to examine whether industrial pollution sites in England were clustered in areas of lower socio-economic status. The researchers found that the most deprived populations faced significant disadvantages, having nearly 
five times more industrial pollution sites located in their wards (Walker et al., 2005, fig. 3).

A significant publication for the use of the Concentration Curve for environmental equity analysis was Su et al. (2009). For Los Angeles county, this study used the Concentration Curve to look at inequity across a variety of environmental hazards by income (defined as the proportion of residents living two times below poverty) and race (defined as the proportion of non-white residents). They examined inequity in $\mathrm{NO}_{2}$ and $\mathrm{PM}_{2.5}$ exposures, Diesel PM cancer risk, as well as two Cumulative Environmental Hazard Inequality Indices that combine the impacts of all three environmental hazards. In all cases, the authors found that low-SES populations were exposed to a greater share of the environmental risk, and that these populations faced a cumulative impact of multiple pollutant exposures.

The Concentration Curve has also been applied beyond exposures to examine the inequality in health burden faced by different subgroups of the population. Recently, Martenies et al. (2017) examined the inequality in mortality and morbidity attributable to $\mathrm{NO}_{2}, \mathrm{PM}_{2.5}, \mathrm{O}_{3}$, and $\mathrm{SO}_{2}$ in Detroit. They found an annual monetized health impact of $\$ 6.5$ billion, and that the environmental burden of disease was largely driven by $\mathrm{PM}_{2.5}$ and $\mathrm{O}_{3}$ exposures. In Detroit, findings suggested that Hispanic/Latino populations are 
disproportionately impacted by industrial emissions, and that low-income populations are disproportionately affected by traffic-related air pollution.

Similar to the Lorenz Curve, the Concentration Curve has the advantage of allowing for a visual representation of inequity. However, the disadvantage of the Concentration Curve is that it is not used as commonly as the Lorenz Curve, and is not as well understood (Koolman \& van Doorslaer, 2004). Much like the Gini Coefficient, the Concentration Index is used to summarize the Concentration Curve, and is equivalent to double the area between the curve and the Line of Equality (Figure 2). The Concentration Index varies from 0 to 1 , where 0 represents maximum equality, and 1 represents maximum inequality (Maguire \& Sheriff, 2011).

\subsubsection{Atkinson Index}

The Atkinson Index is developing into one of the most popular and commonly used environmental inequality metrics, next to the Gini Coefficient. It is unique because it incorporates a constant that can change the sensitivity of the metric to inequality in different parts of the distribution (De Maio, 2007). The Atkinson Index is calculated using Equation 2-1 below:

$$
A I=\left\{\begin{array}{c}
1-\left[\frac{1}{n} \sum_{i=1}^{n}\left[\frac{x_{i}}{\bar{x}}\right]^{1-\varepsilon}\right]^{\frac{1}{1-\varepsilon}}, \quad 0 \leq \varepsilon \neq 1 \\
1-\frac{\prod_{i=1}^{n}\left(x_{i}^{(1 / n)}\right)}{\bar{x}}, \quad \varepsilon=1
\end{array}\right.
$$


For environmental inequality, $x_{i}$ is the exposure of an individual, $\bar{x}$ is the mean exposure, $n$ is the number of individuals in the population, and $\varepsilon$ is the "inequality aversion parameter", which weights the metric based on society's preference for inequality (Atkinson, 1975; Kawachi \& Kennedy, 1997). The Atkinson Index ranges from $0-1$, where 0 represents maximum equality and 1 represents maximum inequality (Atkinson, 1975).

The inequality aversion parameter $(\varepsilon)$ typically ranges from $0.5-2.0$, and is a sensitivity parameter for the distribution. For $0<\varepsilon<1$, the Atkinson Index is more sensitive to changes at the higher end of the distribution, and for $\varepsilon>1$, the Index becomes more sensitive to changes in the lower end of the distribution. In environmental inequality literature, transfers are desirable away from the most exposed (at the higher end of the distribution), so a typical value of 0.75 is selected for the inequality aversion parameter. (Clark et al., 2014; Fann et al., 2011; Levy, Greco, et al., 2009; Marshall et al., 2014; Martenies et al., 2017).

The Atkinson Index was initially used to represent income inequality (Atkinson, 1975; Donaldson \& Weymark, 1980; Yitzhaki, 1983). Much like the Gini Coefficient, early environmental justice studies used the Atkinson Index as a representation of income 
inequality, when examining the relationship between that and environmental risk (Kawachi \& Kennedy, 1997; Lynch et al., 1998).

The Atkinson Index regained popularity for direct analysis in environmental justice studies after publication of a review by Levy, Chemerynski, and Tuchmann (2006). In this work, they reviewed previous publications and developed a list of axioms for the best environmental inequality metrics. Axioms include the Pigou-Dalton transfer principle, scale invariance, anonymity, and subgroup decomposability. The Pigou-Dalton transfer principle requires that inequality always decreases when risk is transferred from a person of higher risk to lower risk, and increases for the opposite transfer. Scale invariance is the axiom that inequality should not change if a constant proportional change is made to the entire population. Anonymity requires that inequality metrics are only based on the metric chosen, and no other characteristics of the population. Subgroup decomposability means that the total inequality can be divided into the inequality of various groups in the population, and the inequality between those groups. Comparing all of the common inequality metrics, they conclude that the Atkinson Index meets the greatest number of the axioms when conducting health benefits analysis.

After publication of this review (Levy et al., 2006), several studies were conducted using the Atkinson Index (Clark et al., 2014; Fann et al., 2011; Levy, Greco, et al., 2009; Levy et al., 2007; Marshall et al., 2014; Martenies et al., 2017; Rosofsky et al., 2018). A classic 
example of the use of the Atkinson Index comes from Levy, Wilson, and Zwack's (Levy et al., 2007) study on the trade-off between equality and efficiency when controlling emissions from power plants in the United States. In this study, the change in the Atkinson Index for $\mathrm{PM}_{2.5}$ health risk was calculated for 16 different proposed power plant emission control scenarios. The change in equality was used to evaluate how the different scenarios compared beyond their improvement of public health. Furthermore, the researchers computed a sensitivity analysis using the Gini Coefficient, Theil's Entropy, Mean log deviation, and three different inequality aversion parameters. Generally, they found that the choice of inequality indicator slightly reordered the choice of control strategies, but the overall conclusions remained the same.

\subsubsection{Other Measures}

While much of the literature uses the above inequality and inequity metrics, there are a few other methodologies worth mentioning.

First, there is a subset of studies that based their inequality analysis on correlation statistics, including regression analysis and spatial auto-correlation (Chakraborty, 2009; Chakraborty et al., 2014; Collins et al., 2015; Collins, Grineski, \& Morales, 2017; Grineski, Bolin, \& Boone, 2007; Grineski, Collins, Chakraborty, \& Montgomery, 2017; Grineski \& Collins, 2010; Havard et al., 2009; Marshall, 2008; Pastor et al., 2005; Pope, Wu, \& 
Boone, 2016; Pratt et al., 2015). While the studies all examined different research questions, the type of analysis undertaken was the same.

A typical example of this kind of study can be found from a recent study by Collins, Grineski and Morales (2017). In this work, the authors tested if there is a correlation between exposure to air toxics and people that identify as lesbian, gay, bisexual, transgender, or queer (LGBTQ). For census tracts across the United States, they examined multivariate associations between cancer risk and respiratory risk (from air toxics exposure) to the number of reported same-sex households, both male and female. Researchers found that mean cancer risk and respiratory risk are $12 \%$ and $24 \%$ higher, respectively, when compared to heterosexual couples. The authors conclude that LGBTQ populations faced environmental inequity across the United States, which can be compounded by other differences in SES.

Another common assessment of inequality is based on comparing ratios, such as quartile, quintile, or decile ratios. Studies varied slightly in their analysis. Some studies compared the geographical areas that faced the highest and lowest pollution exposures, and examined the difference in SES across these areas (Miranda et al., 2011). Other studies focussed instead on the difference in exposure for the most and least vulnerable populations, when sorted by a chosen SES metric (Apelberg et al., 2005; Briggs, Abellan, \& Fecht, 2008; Carrier, Apparicio, Kestens, et al., 2016; Fan et al., 2012; Kawachi \& 
Kennedy, 1997). Other studies still chose a descriptive ratio that combined multiple SES analysis (Boyce et al., 2015; Clark et al., 2017); the most common example of these are studies that computed the ratio of environmental risk of high-income whites (HIW) to low-income non-whites (LIN) (Clark et al., 2014; Marshall et al., 2014; Pinault et al., 2017). In Pinault et al.'s (2017) study, the authors calculated the mean residential fine particulate matter $\left(\mathrm{PM}_{2.5}\right)$ exposure for each Census Metropolitan Area in Canada. The same mean $\mathrm{PM}_{2.5}$ exposure was then calculated for low-income non-whites (LIN) and high-income whites (HIW), and the difference between these values was also reported. The authors found that $\mathrm{PM}_{2.5}$ exposure was higher for minorities, immigrants, and lowincome households.

Finally, a small subset of studies employed Theil's Entropy Index. Developed for calculating income inequality, Theil's Entropy Index is given by Equation 2-2:

$$
T=\frac{1}{n} \sum_{i=1}^{n}\left(\frac{x_{i}}{\mu}\right) \ln \left(\frac{x_{i}}{\mu}\right)
$$

where $n$ represents the size of the population, $x_{i}$ is the environmental risk for an individual in the population, and $\mu$ is the average environmental risk for the population (Levy et al., 2006). The primary benefit of Theil's Entropy Index is that it is easily decomposable into subgroups, allowing for analysis of the inequality within and between different populations. Because of this, it is most popular in studies that seek to compare inequality between countries (Duro \& Teixidó-Figueras, 2013; Padilla \& Duro, 
2013; Sauter, Grether, \& Mathys, 2016). However, there are significant disadvantages to this metric, most notably that the upper limit of the index depends on the size of the population. Despite this, it has been used in certain studies as a representation of income inequality (Brajer et al., 2010), or to perform a sensitivity analysis on a primary environmental inequality metric (Levy, Greco, et al., 2009; Levy et al., 2007).

\subsection{Health Impacts of Air Pollution}

Ambient air pollution carries adverse impacts to human health. This is recognized globally, and countries set air quality standards in order to protect human health. The U.S. EPA sets National Ambient Air Quality Standards for criteria air pollutants to protect public health (U.S. Environmental Protection Agency, 2015), while in Canada there are the Canadian Ambient Air Quality Standards. This thesis focusses on the health impacts of particulate matter $\left(\mathrm{PM}_{2.5}\right)$, which is recognized as a danger to human health in both the U.S. and Canada. A brief review of the epidemiological effects on PM exposure is given here.

In the recent Global Burden of Disease Study of 2015, exposure to $\mathrm{PM}_{2.5}$ pollution is associated with lower respiratory infections; trachea, bronchus, and lung cancers; ischemic heart disease; cerebrovascular disease; and chronic obstructive pulmonary disease (COPD) (Forouzanfar et al., 2016). The impacts of $\mathrm{PM}_{2.5}$ exposure are serious; globally, the authors estimate that 4.2 million deaths are attributable to $\mathrm{PM}_{2.5}$ exposure. 
Furthermore, ambient $\mathrm{PM}_{2.5}$ pollution is responsible for over 103 million disabilityadjusted life-years worldwide. In 2010, it was ranked the $9^{\text {th }}$ leading risk factor to human health (Lim et al., 2012).

Exposure to criteria air pollutants can have a variety of acute and chronic effects. Results of epidemiologic studies are typically expressed in terms of "effect estimates", which quantify the change in a health outcome with a change in pollution concentration (Pappin \& Hakami, 2013a). Studies presented here focus on the impact of pollution exposure on mortality, and results are presented as a percent increase in mortality with an increase in $\mathrm{PM}_{2.5}$ concentration. While there are many kinds of epidemiologic studies, those presented here falls into two categories: time-series studies that examine impacts from short-term $\mathrm{PM}_{2.5}$ exposure, and cohort studies that examine impacts from chronic PM2.5 exposure (Pappin, 2016).

Time-series studies that examine the impacts of short-term $\mathrm{PM}_{2.5}$ exposure have found that $\mathrm{PM}_{2.5}$ exposure increases the risk of mortality in a population. For example, Dominici et al. (2007) found that $\mathrm{PM}_{2.5}$ exposure increased all-cause mortality, over a study period of $1987-2000$. The authors reported all-cause mortality increasing by $0.29 \%$ with an increase in $\mathrm{PM}_{2.5}$ concentrations of $10 \mu \mathrm{g} / \mathrm{m}^{3}$. More recently, Zanobetti and Schwartz (2008) assessed the impact of short-term $\mathrm{PM}_{2.5}$ in 48 U.S. cities from 1999 
- 2005. The authors found a mortality effect estimate of $0.098 \%$ for each $1 \mu \mathrm{g} / \mathrm{m}^{3}$ increase in $\mathrm{PM}_{2.5}$ concentrations.

Studies that consider the impacts of chronic $\mathrm{PM}_{2.5}$ exposure tend to find a stronger association with mortality. A key data set used for this study is the American Cancer Society (ACS) cohort study. For example, Pope et al. (2002) analyzed the epidemiologic data from the ACS cohort study, with an emphasis on chronic $\mathrm{PM}_{2.5}$ exposure and increased mortality. The authors found that the risk of all-cause mortality increased by $0.6 \%$ with each $1 \mu \mathrm{g} / \mathrm{m}^{3}$ increase in average $\mathrm{PM}_{2.5}$ exposure. Krewski et al. (2009) reanalyzed the same ACS data, and found that mortality increased in the population by $0.6 \%$ for each $1 \mu \mathrm{g} / \mathrm{m}^{3}$ increase in 24 -hour average $\mathrm{PM}_{2.5}$ concentrations. Both studies also found larger risks for ischemic heart disease. 


\subsection{Methods}

Atmospheric chemistry and the evolution of concentrations depend on multiple processes: emission, transport, chemistry, and deposition. In atmospheric modelling, these processes can be represented using 3-dimensional models known as atmospheric CTMs. In this thesis, atmospheric CTMs are related to human health, income, and environmental equity, in order to look at the relationship between emissions and the impacts on the environmental justice landscape.

This section introduces brief fundamentals of atmospheric CTMs, sensitivity analysis, and environmental justice analysis. While Chapters 4-5 have detailed methodology sections, this chapter provide a broader overview of key methodologies for this type of analysis in general, but is kept short to avoid redundancy in future chapters.

\subsection{Atmospheric Chemical Transport Models}

Numerical 3-D models that simulate the changing concentrations of chemicals in the atmosphere, across time and space, are known as atmospheric chemical transport models (CTMs). Given the difficulty and cost with performing tests on the atmosphere, atmospheric modelling is a key part of air quality research and policy making. Atmospheric models are well designed to answer policy questions that consider different potential policy scenarios and want to assess the possible impacts. These types of "what if?" policy questions would be costly and time consuming to answer 
experimentally, and so this field of research has come to rely on atmospheric models.

CTMs have a wide range of applications, but are most commonly used to provide information about the relationship between sources and receptors.

Atmospheric CTMs are distinguished from other atmospheric models, such as General Circulation Models, since information about atmospheric dynamics must be provided to the model. Specifically, atmospheric CTMs are given spatially and temporally resolved inputs of emissions and meteorological data. The model will then take this information and propagate the emissions forward in space and time, using the meteorological data and atmospheric chemistry to inform transport and transformation of those emissions. Outputs of chemical transport models will depend on the model and its parameters, but typically are a surface of concentrations of pollutants over a specified domain and timeframe.

Eulerian atmospheric CTMs are gridded models, where three dimensional boxes are spread over the domain. The domain can be global, regional, or local, and the grid resolution will vary over the chosen domain. Global atmospheric CTMs will typically have a resolution as low as hundred(s) of kilometres, while local atmospheric CTMs can have a grid resolution of $1 \mathrm{~km}$. While a refined grid resolution can provide more detail in a model, there is a trade off with computational requirements from running these models, and the requirement for boundary condition information. 
Atmospheric CTMs are governed by the Atmospheric Diffusion Equation (ADE) which is integrated for each grid cell and each time step across the model. The ADE solves for a change in concentration for any given chemical or pollutant with time (Jacob, 2007). A simplified form of the ADE is:

$\frac{\partial C_{i}}{\partial t}=-\nabla \cdot\left(u C_{i}\right)+K \nabla^{2} C_{i}+R_{i}+E_{i}$

In Equation 3-1, $C_{i}$ is the concentration of species $i, t$ is the time, $u$ is the wind vector, $K$ is the turbulent diffusion coefficient, $R_{i}$ are the chemical reactions and equilibria (production and loss, gas and aerosol phases) of species $i$, and $E_{i}$ are emissions of species $i$. The term $\frac{\partial C_{i}}{\partial t}$ on the left-hand side of the equation represents any local accumulation in concentration. The first $\left(-\nabla \cdot\left(u C_{i}\right)\right)$ and second term $\left(K \nabla^{2} C_{i}\right)$ on the right-hand side represent transport through advection and turbulent diffusion, respectively. In this formulation of Equation 3-1, any losses through dry deposition would be included in the vertical diffusion boundary conditions.

Regional CTMs are often referred to as limited area CTMs or Air Quality Models (AQMs). While there are a variety of AQMs that will model different scales of geography at different resolutions, this thesis focusses on the AQM developed and used by the U.S. EPA, described below. 


\subsection{The CMAQ Modelling system}

This thesis uses the AQM known as the Community Multiscale Air Quality (CMAQ) modelling system (Byun \& Schere, 2006). This modelling system has been developed by the U.S. EPA, and is constantly being refined and maintained by this organization and the community at large. As the most widely used AQM worldwide, it is frequently used for regulatory modelling, as well as other applications by a variety of policymakers, academics, consultants, and researchers.

There are several software programs that work together to make up the CMAQ modelling system (Figure 3). To generate the meteorological inputs required for CMAQ, a regional meteorology model is used. For this thesis, Weather Research and Forecasting (WRF) generates meteorological information for the domain and the time period (National Center for Atmospheric Research, 2018), which are then processed using the Meteorology-Chemistry Interface Processor (MCIP), which prepares the meteorological information into a format that can be input in to CMAQ. Emissions are taken from the National Emissions Inventory (NEI) for the United States, and then processed using the Sparse Matrix Operator Kernel for Emissions (SMOKE), to generate model-ready emission files for each day and emission type (Community Modeling and Analysis System, 2018). The initial and boundary conditions of the model (and the ADE) are generated using the Initial Conditions Processor (ICON) and the Boundary Conditions 
Processor (BCON), respectively. Daily clear-sky photolysis rates are calculated using a

Photolysis Rate Processor (JPROC).

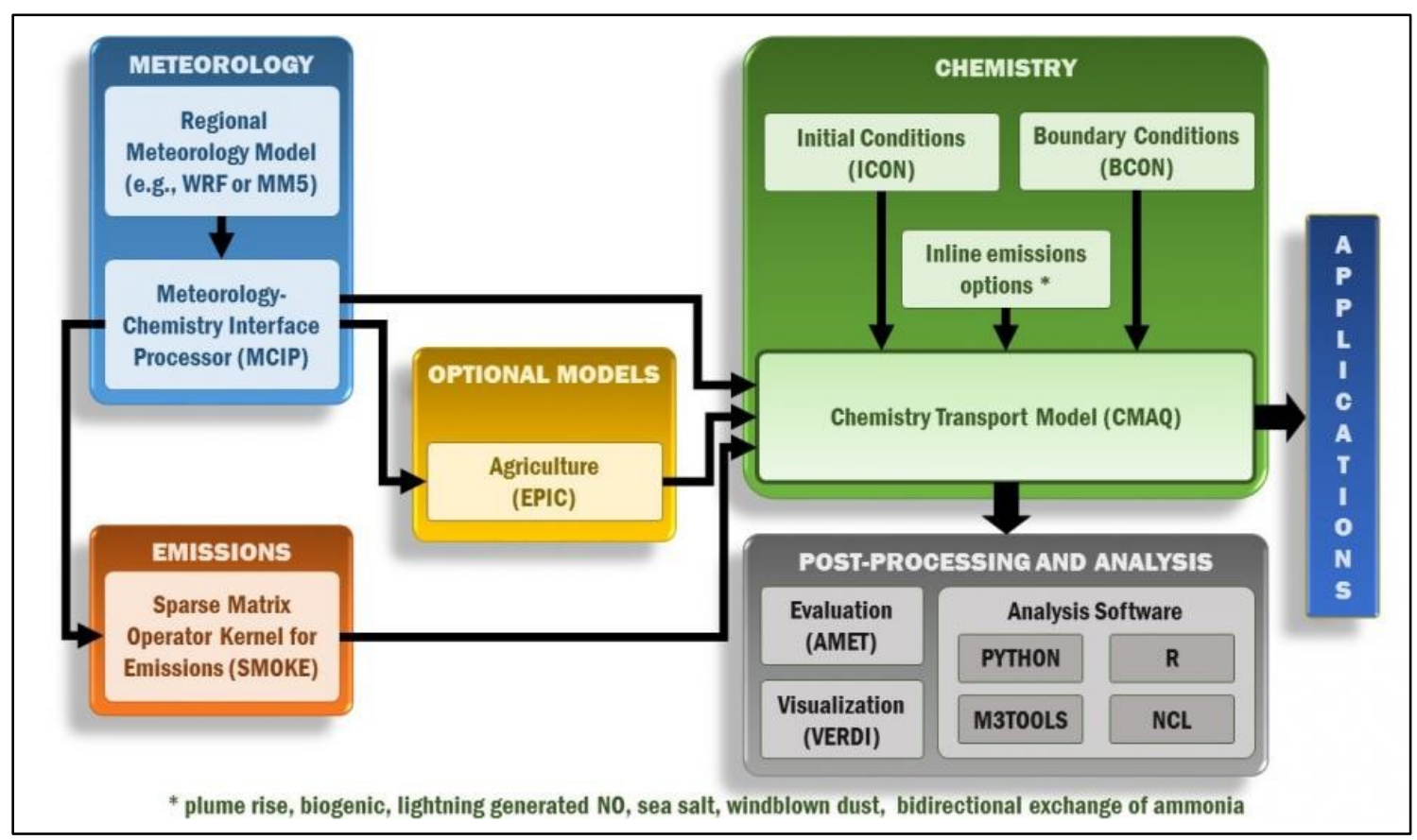

Figure 3. The CMAQ modelling system (U.S. Environmental Protection Agency, 2018a)

\subsection{Sensitivity Analysis}

Sensitivity analysis is commonly used in atmospheric CTMs to provide information on how a change in the inputs of the model will impact the output. This is most commonly seen in atmospheric CTMs by linking the influence of various emissions to the concentrations across a domain. In an atmospheric CTM or an AQM, this can be calculated by differentiating the model outputs with respect to a model input, such as 
the derivative of concentrations with respect to emissions (Yang, Wilkinson, \& Russell, 1997).

Sensitivity information can be used for a variety of purposes, including answering a range of policy-relevant questions regarding the effectiveness of air quality management strategies. For example, by providing information about the influence of various emissions on final concentrations, policies can be developed to target emissions reductions that will carry the greatest impact on pollution concentrations. Model outputs can also be more complex than pollutant concentrations, as models can be expanded to measure human health impacts or environmental justice. In this case, sensitivity analysis can be used to trace the influence of emissions on policy-relevant objectives such as these.

\subsubsection{Forward Sensitivity Analysis}

Most sensitivity analysis techniques can be characterized either as "forward" or "backward" sensitivity analysis. Forward sensitivity analysis amounts to applying a small perturbation in one of the sources or inputs of the model, and allowing that perturbation to be carried to final changes in all of the receptors at the output of the model. This type of sensitivity analysis is receptor specific, meaning that it can characterize the impacts on all receptors from a single source or group of sources. Since 
atmospheric CTMs solve versions of the ADE, forward sensitivity analysis can be based on differentiated ADE as follows (Yang et al., 1997):

$\frac{\partial \delta C_{i}}{\partial t}=-\nabla \cdot\left(u \delta C_{i}\right)+\frac{1}{\rho} \nabla \cdot\left(\rho K \nabla \delta C_{i}\right)+F_{i} \delta C+\delta E_{i}$

where $\rho$ is the density, $\delta E_{i}$ represents a perturbation in emissions, $\delta C_{i}$ represents the change in concentration, and $F_{i}$ is the $i^{\text {th }}$ row of the Jacobian of the nonlinear transformation rates (Hakami et al., 2007). Forward sensitivity analysis is best used to ask policy questions that are specific about the change being made to emissions, and seek to measure the impact at a multitude of locations. An example of this could be, "How will a $10 \%$ reduction in emissions impact air quality at various points across a city?"

\subsubsection{Adjoint Sensitivity Analysis}

Backward, or "adjoint", sensitivity analysis is complementary to forward methods. In this method, a perturbation is made to one receptor or group of receptors at the output of the model, which is then integrated backward in time and space through a set of sensitivity equations that are auxiliary to the forward sensitivity system. Backward integration of these equations allows the adjoint method to trace the influence back on to all sources at the input of the model. Adjoint sensitivity analysis is source-specific, meaning that it can characterize the influence of all sources (at all locations and times) on a single receptor or group of receptors. In this context, a receptor can be the 
concentration of air pollutants at a location, or a grouped metric such as human health or environmental justice.

Adjoint sensitivity analysis depends on an adjoint cost function $(U)$, which relates concentrations to the metric for which sensitivities are being calculated. An adjoint cost function can be any metric that depends on concentration, integrated over space $(\omega)$ and time $(t)$ :

$J=\int_{x, y, z} \int_{t} f(C, \omega, t) d \omega d t$

Then the adjoint variable for which sensitivities are being calculated is the derivative of the cost function with respect to concentration:

$\lambda_{i}=\frac{\partial J}{\partial C_{i}}$

The governing equation of the adjoint model is based on Equation 3-2, which is derived using Lagrange multipliers and integration by parts (Hakami et al., 2007; Henze, Hakami, \& Seinfeld, 2007):

$-\frac{\partial \lambda_{i}}{\partial t}=\nabla \cdot\left(u \lambda_{i}\right)+\nabla \cdot\left(\rho K \nabla \frac{\lambda_{i}}{\rho}\right)+F_{i}^{T} \lambda+\varphi_{i}$

where $F_{i}^{T}$ is the $\mathrm{i}$-th row of the transposed Jacobian of the nonlinear transformation rates, and $\varphi_{i}$ is the forcing term for the adjoint equations. The forcing term is used drive the adjoint equations, and is calculated based on the adjoint cost function (Equation 3- 
3). Similar to the adjoint variable, the forcing term is the derivative of the original metric for which sensitivities are being calculated $(f(C, \omega, t)$ from Equation 3-3), to concentration at a particular location and time:

$\varphi_{i}=\frac{\partial f}{\partial C_{i}}$

Adjoint sensitivity analysis will calculate the derivative of the adjoint cost function with respect to the model inputs. An adjoint model developed for gas-phase processes in the CMAQ model (Hakami et al., 2007), and later expanded to aerosol processes, is used in this thesis to perform sensitivity analysis.

\subsection{Adjoint Cost Function}

The choice of adjoint cost function determines the type of analysis being carried out. Previous works have used cost functions based on attainment (Hakami et al., 2006; Pappin \& Hakami, 2013a), or health effects (Pappin et al., 2016; Pappin, Mesbah, Hakami, \& Schott, 2015; Pappin \& Hakami, 2013b). This thesis uses two main cost functions: the first is for the health impacts of air pollution, while the second is for the inequity of health impacts across income groups. Their formulation is described in more detail below. 


\subsubsection{Health Impacts Forcing Term}

This thesis focusses on the health effects of exposure to air pollution. In particular, the approach used here aims to quantify the monetary value of increased mortality resulting from chronic exposure to $\mathrm{PM}_{2.5}$. Mortality effects are chosen since their economic valuation dwarfs morbidity and other health impacts. This type of health analysis has been previously conducted using adjoint sensitivity analysis (Pappin et al., 2016, 2015, Pappin \& Hakami, 2013a, 2013b).

A change in $\mathrm{PM}_{2.5}$ concentration $(\Delta C)$ will cause a change in mortality $(\Delta M)$, according to the following epidemiological concentration response function:

$\Delta M=M_{0} \times P\left(1-e^{-\beta \Delta C}\right)$

where $M_{0}$ is the baseline mortality rate (BMR), $P$ is the population, and $\beta$ is an epidemiological constant representing each pollutant's concentration-response.

In this thesis, BMR data is taken from two places. First, county-level BMR data is taken from the U.S. EPA Environmental Benefits Mapping and Analysis Program (BENMAP). BENMAP is used to calculate "the number and economic value of air pollution-related deaths and illnesses" (U.S. Environmental Protection Agency, 2017a), but in this study is only accessed to extract BMR from the software database. A more refined dataset of BMR was taken at the zip code level for NYC, and was provided by the New York City 
Department of Health and Mental Hygiene. The refined dataset is used within the NYC, while BENMAP is used to generate BMR values outside the boundaries of the city. Population data was taken from the 2010-2014 American Community Survey 5-Year Estimates, provided by the U.S. Census Bureau. This data provides the number of households in each census tract, divided across multiple income bins. Based off the commonly used work of Krewski et al. (2009), a $\beta$-value of $0.005827\left(\mu \mathrm{g} / \mathrm{m}^{3}\right)^{-1}$ was used, for 24-hour average $\mathrm{PM}_{2.5}$ concentration.

To assign a monetary value to reduced mortality, we employ a common economic valuation known as the Value of Statistical Life (VSL), which is developed based on an average individual's willingness to pay money to reduce their likelihood of death. Using data from the U.S. EPA, a VSL of \$7.9M USD is used for 2008. Multiplying Equation 3-7 by the VSL, one obtains Equation 3-8:

$\Delta M_{\$}=M_{0} \times P\left(1-e^{-\beta \Delta C}\right) \times V_{S L}$

To calculate the adjoint cost function for sensitivity analysis, the derivative of Equation 3-8 is taken with respect to concentration at each location $(x$, with a total of $N$ locations) and time ( $i$, with a total of $n$ timesteps), giving Equation 3-9:

$J_{m}=\sum_{x=1}^{N} \sum_{i=1}^{n} M_{0_{x}} P_{x} \beta e^{\beta \Delta C_{i}, x} \times V_{S L}$ 
This cost function can be used to drive an adjoint sensitivity analysis, which will trace the influence of emissions at individual locations and times on domain-wide mortality from chronic $\mathrm{PM}_{2.5}$ exposure.

\subsubsection{Inequity Impacts Forcing Term}

As well as the health effects of air pollution exposure, this thesis is concerned with the distribution of environmental hazards across income groups, also called environmental equity. In this case, environmental equity was measured using the Concentration Index. The Concentration Index was selected based on its ability to capture information about income inequality and air pollution exposure inequality in one parameter. Furthermore, the Concentration Curve on which the Index is based is a valuable tool to analyze current levels of inequity prior to sensitivity analysis.

When developing the Concentration Curve, we plot the cumulative fraction of the measure of interest against the cumulative fraction of the population, sorted by income. In this work, two measures of interest were used: the first is air pollution exposure, while the second is the health impact from air pollution (Equation 3-7).

The Concentration Curve will show the distribution of environmental hazards across income groups. If higher-income populations are exposed to more air pollution, the 
Concentration Curve will fall below the line of equity. On the other hand, if lowerincome populations carry a disproportionate burden of the air pollution, the Concentration Curve will fall above the line of equity (as is the situation in the hypothetical curve shown in Figure 2).

The adjoint cost function was calculated based on the Concentration Index, which is a normalized value ranging from 0 (maximum equality) to 1 (maximum inequality), and is equivalent to double the area between the Concentration Curve and Line of Equity. Since the Concentration Index is based on the geometric properties of the curve, and is not based on a closed-form equation that can be manipulated, the adjoint cost function cannot be represented by a single equation.

To generate the forcing terms for adjoint sensitivity analysis of inequity, a brute-force approach was employed. First, the original Concentration Index was calculated for the domain. Then, for each grid cell, a small perturbation was made to the average concentration of the selected air pollutant, and the Concentration Index was recalculated. The change in Concentration Index based on the perturbation was stored as the forcing term for that grid cell. Various perturbation levels are used to ensure stable forcing calculations. 
This method allows the importance of each location and each time to be captured in the forcing terms. These forcing terms are then used in the adjoint equations, which will trace the influence of emissions at individual locations and times on domain-wide environmental inequity from $\mathrm{PM}_{2.5}$ exposure and its related health risks.

The following two chapters employ these methods to examine current levels of environmental equity in a metropolitan area, and how emission reductions can be targeted to effectively reduce inequity concerns. In Chapter 4, we quantify the current levels of environmental inequity for NYC and the surrounding area. This research relies on a variety of methods for measuring inequity (as described in Section 2.3), and examining three different concentration datasets.

In Chapter 5, adjoint sensitivity analysis is used to trace the influence of emissions at all locations and times on the current levels of inequity and health impacts. Depending on the adjoint forcing term used, the results show the areas where emission reductions should be targeted to reduce mortality from $\mathrm{PM}_{2.5}$ exposure (based on Section 3.4.1), or to reduce the inequity of the distribution of $\mathrm{PM}_{2.5}$ health risk across income groups (based on Section 3.4.2). This manuscript examines the individual influences for both policy metrics, and then combines them to examine how emission reductions can be targeted to meet multiple policy goals. 


\subsection{High-Resolution Air Quality Modelling in Support of Environmental Justice Studies in a Metropolitan Area}

This chapter is in preparation for publication in Environmental Research Letters. It consists of original research for which Robyn Chatwin-Davies is the main contributor $(90 \%)^{1}$.

\subsection{Introduction}

Ambient air pollution carries significant adverse health effects on the population.

However, these adverse health impacts are not distributed evenly across a population.

The field of environmental equity has established that socioeconomic status (SES) has a significant correlation with an individual's level of exposure to environmental pollution (Agyeman et al., 2016; Mohai \& Saha, 2015). Many studies have established that lowSES populations are exposed to higher levels of air pollution (Miranda et al., 2011; Morello-Frosch \& Jesdale, 2006; Zwickl, Ash, \& Boyce, 2014), compounding the disproportionate health burden faced by these populations that are already vulnerable and susceptible to these health risks (O'Neill et al., 2003).

Researchers and policy makers alike strive to assess the state of environmental equity across cities, regions, and nations, as it relates to various pollutants. In order to provide

\footnotetext{
${ }^{1}$ Co-authors on this work include: Burak Oztaner, Shunliu Zhao, Melanie Fillingham, Marjan Soltanzadeh, Amir Hakami (Carleton University); lyad Kheirbek, Kazuhiko Ito (New York City Department of Health and Mental Hygiene); Jay Haney, and Sharon Douglas (ICF International).
} 
a spatially resolved analysis of environmental equity, equally refined spatial representation is required for air pollution and SES. Air pollution concentrations are typically the limiting factor on providing highly detailed analyses of environmental equity.

To measure environmental equity, many studies focus only on populations that live in near proximity to monitoring locations, and interpolate concentrations based on measurements at specific locations (Bell \& Ebisu, 2012; Miranda et al., 2011). In other cases, studies use land-use regression (LUR) models to provide concentrations at a refined spatial resolution (Brunt et al., 2016; Clark et al., 2014, 2017; Rosofsky et al., 2018; Temam et al., 2017). Other studies rely on point-source emissions, generating concentrations through source-receptor matrices (Levy et al., 2007), or through the use of atmospheric dispersion models (Martenies et al., 2017; Poorfakhraei et al., 2017; Pratt et al., 2015; Tayarani et al., 2016).

Other researchers have opted to skip modelling concentrations, and to directly examine the distribution of health risks across SES. For example, Requia et al. (2017) generate detailed emissions, and then apply the Intake Fraction method to estimate the human exposure to traffic-related air pollution. Similarly, many studies use the human health risks calculated through the National-Scale Air Toxics Assessment model (Chakraborty, 2009; Chakraborty et al., 2014; Collins et al., 2015, 2011; Grineski \& Collins, 2010; 
Grineski et al., 2014), which models certain individual air toxics using U.S. EPA's

Community Multiscale Air Quality (CMAQ) model at a $12 \mathrm{~km}$ grid resolution.

Very few papers model concentrations directly using detailed Chemical Transport Models (CTMs); three exceptions are the use of the Comprehensive Air Quality Model with Extensions (CAMx) by Marshall, Swor, and Nguyen (2014) and Nguyen and Marshall (2018); as well as the use of the Community Multiscale Air Quality (CMAQ) modelling system by Fann et al. (2011). The benefit of using a CTM is illustrated in these papers; there is flexibility in a model to change parameters and model multiple scenarios. As well as assessing current levels of environmental equity, proposed policy scenarios can be tested for their impacts on environmental equity.

The methodology used to measure and quantify environmental justice varies significantly across existing literature as well. Some studies focus on the distribution of air pollutants across the population without considering SES, most typically termed "environmental equality". Examples of this include the use of the Gini Coefficient (Boyce et al., 2015; Millimet \& Slottje, 2002b, 2002a), Atkinson Index (Clark et al., 2014; Fann et al., 2011; Levy et al., 2006; Marshall et al., 2014), or Theil's Entropy Index (Brajer et al., 2010; Levy, Baxter, \& Schwartz, 2009; Levy et al., 2007). Other studies include SES (such as income, race, or education) in their analysis, resulting in analyses of what is often termed as "environmental equity". Examples of this include usage of correlation 
statistics or ratios, to identify a relationship between SES and the levels of pollution exposure for the most and least vulnerable populations (Apelberg et al., 2005; Chakraborty, 2009; Fan et al., 2012; Marshall, 2008; Miranda et al., 2011; Pastor et al., 2005; Pope et al., 2016). Recently, new indices that include both SES and pollution, such as the Concentration Index, are also being used (Sarabia \& Jorda, 2013; Su et al., 2009; Walker et al., 2005). While certain reviews have attempted to quantify the benefits of the various metrics (De Maio, 2007; Levy et al., 2006; Maguire \& Sheriff, 2011), and past studies have called for better standardization, the fact remains that many different methodologies are used to measure environmental justice.

Using the case study for New York City (NYC), we assess the status of environmental justice, specifically focused on the distribution of $\mathrm{PM}_{2.5}$ air pollution (environmental equality), and the relationship between income and $\mathrm{PM}_{2.5}$ concentrations (environmental equity). In this study, we compare two sets of air pollution concentrations: first is eight years of measurements across NYC, modelled and mapped using a LUR model. Second is from a CMAQ, a widely used CTM for research and regulatory purposes. This dataset is compared with the LUR data to assess the appropriateness of regional CTMs for high-resolution environmental equity analysis. We use concentration surfaces from these two approaches to estimate population exposure, while recognizing that our approach to exposure assessment is a simplification and only approximates individual exposures. 
Furthermore, this case study is novel since it examines multiple indices to quantify environmental equality and equity across the dataset. As well as providing a more complete picture of the levels of inequality and inequity, this allows for comparison of multiple indices within the same datasets.

\subsection{Methods}

\subsubsection{Health Impacts from Air Pollution Exposure}

This study is focused on the health effects caused by exposure to fine particulate matter $\left(\mathrm{PM}_{2.5}\right)$. The U.S. EPA has identified $\mathrm{PM}_{2.5}$ as a criteria air pollutant, and has set national ambient air quality standards to protect public health (U.S. Environmental Protection Agency, 2015). Unlike some criteria air pollutants, there is no safe threshold for $\mathrm{PM}_{2.5}$ exposure. Exposure to $\mathrm{PM}_{2.5}$ is associated with adverse health effects, with studies linking it to heart attacks, aggravated asthma, decreased lung function, and premature death of people with heart or lung disease (U.S. Environmental Protection Agency, 2016). A recent Global Burden of Disease study estimates that ambient $P M_{2.5}$ pollution is responsible for 4.2 million deaths annually worldwide (Forouzanfar et al., 2016).

When examining environmental justice across a metropolitan area, we characterize both the inequality of health impacts from air pollution exposure, and its distribution across income groups. Specifically, we focus on the mortality resulting from chronic 
exposure to concentrations of $\mathrm{PM}_{2.5}$. This is calculated through an epidemiological concentration-response function (Equation 4-1), which relates a change in mortality $(\Delta M)$ to a change in pollutant concentration $(\Delta C)$ :

$\Delta M=M_{0} \times P\left(1-e^{-\beta \Delta C}\right)$

where $M_{0}$ is the baseline mortality rate, $P$ is the population, and $\beta$ is an epidemiological constant representing each pollutant's concentration-response.

The epidemiological concentration-response for $\mathrm{PM}_{2.5}$ is based on the re-analysis of the American Cancer Society cohort by Krewski et al. (2009). They identify a $\beta$-value of 0.005827 for each $1 \mu \mathrm{g} / \mathrm{m}^{3}$ increase in 24-hour average $\mathrm{PM}_{2.5}$, when considering mortality from chronic exposure, for people aged 30-99. Baseline mortality rate (BMR) was provided by the New York City Department of Health and Mental Hygiene, for each zip code in NYC. BMR is calculated from the average of all-cause mortality rates for 2012-2014, for people aged 30-99 and applied for the entire period of study.

\subsubsection{Measures of Environmental Inequality and Inequity}

One of the primary concerns of environmental justice studies is distributional equality of health risks across a population, regardless of background or SES. There are many ways that this can be quantified. Classically, "equality" refers to the distribution of environmental pollutants across a population without considering SES. Meanwhile, environmental "equity" is concerned with whether the distribution of pollution is 
correlated with SES, and most studies find that lower-SES populations tend to be exposed to higher levels of pollution. In this work, we consider two popular measures of environmental equality (the Atkinson Index and Gini Coefficient), and two measures of environmental equity (the Concentration Index and decile ratios).

The Atkinson Index explicitly contains normative judgements about the value of achieving equality (De Maio, 2007):

$A I=\left\{\begin{array}{c}1-\left[\frac{1}{n} \sum_{i=1}^{n}\left[\frac{x_{i}}{\bar{x}}\right]^{1-\varepsilon}\right]^{\frac{1}{1-\varepsilon}}, \quad 0 \leq \varepsilon \neq 1 \\ 1-\frac{\prod_{i=1}^{n}\left(x_{i}^{(1 / n)}\right)}{\bar{x}}, \quad \varepsilon=1\end{array}\right.$

where $x_{i}$ in this case is the $\mathrm{PM}_{2.5}$ health burden of population segment $i, \bar{x}$ is the mean $\mathrm{PM}_{2.5}$ health burden, $n$ is the number of individuals in the population, and $\varepsilon$ is the "inequality aversion parameter". The inequality aversion parameter weights the Atkinson Index based on society's preference for inequality (Atkinson, 1975; Kawachi \& Kennedy, 1997). The inequality aversion parameter typically ranges from $0.5-2.0$, with a typical value of 0.75 selected in most environmental justice literature(Clark et al., 2014; Fann et al., 2011; Levy, Greco, et al., 2009; Marshall et al., 2014; Martenies et al., 2017). The Atkinson Index varies from 0 to 1 , with 0 being equality and 1 being inequality (Atkinson, 1975). 
The Gini Coefficient has been previously used to measure inequality in emissions and exposure to environmental hazards (Boyce et al., 2015; Fann et al., 2011; Levy, Baxter, et al., 2009; Levy et al., 2007; Millimet \& Slottje, 2002a, 2002b). The Gini Coefficient is based on the Lorenz Curve, which plots the cumulative fraction of the measure of interest held by the cumulative fraction of the population, sorted by the same measure of interest (Arnold, 2005; De Maio, 2007). The further that the Lorenz Curve deviates below the line of equality, the more unequal the distribution is.

In this study, we plot the cumulative fraction of $\mathrm{PM}_{2.5}$ health burden against the cumulative fraction of the population, sorted by the same metric. The Gini Coefficient is equivalent to the area between the line of equality and the Lorenz Curve, divided by the total area under the line of equality. The Gini Coefficient ranges from 0 to 1 , where 0 represents equality and 1 represents maximum inequality.

The Concentration Curve is a modified version of the Lorenz Curve that incorporates information about SES. The formulation of the Concentration Index has been discussed in previous works (Kakwani et al., 1997; Koolman \& van Doorslaer, 2004; Wagstaff, 2002; Wagstaff et al., 1989), and its applications in environmental equity studies are well documented (Martenies et al., 2017; Sarabia \& Jorda, 2013; Su et al., 2009; Walker et al., 2005). In this study, we plot the cumulative fraction of $\mathrm{PM}_{2.5}$ health burden against the cumulative fraction of the population, sorted from lowest to highest income 
group. Much like the Lorenz Curve, inequity is estimated by deviation from the $45^{\circ}$ line of equality. If the Concentration Curve falls above the line of equality, this shows that lower-SES populations are exposed to more pollution, and vice versa. The Concentration Index is used to summarize the Concentration Curve. It is calculated by dividing the area between the Concentration Curve and Line of Equality by the total area under the Line of Equality. Much like the Gini Coefficient, the Concentration Index ranges from 0 (equality) to 1 (inequality).

Another method for measuring environmental inequity is based on comparing ratios across the population. There are a wide variety of methodologies employed in the literature, but most commonly this analysis involves comparing the levels of exposure for the most and least vulnerable populations (Apelberg et al., 2005; Briggs et al., 2008; Carrier, Apparicio, Kestens, et al., 2016; Clark et al., 2014, 2017; Fan et al., 2012; Kawachi \& Kennedy, 1997; Marshall et al., 2014; Pinault et al., 2017). In this work, we consider quintile and decile ratios, for the population sorted by income. The population is sorted into 10 and 5 equal-sized groups from lowest to highest income, for decile and quintile ratios, respectively. The average $\mathrm{PM}_{2.5}$ health burden is calculated for each decile and quintile. The decile and quintile ratios summarize this by dividing the highest and lowest decile or quintile, respectively. A ratio less than one indicates that lower income populations are exposed to more air pollution. The further the ratio varies from 1 , the more inequity is increasing. 


\subsubsection{Metropolitan Area Case Study}

Environmental equality and environmental equity are assessed for $\mathrm{PM}_{2.5}$ exposure and health burden over NYC. With a population of over 8.5 million people, it is the most densely populated major city in the United States. Because of this, there is significant variation in the demographics and air pollution in a small area, making it well suited to an environmental equity case study.

$\mathrm{PM}_{2.5}$ concentrations are obtained from two sources. First is a longitudinal dataset from the New York City Community Air Survey (NYCCAS) (New York City Department of Health and Mental Hygiene, 2018). The NYCCAS network includes daily measurements of multiple criteria air pollutants at 100 locations across NYC. Using Land-Use Regression (LUR), a surface of $\mathrm{PM}_{2.5}$ average concentrations are generated. There are 8 years of data for average annual PM 2.5 concentrations, from 2009 to 2016, apportioned to a grid with $1 \mathrm{~km} \times 1 \mathrm{~km}$ cells, shown in Figure 4 . 


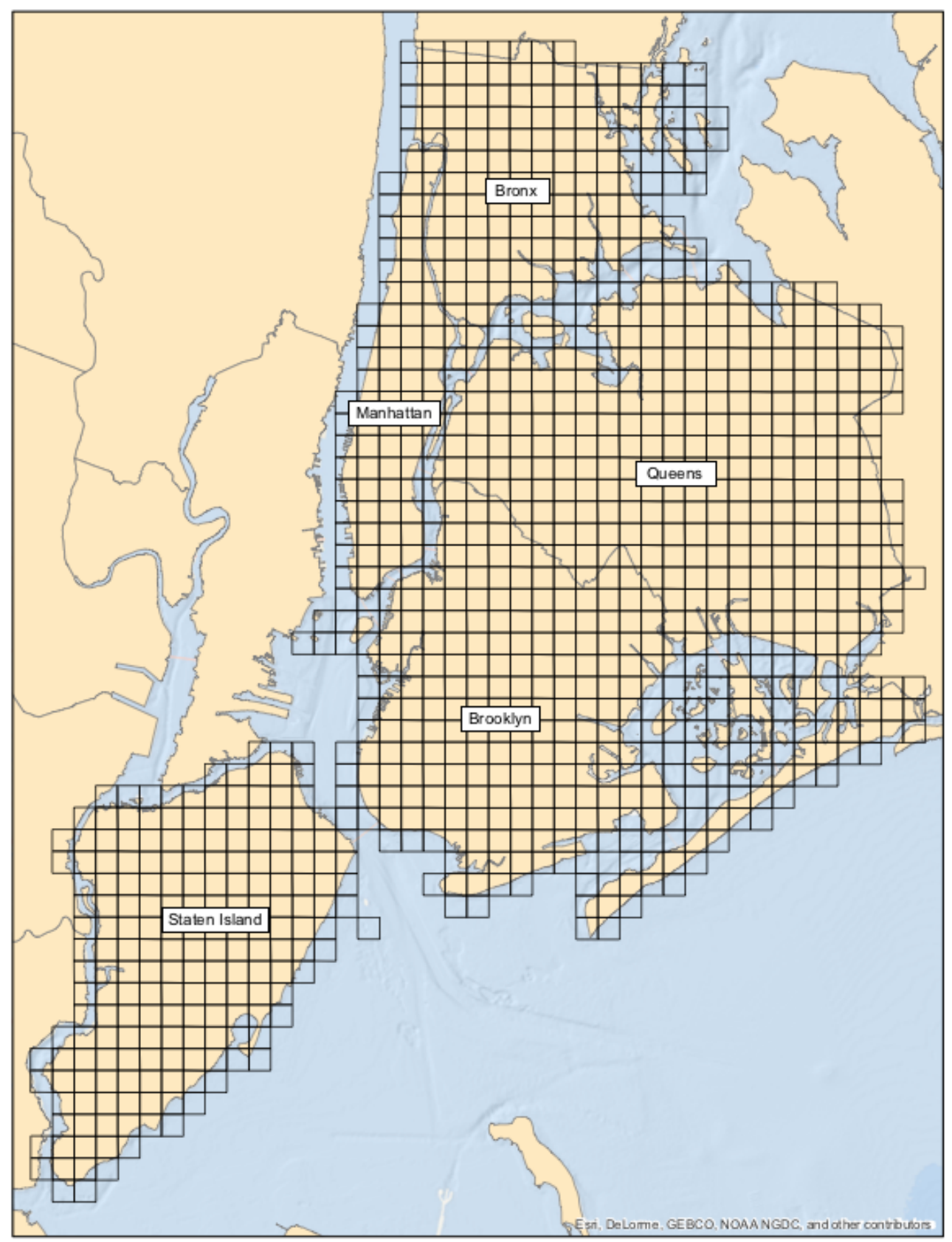

Figure 4. Map of domain used for LUR and CTM air pollution concentrations

The second concentration surface is developed using U.S. EPA's CMAQ model. A unique high-resolution $1 \mathrm{~km}$ dataset was developed for the year 2008 , for NYC and the surrounding areas. The development of this model is described in more detail elsewhere (Kheirbek et al., 2014; Kheirbek, Haney, Douglas, Ito, \& Matte, 2016). A surface of air 
pollution concentrations was generated in CMAQ, targeting a two-week period from July $1-14,2008$. For the environmental equity analysis, only the grid cells that match the LUR data are used, corresponding to Figure 4.

To include SES, income information was taken from the U.S. Census Bureau American Community Survey 5-Year Estimates, for each year from 2009 to 2016 . For each census tract, this data provides the number of households that fall into distinct income bins, when considering 12-month household income. The distribution of income bins is given in Table 1 below. The distribution of the population across income groups was spatially allocated from each census tract to the corresponding model grid cells.

We model environmental equity across the domain, focused on the relationship between $\mathrm{PM}_{2.5}$ concentrations and household income. By assessing the status of environmental equity and equality across multiple models and indices, we can analyze the performance of a high-resolution CTM for air pollution-focused environmental justice analysis. 
Table 1. Income Distribution Categories Provided by the U.S. Census

\begin{tabular}{|c|c|}
\hline Bin \# & 12-month Household Income range \\
\hline 1 & Less than $\$ 10,000$ \\
\hline 2 & $\$ 10,000$ to $\$ 14,999$ \\
\hline 3 & $\$ 15,000$ to $\$ 19,999$ \\
\hline 4 & $\$ 20,000$ to $\$ 24,999$ \\
\hline 5 & $\$ 25,000$ to $\$ 29,999$ \\
\hline 6 & $\$ 30,000$ to $\$ 34,999$ \\
\hline 7 & $\$ 35,000$ to $\$ 39,999$ \\
\hline 8 & $\$ 40,000$ to $\$ 44,999$ \\
\hline 9 & $\$ 45,000$ to $\$ 49,999$ \\
\hline 10 & $\$ 50,000$ to $\$ 59,999$ \\
\hline 11 & $\$ 60,000$ to $\$ 74,999$ \\
\hline 12 & $\$ 75,000$ to $\$ 99,999$ \\
\hline 13 & $\$ 100,000$ to $\$ 124,999$ \\
\hline 14 & $\$ 125,000$ to $\$ 149,999$ \\
\hline 15 & $\$ 150,000$ to $\$ 199,999$ \\
\hline 16 & $\$ 200,000$ or more \\
\hline
\end{tabular}




\subsection{Results and Discussion}

To visualize some of the relevant demographics across the domain, Figure 5 depicts the population across NYC, Figure 6 shows the share of income in each grid cell, and Figure 7 shows the median income for each NYC census tract. The most populated areas correspond to Manhattan and The Bronx, as well as areas of Brooklyn and Queens. The wealthiest areas are found in Manhattan, while the low-income neighbourhoods are found mostly in Harlem and The Bronx.

Share of New York City Households
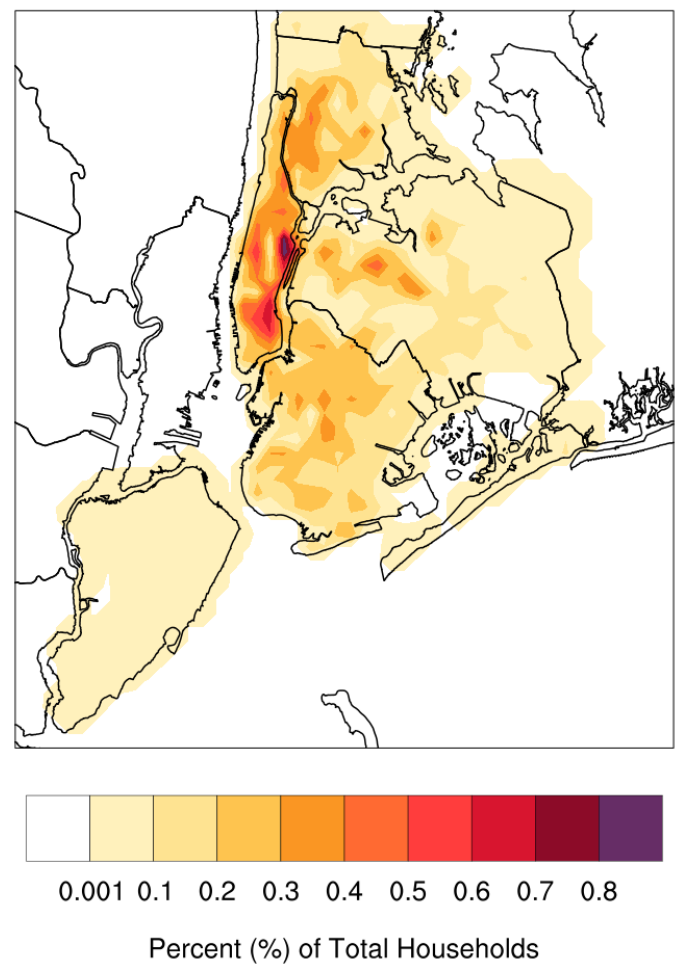

Figure 5. NYC Households, as a percent of the total number of households
Share of New York City Income
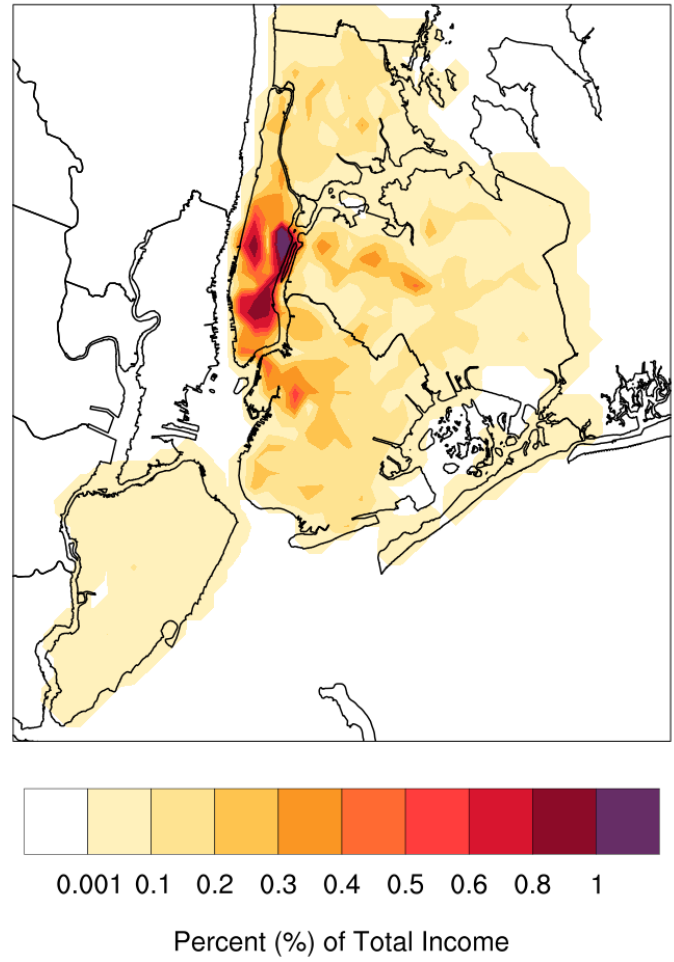

Figure 6. NYC Income, as a percent of the total income 


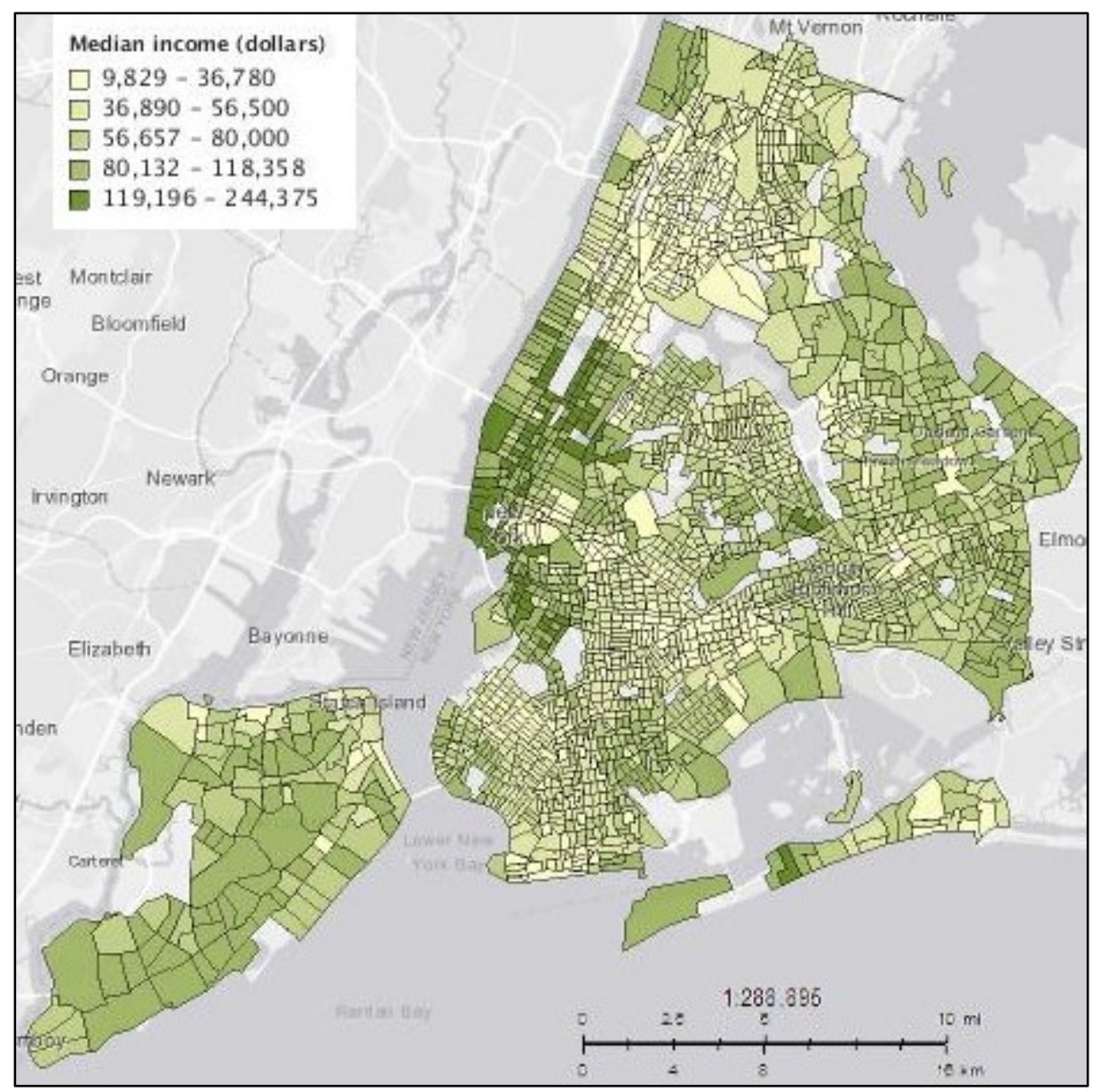

Figure 7. Median Household Income for NYC Census Tracts (2015 American Community Survey 5-year Estimates, U.S. Census)

The average annual $\mathrm{PM}_{2.5}$ concentrations across the domain are shown, from the LUR model, for years 2009-2016 (Figure 8). The longitudinal data shows that $\mathrm{PM}_{2.5}$ concentrations are consistently elevated in Manhattan, the Bronx, and in Western Queens. Overall, annual average $\mathrm{PM}_{2.5}$ concentrations have decreased over the 8-year period, despite certain yearly increases, such as 2011 . 
For the CMAQ model, average $\mathrm{PM}_{2.5}$ concentrations were calculated for the 14-day period, shown in Figure 9. The CMAQ concentrations show a similar spatial pattern to the LUR dataset, with elevated concentrations in Manhattan, Western Queens, and Brooklyn. Note that the CMAQ concentrations are for a 2-week period during the summer, which corresponds to a period with high $\mathrm{PM}_{2.5}$ concentrations. This explains why magnitudes of the CMAQ model are higher than the annual average concentrations shown in the LUR concentrations. Annual average PM2.5 concentrations previously modelled in CMAQ were found to be in a similar range as both the CMAQ and the LUR data, ranging from $7.6-21.8 \mu \mathrm{g} / \mathrm{m}^{3}$ across NYC (Kheirbek et al., 2014). 


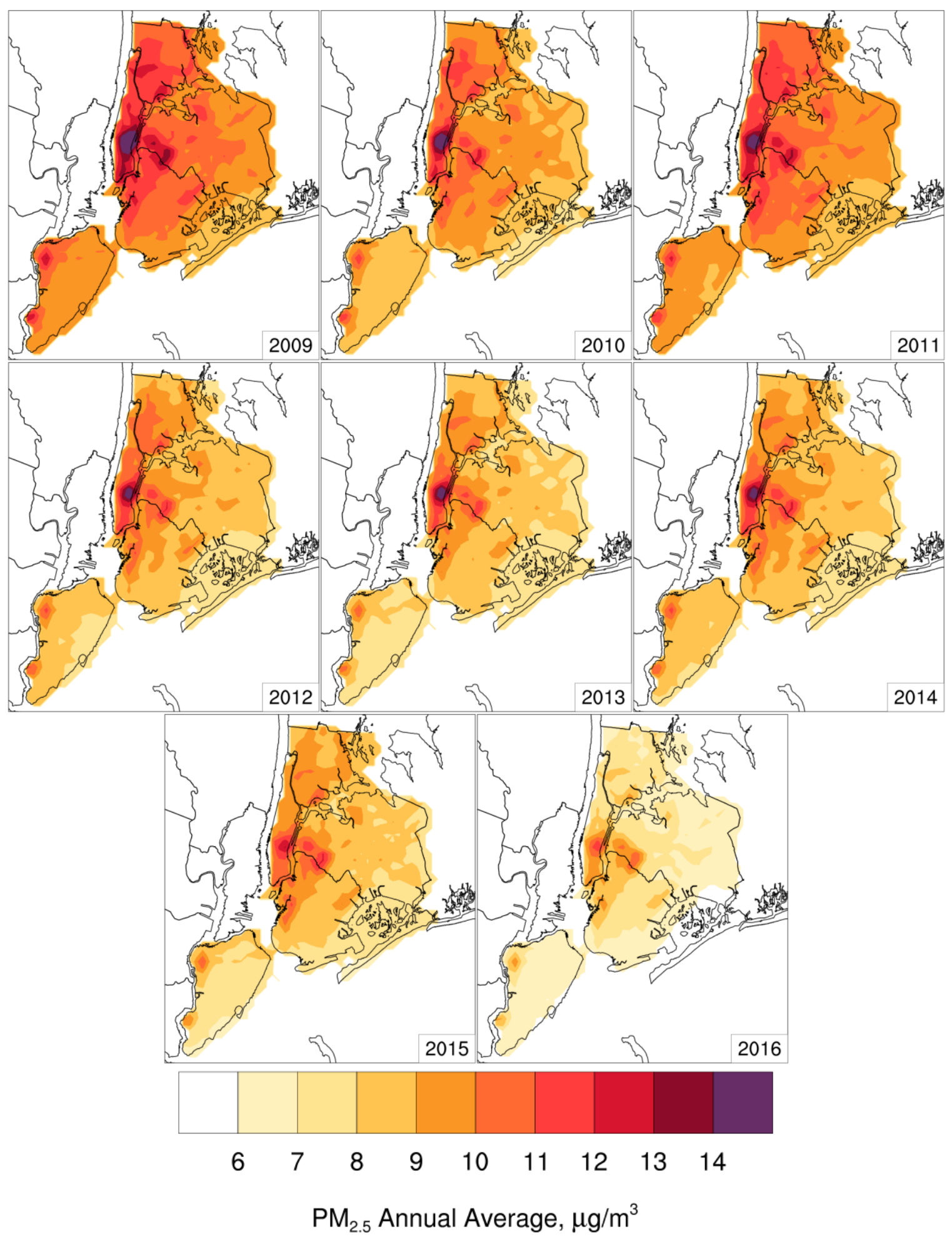

Figure 8. Average Annual PM2.5 Concentrations over 8 Year, from Land-Use Regression 


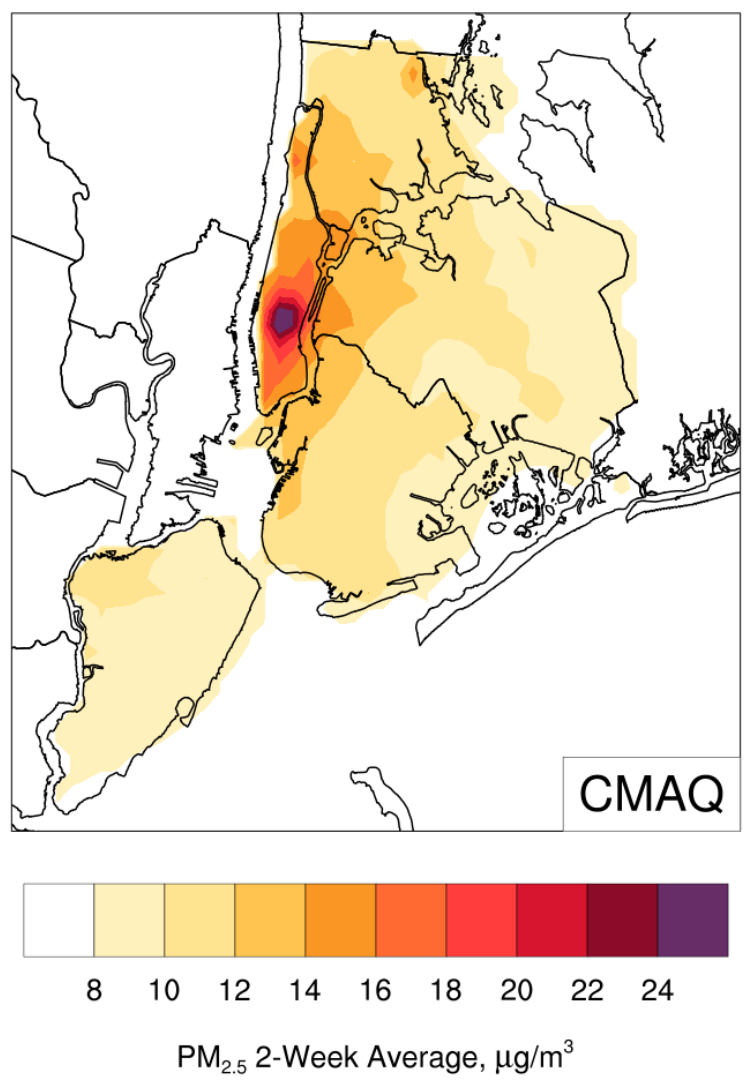

Figure 9. Average 2-week $\mathrm{PM}_{2.5}$ Concentrations Generated by CMAQ

Environmental equity results are shown in Table 2, for $\mathrm{PM}_{2.5}$ health burden. These results consider the mortality from chronic $\mathrm{PM}_{2.5}$ exposure as a representation of environmental risk faced by the population in each area. A one sample t-test was performed for each metric. In all cases, the results are significantly greater than zero, with a 99\% confidence interval. The one sample t-test results are shown in Table 3. 
Table 2. Environmental Justice Results for $\mathrm{PM}_{2.5}$ Health Risk

\begin{tabular}{|c|c|c|c|c|c|c|}
\hline \multirow[b]{2}{*}{ Data Source } & \multirow[b]{2}{*}{ Year } & \multicolumn{2}{|c|}{ Environmental equality } & \multicolumn{3}{|c|}{ Environmental equity (includes income) } \\
\hline & & $\begin{array}{l}\text { Atkinson Index } \\
\qquad\left(\times 10^{-2}\right)\end{array}$ & $\begin{array}{l}\text { Gini Coefficient } \\
\qquad\left(\times 10^{-2}\right)\end{array}$ & $\begin{array}{l}\text { Concentration Index } \\
\qquad\left(\times 10^{-2}\right)\end{array}$ & Quintile Ratio & Decile Ratio \\
\hline CMAQ & 2008 & 3.26 & 10.1 & 1.41 & 0.914 & 0.879 \\
\hline \multirow{8}{*}{ LUR } & 2009 & 2.41 & 5.38 & 1.33 & 0.942 & 0.920 \\
\hline & 2010 & 2.65 & 6.92 & 1.48 & 0.947 & 0.925 \\
\hline & 2011 & 2.58 & 5.76 & 1.52 & 0.944 & 0.915 \\
\hline & 2012 & 2.59 & 6.18 & 1.33 & 0.949 & 0.926 \\
\hline & 2013 & 2.61 & 6.48 & 1.23 & 0.939 & 0.915 \\
\hline & 2014 & 2.54 & 5.82 & 1.22 & 0.935 & 0.913 \\
\hline & 2015 & 2.47 & 5.25 & 1.52 & 0.931 & 0.908 \\
\hline & 2016 & 2.49 & 5.62 & 1.31 & 0.940 & 0.926 \\
\hline
\end{tabular}


Table 3. One-Sample t-test Results for Environmental Justice Analysis of LUR and CMAQ Results, 2008-2016

\begin{tabular}{|c|c|c|c|c|c|}
\hline & Atkinson Index & Gini Coefficient & Concentration Index & Quintile Ratio & Decile Ratio \\
\hline Mean & $2.62 \mathrm{E}-02$ & $6.39 \mathrm{E}-02$ & $1.29 \mathrm{E}-02$ & 0.938 & 1.914 \\
\hline Standard Deviation & $2.5 \mathrm{E}-03$ & $1.5 \mathrm{E}-02$ & $2.6 \mathrm{E}-03$ & 8 & 8 \\
\hline Degrees of freedom, $\mathrm{df}$ & 8 & 8 & 8 & 269.1 & 1.02 \\
\hline t-statistic, $\mathrm{t}(\mathrm{df})$ & 31.2 & 12.9 & 14.7 & $2.0 \mathrm{E}-17$ & $3.3 \mathrm{E}-16$ \\
\hline p-value, $p$ & $6.0 \mathrm{E}-10$ & $6.1 \mathrm{E}-07$ & $2.3 \mathrm{E}-07$ & Yes & Yes \\
\hline Significant, $p<0.01 ?$ & Yes & Yes & Yes & & 8 \\
\hline
\end{tabular}


Results from Table 2 show that there is inequality (as measured through the Atkinson Index, or Gini Coefficient) in PM2.5 health burden in NYC. For the LUR data, the Atkinson Index varies from 2.41 E-02 to $2.65 \mathrm{E}-02$, with an average Index of 2.54 E-02. The CMAQ data has an Atkinson Index of a similar magnitude, at 3.26 E-02. These values are similar to the Atkinson Index that is reported for other urban centres: Martenies et al. (2017) report an Atkinson Index of 0.040 for $\mathrm{PM}_{2.5}$ health risk inequality in Detroit, while Levy et al. (2009) report an Atkinson Index of 0.025 for $\mathrm{PM}_{2.5}$ mortality in Boston.

Meanwhile, the Gini Coefficient varies from 5.25 E-02 to 6.92 E-02 for the LUR data, with an average Coefficient of 5.93 E-02 for LUR surfaces, and 10.1 E-02 for CMAQ. These values are similar to those reported in the literature, for example, national $\mathrm{PM}_{2.5}$ inequality is reported with the Gini Coefficient as ranging from 6.0 E-02 to 13.9 E-02 (Goodkind, Coggins, \& Marshall, 2014), and Boston was found to have a Gini Coefficient of 13 E-02 for PM2.5 mortality (Levy, Greco, et al., 2009).

When considering either the Atkinson Index or the Gini Coefficient, the CMAQ data and LUR data have levels of inequality within the same order of magnitude. However, in both cases, the CMAQ data shows slightly less inequality than the LUR data.

The Atkinson Index, Gini Coefficient, and Lorenz Curve are measures of environmental equality, and do not include information regarding the distribution of $\mathrm{PM}_{2.5}$ health 
burden by SES. Rather, these results show that there are somewhat unequal levels of PM2.5 health risk across NYC regardless of income.

The right-hand side of Table 2 shows the same data analyzed for environmental equity, or the relationship between $\mathrm{PM}_{2.5}$ health burden and household income. This is measured through the Quintile Ratio, Decile Ratio, and the Concentration Index. The Quintile Ratio varies from 0.931 to 0.949 , with a mean value of 0.941 . The CMAQ data has a smaller Quintile Ratio of 0.914 . For the decile ratio, the LUR data varies from 0.908 to 0.926 , with a mean of 0.918 , and the CMAQ data has a smaller decile ratio of 0.879 . For the Concentration Index, the LUR varies from $1.22 \mathrm{E}-02$ to $1.52 \mathrm{E}-02$, with a mean of 1.37 E-02. The CMAQ data has a Concentration Index of $1.41 \mathrm{E}-02$, falling very close to the mean of the LUR data. These values are similar to those reported in the literature, such as $2.0 \mathrm{E}-02$ to $3.1 \mathrm{E}-02$ for Los Angeles (Su et al., 2009), or 1.0 E -02 to 6.7E -02 for Detroit (Martenies et al., 2017).

With the decile and quintile ratios, inequality increased as the values diverge from 1. Thus, the decile ratio suggests a greater level of inequality than the quintile ratio. For NYC, this indicates that environmental inequity is most pronounced for extremes of income, and less pronounced for middle income ranges. In both cases, while the CMAQ data has a similar magnitude to the LUR data, it indicates higher levels of inequality than the LUR data set. 
The Gini Coefficient and Concentration Index are based off the Lorenz Curve and Concentration Curve, respectively. Figure 10 shows the Lorenz Curve (A) and Concentration Curve (B) for a representative year. The year 2009 was selected since the median Atkinson Index, Concentration Index, and Decile Ratio all occur for this year. Furthermore, this year is the closest year to CMAQ simulations. Lorenz Curves for each year of LUR data are shown in Appendix 1, while Concentration Curves for each year of LUR data are shown in Appendix 2. The same curves are plotted for the CMAQ data (Figure 11, A and B). 


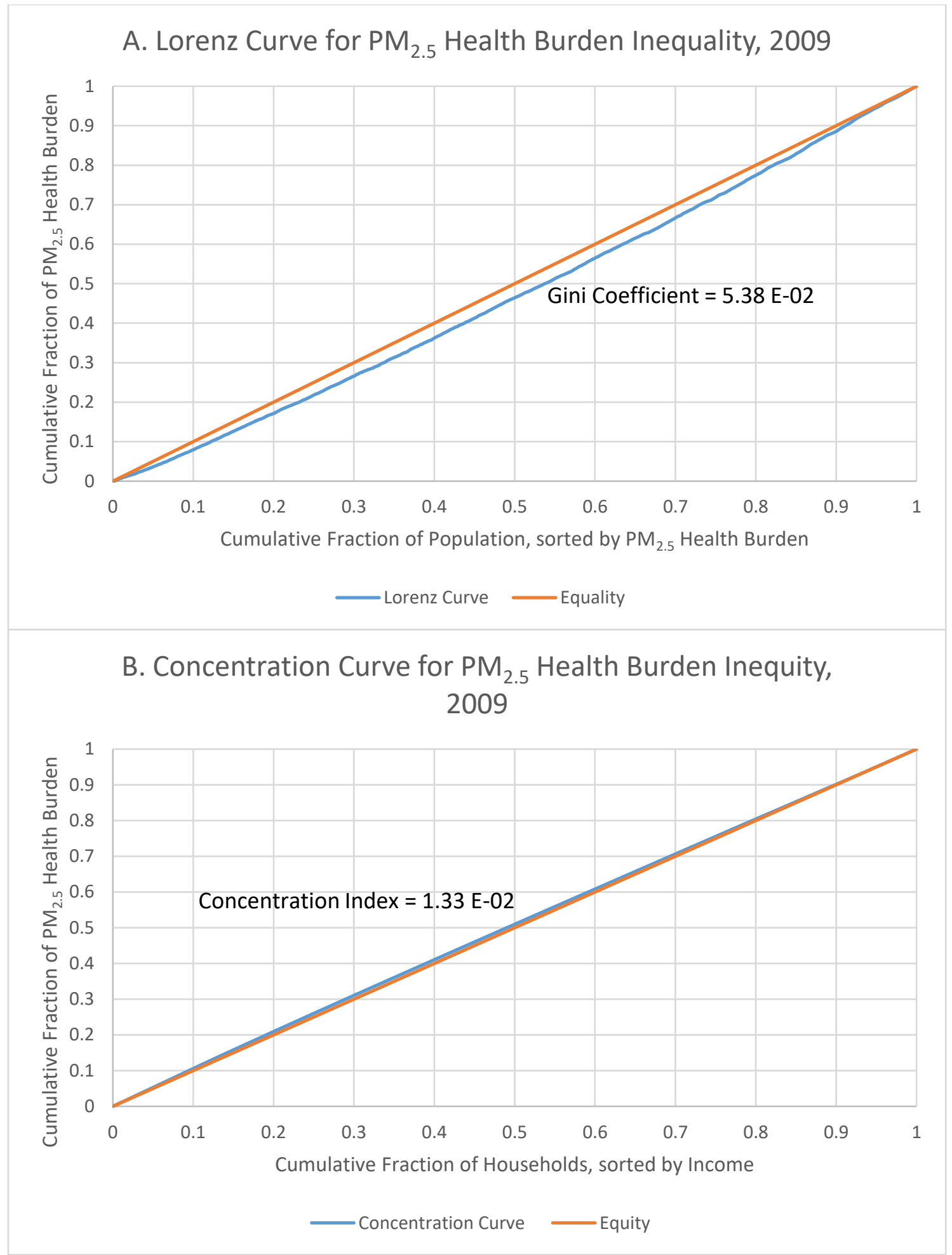

Figure 10. Lorenz Curve (A) and Concentration Curve (B) for Land-Use Regression Data for 2009 


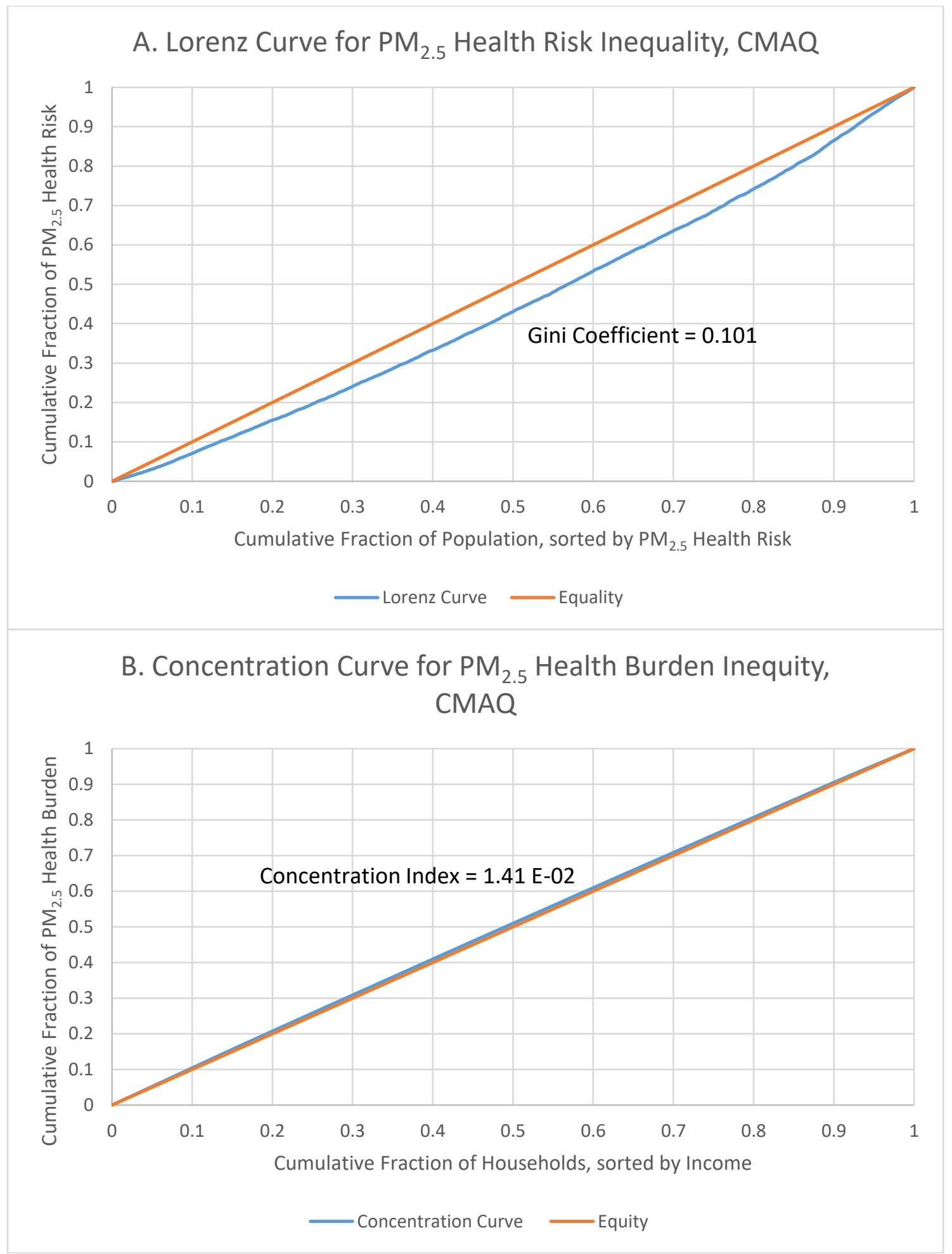

Figure 11. Lorenz Curve (A) and Concentration Curve (B) for CMAQ data for July 2008 
Figure $10 \mathrm{~A}$ shows that there is inequality across NYC, where the $10 \%$ least exposed are exposed to $7.9 \%$ of the overall $\mathrm{PM}_{2.5}$ health burden. Meanwhile, the $10 \%$ most exposed are exposed to $11.9 \%$ of the overall $\mathrm{PM}_{2.5}$ health burden. The CMAQ dataset's Lorenz Curve is shown in Figure 11A. The inequality in the CMAQ data is pronounced, with the $10 \%$ least exposed holding $7.1 \%$ of the $\mathrm{PM}_{2.5}$ health burden, and the $10 \%$ most exposed holding $13.3 \%$ of the $\mathrm{PM}_{2.5}$ health burden.

For both Figure $10 \mathrm{~B}$ and Figure 11B, the Concentration Curve falls above the Line of Equity, indicating that lower-income people are exposed to more $\mathrm{PM}_{2.5}$ health burden than higher-income populations. This is broken out for both the LUR and CMAQ data in Table 4, which compares each income group's share of total income and total $\mathrm{PM}_{2.5}$ health burden. If the share of overall $\mathrm{PM}_{2.5}$ health burden is larger than the share of overall income, that income group is considered disadvantaged. For the LUR data, all households with an annual income below $\$ 30,000 /$ year are disadvantaged. For the CMAQ data, all households with an annual income below $\$ 25,000 /$ year are similarly found to be disadvantaged. The same table is reproduced for other years of data in Appendix 3. In general, the CMAQ dataset more closely underestimates the overall levels of inequity seen in the LUR data for the Concentration Index than for any of the other inequality/inequity parameters. 
Table 4. Share of Total Income and Total PM2.5 Health Risk by Income Group, for LUR year 2009 and CMAQ July 2008

\begin{tabular}{|c|c|c|c|c|c|c|}
\hline \multirow[b]{2}{*}{$\begin{array}{l}\text { 12-month Household } \\
\text { Income range }\end{array}$} & \multicolumn{3}{|c|}{ LUR Year 2009} & \multicolumn{3}{|c|}{ CMAQ July 2008} \\
\hline & $\begin{array}{l}\text { Share of total } \\
\text { income (\%) }\end{array}$ & $\begin{array}{l}\text { Share of total } \\
\mathrm{PM}_{2.5} \text { health } \\
\text { risk (\%) }\end{array}$ & $\begin{array}{c}\text { Health risk } \\
\text { share }>\text { income } \\
\text { share }\end{array}$ & $\begin{array}{c}\text { Share of total } \\
\text { income (\%) }\end{array}$ & $\begin{array}{l}\text { Share of total } \\
\mathrm{PM}_{2.5} \text { health } \\
\text { risk (\%) }\end{array}$ & $\begin{array}{c}\text { Health risk } \\
\text { share }>\text { income } \\
\text { share }\end{array}$ \\
\hline Less than $\$ 10,000$ & $10.93 \%$ & $11.56 \%$ & True & $10.28 \%$ & $10.79 \%$ & True \\
\hline$\$ 10,000$ to $\$ 14,999$ & $6.14 \%$ & $6.37 \%$ & True & $6.20 \%$ & $6.46 \%$ & True \\
\hline$\$ 15,000$ to $\$ 19,999$ & $5.31 \%$ & $5.43 \%$ & True & $5.53 \%$ & $5.60 \%$ & True \\
\hline$\$ 20,000$ to $\$ 24,999$ & $5.10 \%$ & $5.16 \%$ & True & $5.11 \%$ & $5.13 \%$ & True \\
\hline$\$ 25,000$ to $\$ 29,999$ & $4.80 \%$ & $4.82 \%$ & True & $4.56 \%$ & $4.53 \%$ & False \\
\hline$\$ 30,000$ to $\$ 34,999$ & $4.73 \%$ & $4.73 \%$ & False & $4.47 \%$ & $4.46 \%$ & False \\
\hline$\$ 35,000$ to $\$ 39,999$ & $4.38 \%$ & $4.37 \%$ & False & $4.04 \%$ & $4.00 \%$ & False \\
\hline$\$ 40,000$ to $\$ 44,999$ & $4.24 \%$ & $4.21 \%$ & False & $4.14 \%$ & $4.08 \%$ & False \\
\hline$\$ 45,000$ to $\$ 49,999$ & $3.81 \%$ & $3.77 \%$ & False & $3.42 \%$ & $3.36 \%$ & False \\
\hline$\$ 50,000$ to $\$ 59,999$ & $7.34 \%$ & $7.24 \%$ & False & $6.82 \%$ & $6.68 \%$ & False \\
\hline$\$ 60,000$ to $\$ 74,999$ & $9.16 \%$ & $9.00 \%$ & False & $8.67 \%$ & $8.45 \%$ & False \\
\hline$\$ 75,000$ to $\$ 99,999$ & $11.13 \%$ & $10.90 \%$ & False & $11.00 \%$ & $10.64 \%$ & False \\
\hline$\$ 100,000$ to $\$ 124,999$ & $7.32 \%$ & $7.11 \%$ & False & $7.71 \%$ & $7.48 \%$ & False \\
\hline$\$ 125,000$ to $\$ 149,999$ & $4.46 \%$ & $4.34 \%$ & False & $4.98 \%$ & $4.88 \%$ & False \\
\hline$\$ 150,000$ to $\$ 199,999$ & $4.80 \%$ & $4.67 \%$ & False & $5.74 \%$ & $5.65 \%$ & False \\
\hline$\$ 200,000$ or more & $6.35 \%$ & $6.31 \%$ & False & $7.33 \%$ & $7.82 \%$ & True \\
\hline
\end{tabular}


The temporal trend in the LUR dataset is plotted in Figure 12, along with linear trend lines and their corresponding $\mathrm{R}^{2}$ values. Environmental equality, shown through the Atkinson Index (Figure 12A) and the Gini Coefficient (Figure 12B) track a similar pattern, with the same pattern of rising and falling levels of inequality. Different between the two metrics are the magnitudes of the change in inequality. For example, the year 2010 sees a large increase in inequality for the Atkinson Index, and a smaller increase in inequality for the Gini Coefficient. This change in magnitude can be attributed to the formulation of the Atkinson Index, and the selection of an inequality aversion parameter. Using a value of 0.75 , the Atkinson Index is more sensitive to transfers at the higher end of the distribution (Atkinson, 1975). The larger jumps in the Atkinson Index correspond to transfers in the higher end of the distribution (among those that are already the most exposed), which has more of an effect on the Atkinson Index.

The Concentration Index (Figure 12C) and Decile/Quintile Ratio (Figure 12D) show a different picture of environmental equity in NYC. Consider the year 2015, which corresponds to an improvement in environmental equality according to the Atkinson Index (Figure 12A) and Gini Coefficient (Figure 12B). Referring to Figure 8, 2015 has annual average $\mathrm{PM}_{2.5}$ concentrations that were lower than the previous year, which could explain the improvement in environmental equality seen. However, the Concentration Index and Quintile/Decile Ratios suggest that environmental inequity got worse than the preceding years. This suggests that the decreasing $\mathrm{PM}_{2.5}$ concentrations 
carried more health benefits for higher-income populations, and less to lower-income populations. This example illustrates the importance of considering both environmental equality and equity; while $\mathrm{PM}_{2.5}$ concentrations might be decreasing and improving the average health of New Yorkers, there can be an unintended consequence of widening the disparity between low-income and high-income populations.

Across all metrics seen in Figure 12, the linear trend appears to be decreasing inequality and inequity. However, corresponding $R^{2}$ values do not suggest that this trend is statistically significant. Over the 8 years, NYC has seen a sizeable decrease in $\mathrm{PM}_{2.5}$ concentrations (Figure 8). These results suggest that this decrease has not been accompanied by improving levels of environmental equality and equity. While decreases in $\mathrm{PM}_{2.5}$ concentrations over the 8-year period suggest that $\mathrm{PM}_{2.5}$ health burden is decreasing, its distribution is not becoming significantly more equitable. 

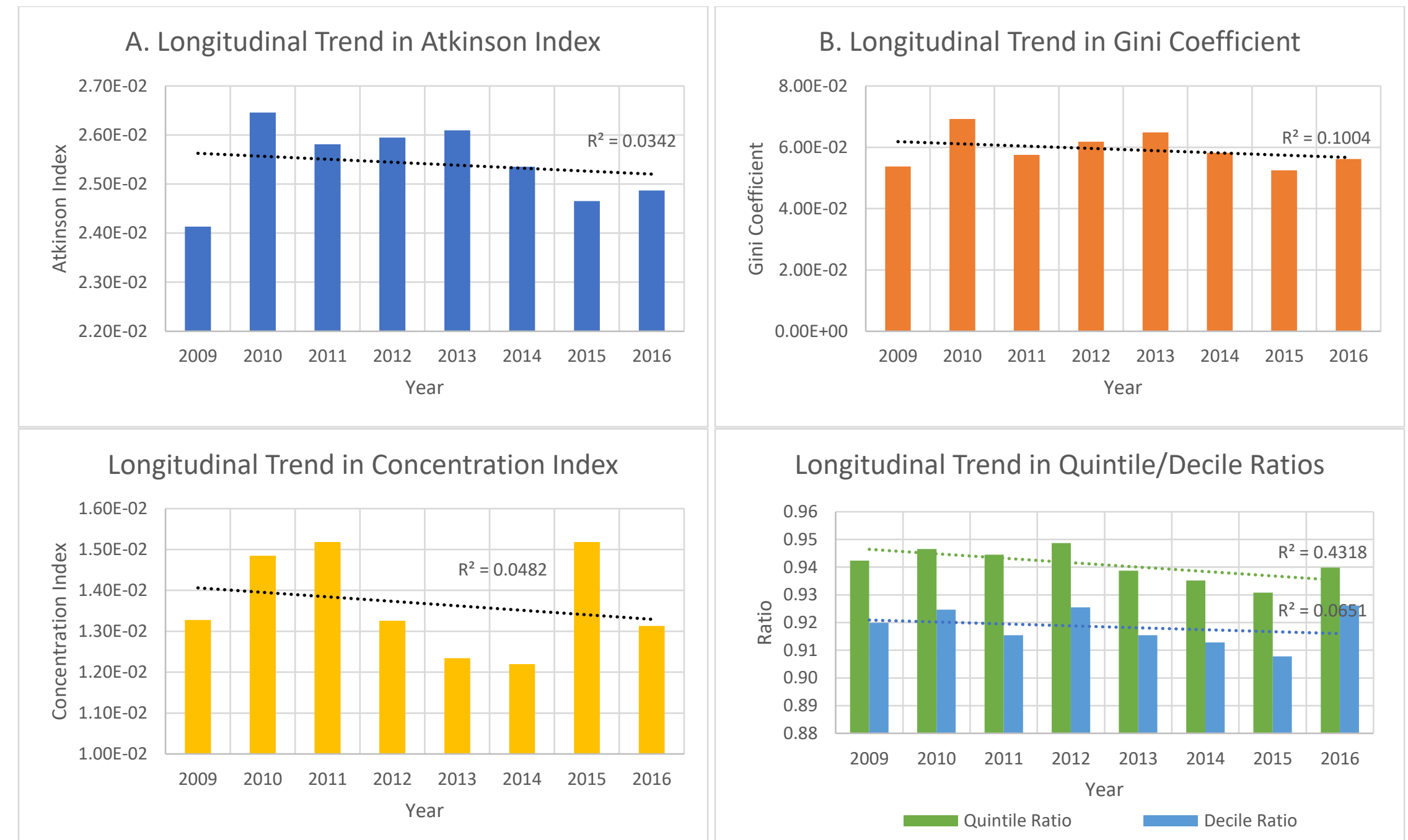

Figure 12. Temporal Trend in Inequality and Inequity of PM 2.5 Health Risk for 8-years of LUR data 


\subsection{Conclusions}

In this paper, the status of environmental justice as it relates to $\mathrm{PM}_{2.5}$ exposure is assessed for NYC, using contrasting data sets and analysis methods. Overall, results suggest that levels of environmental inequality and inequity persist in NYC, despite that temporal reductions in $\mathrm{PM}_{2.5}$ concentrations can be observed.

Environmental justice is examined using multiple metrics, including those that measure the equality of the distribution across the entire population, and those that measure the equity of the distribution across socio-economic groups in the population. Importantly, this work shows that an improvement in equality does not always translate to an improvement in equity. Without considering income or other SES metrics, it would be possible to continue to disadvantage low-income populations in the City, despite seeing significant reductions in average annual $\mathrm{PM}_{2.5}$ concentrations, and improvements in environmental equality. In future works, exploring a combination of environmental equality and environmental equity metrics to ensure the best understanding of the environmental justice landscape is recommended.

Temporally, while the LUR dataset for NYC shows a decreasing linear trend, these results are not statistically significant and do not suggest that equality and equity have been improving over the last 8 years. While annual $\mathrm{PM}_{2.5}$ concentrations have been decreasing consistently, these concentrations are not always decreasing in a manner 
that fosters equity across the region. As mentioned above, environmental inequity persists more strongly than environmental inequality, where low-income populations are disadvantaged over other populations in the region.

When comparing the LUR and CMAQ datasets, both are within similar orders of magnitude when predicting environmental equality and equity in the NYC region, despite overestimations by CMAQ. The LUR data typically shows overall higher levels of inequality and inequity than the CMAQ data. This can likely be attributed to the timeframe of the two datasets. While the LUR data represents annual average $\mathrm{PM}_{2.5}$ concentrations, the CMAQ data only models two weeks of data in July. Despite this, the results show that CMAQ and other CTMs of comparable resolution can be used to assess the levels of environmental justice in a metropolitan area.

There are some limitations to this study to consider. First, the various datasets do not always match each other temporally. For example, the baseline mortality rates are only available as three-year averages from 2012-2014, while the household income data and $\mathrm{PM}_{2.5}$ concentrations are changing year to year and across datasets. This paints a more limited picture of changing environmental justice in the region, since mortality rates have likely changed over the 9 years of this study. A valuable next step in this research would be to analyze the same concentrations with more refined mortality data. While changing air quality is captured in this study, it does not include all of the changes that 
reflect the livelihoods of people living in NYC. This is important since efforts to improve environmental equity can be achieved by reducing air pollution, but also by improving the other socio-economic disparities among the exposed populations.

In future work, one possible consideration is examining other metrics of SES, such as education or race. While there are levels of environmental inequity in NYC when considering household income, it is currently unknown if these levels of inequity persist when considering other forms of SES.

Beyond this, the next logical step in assessing environmental justice in NYC is to consider how the situation might be improved. Demonstrating the usefulness of CMAQ and other CTMs is especially important to this line of future work, since these models can be used to test proposed air pollution control strategies and a variety of future scenarios. Furthermore, sensitivity analysis of these models can be used to trace the relative importance of different emission sources on the current levels of environmental inequity. In combination with understanding the current levels of environmental inequity, these future studies can better inform policies to improve air quality and environmental justice simultaneously. 


\subsection{Quantifying Impacts of Emission Reductions on Environmental Justice and Human Health in New York City}

This chapter is in preparation for publication in Environmental Science and Technology. It consists of original research for which Robyn Chatwin-Davies is the main contributor $(70 \%)^{2}$.

\subsection{Introduction}

Air pollution is a primary health concern; globally, ambient air pollution accounts for approximately 4.2 million premature deaths every year (Forouzanfar et al., 2016), and is considered by the World Health Organization (2014) to be one of the largest environmental health risks. As such, there remains a strong imperative to control ambient air pollution and its impacts on human health.

Air pollution is a form of environmental exposure that is highly variable in space, and urban areas with a wide range of demographic variation are particularly affected by ambient air pollution concentrations. The field of environmental justice is concerned with the distribution of environmental burdens and benefits across a population. Previous research has established that people of lower socioeconomic status (SES) tend to be exposed to greater environmental burdens, and are more susceptible to the

${ }^{2}$ Co-authors on this work include: Burak Oztaner, Shunliu Zhao, Melanie Fillingham, Marjan Soltanzadeh, Matthew Russell, Amir Hakami (Carleton University); Amanda Pappin (Health Canada); Iyad Kheirbek, Kazuhiko Ito (New York City Department of Health and Mental Hygiene); Jay Haney, Sharon Douglas (ICF International); and the Adjoint Development Group. 
effects of environmental hazards in turn (Clark et al., 2014). Because of spatial variability, particularly in urban areas, air pollution has been widely studied within the field of environmental justice. Many studies have focused on characterizing the relationship between ambient air pollution and income, whether for a single city (Anderson et al., 1978; Brajer \& Hall, 2005; Grineski et al., 2007; Marshall, 2008; Molitor et al., 2011; Pope et al., 2016; Su et al., 2009, 2012) or across a region (Bell \& Ebisu, 2012; Clark et al., 2014; Miranda et al., 2011; Morello-Frosch \& Jesdale, 2006; Zwickl et al., 2014). Previous U.S. studies have found that lower income households are more often located in areas with higher air pollution (Clark et al., 2014; Grineski et al., 2007; Morello-Frosch, Pastor, \& Sadd, 2001). Similar results are found in Canada (Buzzelli \& Jerrett, 2003; Carrier, Apparicio, Kestens, et al., 2016; Carrier et al., 2014b; Jerrett et al., 2007; Pinault et al., 2016), and in Europe (Briggs et al., 2008; Brunt et al., 2016; Havard et al., 2009).

Building on the existing body of literature, understanding how environmental inequity might be reduced remains an area of interest. Previous works have investigated how the reduction of emissions can impact environmental justice through the analysis of specific proposed policies (Fann et al., 2011), or hypothetical emission reductions scenarios (Levy, Greco, et al., 2009; Levy et al., 2007; Marshall et al., 2014). These studies require SES and pollution datasets at a refined spatial scale. Many studies rely on land-use regression models (Brunt et al., 2016; Clark et al., 2014; Rosofsky et al., 2018; Temam et 
al., 2017) or atmospheric dispersion models (Martenies et al., 2017; Poorfakhraei et al., 2017; Pratt et al., 2015; Tayarani et al., 2016) to provide the necessary spatial resolution, while a small number of papers model concentrations using Chemical Transport Models (CTMs) (Fann et al., 2011; Marshall et al., 2014; Nguyen \& Marshall, 2018). The benefit of using a CTM is the flexibility to change parameters and model future scenarios. Furthermore, sensitivity analysis can be used to better quantify the relationship between sources and receptors.

Sensitivity analysis is one possible approach to quantifying how health and equity metrics respond to changes in emissions. In traditional (i.e. forward) sensitivity analysis, a perturbation is made in the forward CTM, followed by a map of influence on all locations from the change in emissions. Forward sensitivity analysis has receptor specificity, but lacks details about multiple individual sources. In order to quantify the influence of each emission source with source-specificity, this study relies on backward or adjoint sensitivity analysis (Sandu, Daescu, Carmichael, \& Chai, 2005). Adjoint sensitivity analysis provides information about the specific impacts of each source on a policy metric, making it particularly relevant to target the most influential emissions sources (Hakami et al., 2006; Pappin \& Hakami, 2013b).

We model the distribution of a criteria air pollutant $\left(\mathrm{PM}_{2.5}\right)$ over New York City (NYC) and surrounding areas using a regional CTM, and quantify levels of inequity across 
income groups. Expanding on previous works, this study quantifies how reducing emissions on a location-by-location basis might impact the landscape of public health and environmental equity across a domain, as well as potential synergies that may exist between policies that address these two endpoints.

\subsection{Materials and Methods}

Environmental inequity comprises a wide variety of environmental hazards and socioeconomic markers. However, this study focuses on the relationship between air pollution and income within NYC.

This study uses a domain encompassing NYC and its surrounding areas, and examines a two-week period from July 1 through July 14, 2008. A surface of air pollution concentrations is generated using the U.S. EPA's Community Multiscale Air Quality (CMAQ) model at a $1 \mathrm{~km}$ grid-resolution (shown in Figure 13). This application of CMAQ over NYC is described elsewhere (Kheirbek et al., 2014, 2016). The high-resolution dataset is particularly important in the analysis of environmental inequity, since both income and air pollution are highly spatially variable across the domain. 


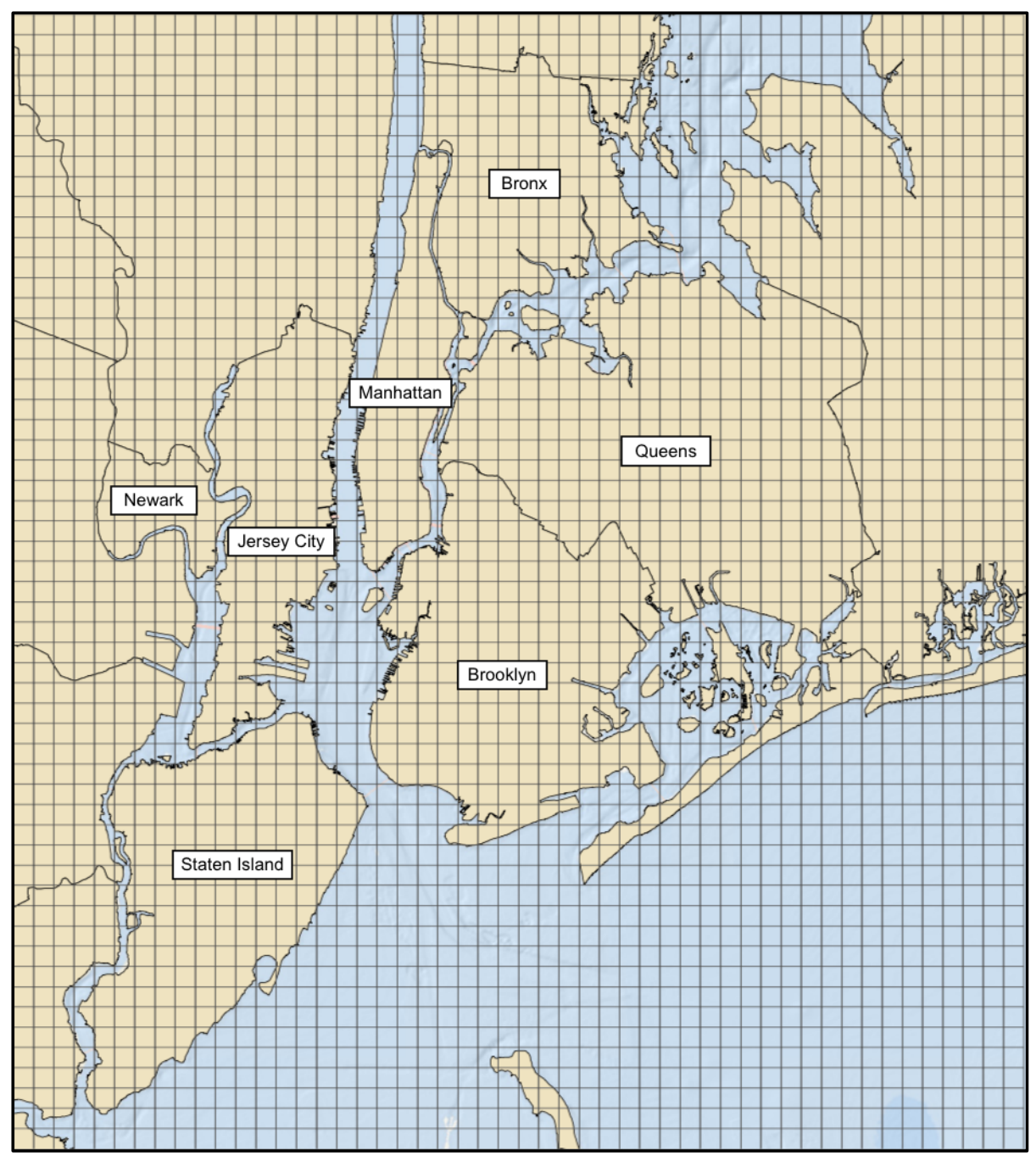

Figure 13. Modelling domain of New York City and surrounding areas. The CMAQ modelling grid is $50 \mathrm{~km} \times 56 \mathrm{~km}$, and each grid cell is a size of $1 \mathrm{~km} \times 1 \mathrm{~km}$.

The CMAQ model is driven by meteorological inputs from the Weather Research and

Forecasting (WRF) model (National Center for Atmospheric Research, 2018). Emissions

were prepared on an hourly basis using the Sparse Matrix Operator Kernel Emissions

(SMOKE) model (Community Modeling and Analysis System, 2018), using emissions from

the 2008 National Emissions Inventory. 
Income data is based on 12-month household income, taken from the 2010-2014 American Community Survey 5-Year Estimates in the U.S. Census. This data provides the number of households in each census tract divided between 16 income bins, ranging from a household income less than $\$ 10,000 /$ year to greater than $\$ 200,000 /$ year. Income and population information were then re-gridded to the CMAQ grid.

Adjoint sensitivity analysis estimates the influence of emissions from all sources (at all locations and times) on a single receptor or group of receptors. It is complementary to forward sensitivity analysis, and provides source-specific information. In air quality modelling, adjoint sensitivities are calculated using the adjoint of the underlying CTM (in this case, $\mathrm{CMAQ}$ ), integrated backward in time and space to trace the influence on an outcome, back to all sources at the input of the model. A detailed description of adjoint sensitivity analysis can be found in previous publications (Hakami et al., 2005, 2007; Henze et al., 2007).

A key parameter in adjoint sensitivity analysis is the definition of an adjoint cost function $(J)$, which is a scalar metric with known functionality to relate the concentrations at a receptor to the outcome for which sensitivity information is being sought. Examples from previous works include cost functions based on the attainment of air quality standards (Hakami et al., 2006; Pappin \& Hakami, 2013a), or the air pollution impacts on public health (Pappin et al., 2016, 2015; Pappin \& Hakami, 2013b; Turner, Henze, Capps, 
et al., 2015; Turner, Henze, Hakami, et al., 2015). We define $J$ as a function of $\mathrm{PM}_{2.5}$ concentration for two sets of model simulations: for the health impacts of air pollution exposure, and for the inequity of health impacts across income groups.

\subsubsection{Estimating Health Impacts of Air Pollution Exposure}

We define our health-based adjoint cost function as the monetary value of mortality $(M)$ resulting from chronic exposure to $\mathrm{PM}_{2.5}$. This cost function is calculated based on an epidemiological concentration response function, where a change in pollutant concentration $(\Delta C)$ produces a change in mortality $(\Delta M)$ given by the following equation:

$\Delta M=M_{0} \times P\left(1-e^{-\beta \Delta C}\right)$

where $M_{0}$ is the baseline mortality rate (BMR), $P$ is the population, and $\beta$ is an epidemiological constant representing each pollutant's concentration-response. For $\mathrm{PM}_{2.5}$, a $\beta$-value of $0.005827 / \mu \mathrm{g} / \mathrm{m}^{3}$ for 24 -hour average $\mathrm{PM}_{2.5}$ concentration was used, based on the widely used work of Krewski et al.(2009). BMR was provided by the New York City Department of Health and Mental Hygiene at a high resolution, i.e., for each zip code in NYC. Both the BMR and $\beta$-value are based on all-cause mortality from chronic exposure to $\mathrm{PM}_{2.5}$, for people aged 30-99.

A change in mortality can be monetized by multiplying Equation 5-1 by the value of statistical life (VSL), which is based on the average individual's willingness to pay to 
reduce the likelihood of death. Using data from the U.S. EPA (U.S. Environmental Protection Agency, 2018b), we applied a VSL of \$7.9M USD, giving Equation 5-2:

$\Delta M_{\$}=M_{0} \times P\left(1-e^{-\beta \Delta C}\right) \times V_{S L}$

By deriving Equation 5-2 with respect to concentration, at each location ( $x$, with a total of $N$ locations) and each time ( $i$, with a total of $n$ timesteps), we developed the healthbased adjoint cost function $\left(U_{m}\right)$ :

$J_{m}=\sum_{x=1}^{N} \sum_{i=1}^{n} M_{0_{x}} P_{x} \beta e^{-\beta \Delta C_{i, x}} \times V_{S L}$

This forcing term drives the backward integration of adjoint sensitivity equations in the same way that emissions drive evolution of concentrations in the forward CMAQ model. Through this backward integration, the adjoint model traces the influence on domainwide chronic $\mathrm{PM}_{2.5}$ exposure mortality back to emissions at individual locations and times.

\subsubsection{Quantifying Environmental Inequity}

There are a number of existing methods to quantify environmental equity, with the Lorenz Curve, Concentration Curve, and Atkinson Index among the most well-known. Maguire and Sheriff (2011) review these indices and provide detail on their technical formulation. We define our equity-based adjoint cost function from the Concentration 
Curve, a modified form of the Lorenz Curve, as it incorporates information about SES directly (Kakwani et al., 1997; Koolman \& van Doorslaer, 2004; Wagstaff, 2002; Wagstaff et al., 1989), and its application in environmental equity studies is well documented (Martenies et al., 2017; Sarabia \& Jorda, 2013; Su et al., 2009; Walker et al., 2005).

The Concentration Curve depicts the cumulative fraction of the measure of interest (health burden from $\mathrm{PM}_{2.5}$ exposure), against the cumulative fraction of the population, sorted from lowest to highest income group. The Concentration Curve allows a visual representation of the inequity, estimated by the deviation from the $45^{\circ}$ line of equity. The Concentration Index is a summary statistic, which is a normalized value ranging from 0 (maximum equity) to 1 (maximum inequity), and is equivalent to double the area between the Concentration Curve and line of equity.

We use the Concentration Index to characterize the current levels of environmental inequity, and as the cost function for adjoint sensitivity analysis. The Concentration Index cannot be represented by a closed-form equation, so a brute-force approach was employed to generate the forcing terms. The average concentration was perturbed in each grid cell across the domain, and the corresponding change in the Concentration Index is stored as the forcing term, with multiple perturbation levels being used to ensure stable forcing calculations. The importance of each location and each time is 
captured in the forcing terms, and adjoint sensitivity analysis will trace the influence of each source location on the domain-wide environmental inequity.

We further propose an approach for valuation of the inequity sensitivities to better compare the impacts of emission reductions on inequity and health. The obvious approach to improving environmental equity involves reducing emissions such that the ambient concentrations are equivalent to income levels across the domain.

Alternatively, environmental equity could be achieved by increasing income to equilibrate the levels of air pollution exposure at each location. While not practical for policy implementation, this relationship provides a basis for the monetization of an incremental change in inequity.

We calculate the minimum amount of added income needed to match the change in inequity from the simulated adjoint sensitivities. This entails the hypothetical transfer of an individual from the lowest income group (annual household income $<\$ 10,000$ ) to the second income group (annual household income $\$ 10,000$ - $\$ 14,999$ ) in each grid cell, and subsequent calculation of the reduction in domain-wide inequity. The maximum reduction in inequity, or the minimum amount of added income for a given change in inequity, corresponds to the calculated value for the grid cell with the highest air pollution concentrations. Assuming transfer of one individual from lowest to secondlowest income group can be valued at $\$ 5,000$ increase in average household income, we 
scale this cost to represent the monetized change in inequity for unit emissions in any given grid cell.

\subsection{Results and Discussion}

We estimate the health benefits from primary PM emission reductions at each location (Figure 14). The marginal health benefits are reported in $\$ 1,000,000$ 's for a reduction of primary PM emissions by 1 tonne/year, and represent the annual health benefits experienced across the domain. A value of $\$ 3,000,000$ indicates that a 1 tonne/year reduction in primary PM emissions at that location would benefit the region with $\$ 3,000,000$ in valuated reduced mortality. The marginal health benefits from secondary $\mathrm{PM}_{2.5}$ formation from $\mathrm{SO}_{2}$ emissions are shown in Appendix 4.

Marginal benefits are highly sensitive to population density. In this model, the greatest benefits correspond to locations with large populations, particularly in downtown Manhattan. Emission reductions originating in Lower Manhattan have the single largest influence, with overall health benefits exceeding \$10 million per tonne of annual primary PM. Other areas in which emission reductions result in significant marginal health benefits include the East Village, East Harlem, and the John F. Kennedy airport in Queens. 


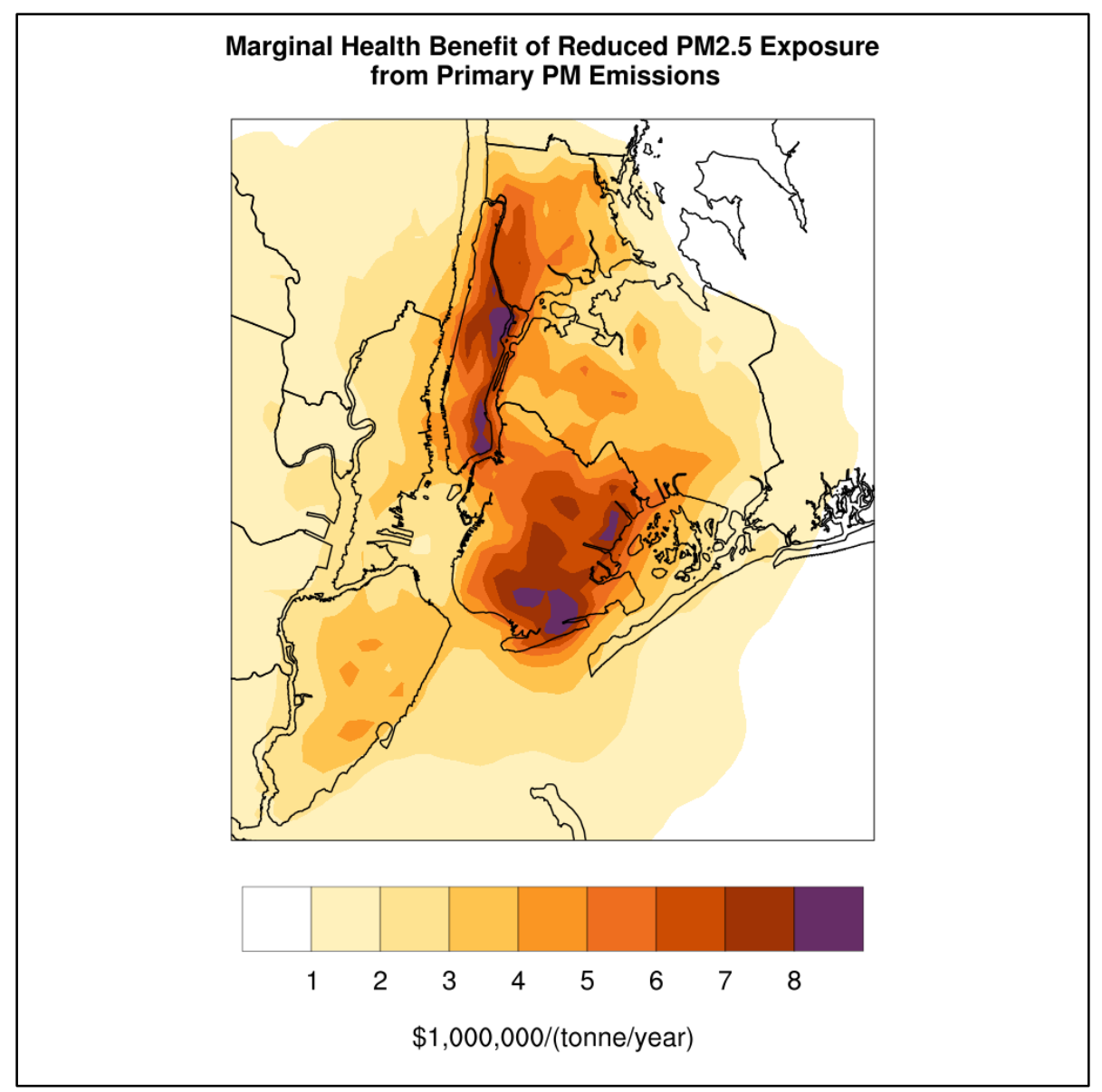

Figure 14. Marginal Health Benefits from individual locations for a 1 tonne/year reduction in primary PM emissions.

These results are subject to certain limitations. Adjoint sensitivities show the response of a domain-wide health metric to emission reductions from each source location across the domain. They provide source-specificity, as they can directly trace the magnitudes of influence exerted by various sources. However, adjoint sensitivity cannot determine the distribution of impacts across the domain, as this is more appropriately quantified in forward sensitivity analysis. 
Another limitation is that emissions transported outside the domain prior to affecting human health are not captured in this model, due to a lack of boundary influences. Given both the relatively small domain size, as well as the many populated areas located just outside the domain boundaries, it is likely that emissions within the domain have impacts outside its boundaries. Future refinements of this model will include nesting within a larger modelling domain to inform out-of-domain influences at the boundary. This refinement may change the relative importance of emissions along the edges of the current modelling domain.

The Concentration Curve shown in Figure 15 estimates the current levels of environmental inequity for $\mathrm{PM}_{2.5}$ health burden across income groups, with a corresponding Concentration Index of 0.0205 . This is within the same order of magnitude as the Concentration Index reported for $\mathrm{PM}_{2.5}$ in Los Angeles, ranging from 0.020 to 0.031 (Su et al., 2009), and in Detroit, ranging from 0.010 to 0.067 (Martenies et al., 2017). 


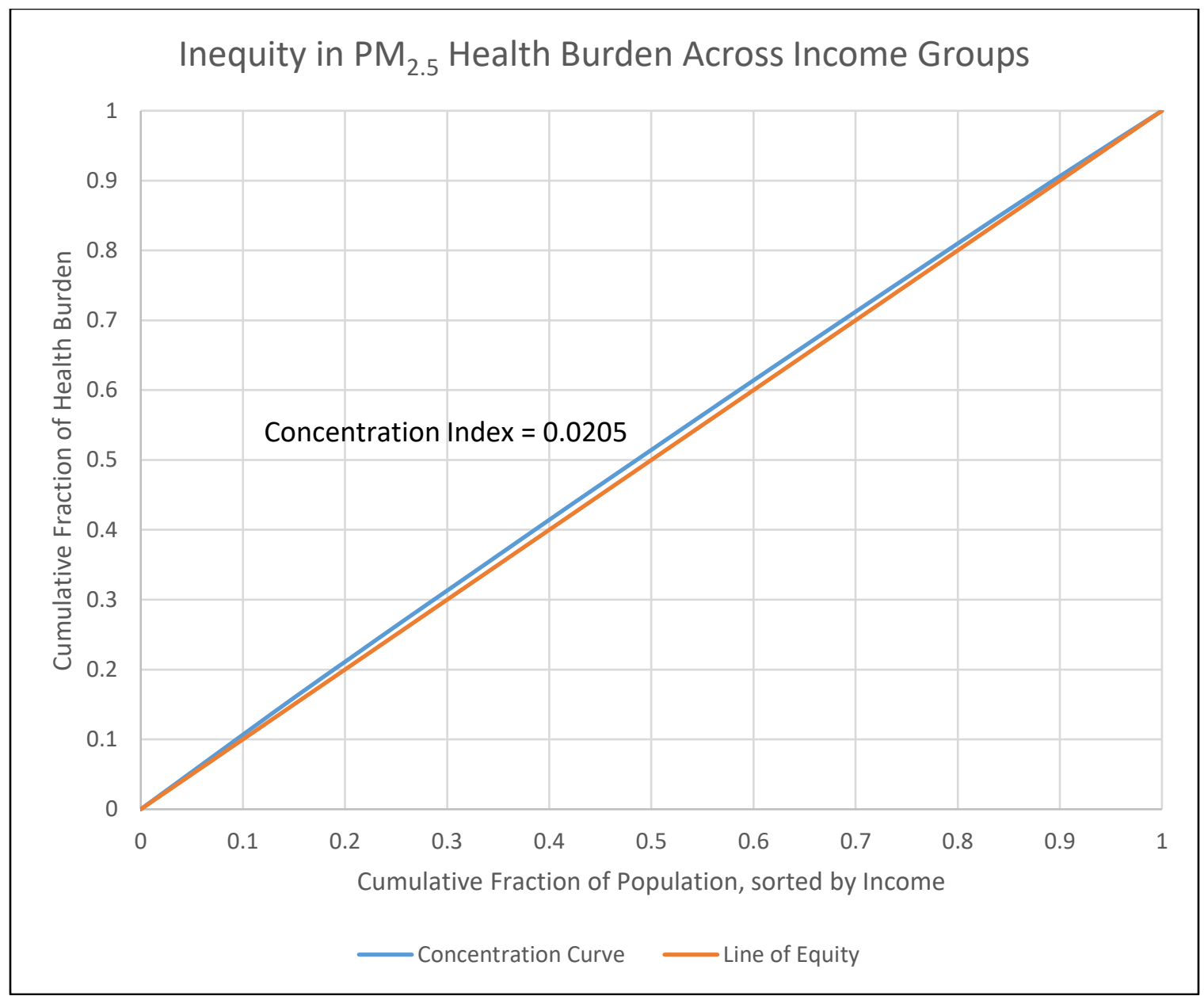

Figure 15. Concentration Curve for $\mathrm{PM}_{2.5}$ Health Burden Inequity. The Line of Equity represents a scenario where the entire population is exposed to the same levels of health burden, regardless of income. Since the Concentration Curve falls above the Line of Equity, lower income populations have a higher share of the overall $\mathrm{PM}_{2.5}$ health burden.

These results show that lower-income populations face systematically higher health burden, when compared to higher-income populations. Table 5 presents the basis for this conclusion, through a comparison between each income group's share of total income and its share of overall $\mathrm{PM}_{2.5}$ health burden. If an income group's share of overall health burden exceeds their share of total income (households with an annual income below $\$ 45,000 /$ year in Table 1$)$, they are characterized as disadvantaged. 
Table 5. Share of total income and total $\mathrm{PM}_{2.5}$ health burden by income group

\begin{tabular}{|c|c|c|c|}
\hline $\begin{array}{l}\text { 12-month Household } \\
\text { Income range }\end{array}$ & $\begin{array}{l}\text { Share of total } \\
\text { income (\%) }\end{array}$ & $\begin{array}{c}\text { Share of total } \mathrm{PM}_{2.5} \\
\text { health burden (\%) }\end{array}$ & $\begin{array}{c}\text { Health burden share } \\
>\text { income share }\end{array}$ \\
\hline Less than $\$ 10,000$ & $9.55 \%$ & $10.19 \%$ & True \\
\hline$\$ 10,000$ to $\$ 14,999$ & $5.86 \%$ & $6.20 \%$ & True \\
\hline$\$ 15,000$ to $\$ 19,999$ & $5.32 \%$ & $5.48 \%$ & True \\
\hline$\$ 20,000$ to $\$ 24,999$ & $4.95 \%$ & $5.08 \%$ & True \\
\hline$\$ 25,000$ to $\$ 29,999$ & $4.52 \%$ & $4.57 \%$ & True \\
\hline$\$ 30,000$ to $\$ 34,999$ & $4.41 \%$ & $4.47 \%$ & True \\
\hline$\$ 35,000$ to $\$ 39,999$ & $3.97 \%$ & $4.02 \%$ & True \\
\hline$\$ 40,000$ to $\$ 44,999$ & $4.09 \%$ & $4.13 \%$ & True \\
\hline$\$ 45,000$ to $\$ 49,999$ & $3.44 \%$ & $3.43 \%$ & False \\
\hline$\$ 50,000$ to $\$ 59,999$ & $6.80 \%$ & $6.79 \%$ & False \\
\hline$\$ 60,000$ to $\$ 74,999$ & $8.77 \%$ & $8.70 \%$ & False \\
\hline$\$ 75,000$ to $\$ 99,999$ & $11.22 \%$ & $11.01 \%$ & False \\
\hline$\$ 100,000$ to $\$ 124,999$ & $7.95 \%$ & $7.75 \%$ & False \\
\hline$\$ 125,000$ to $\$ 149,999$ & $5.25 \%$ & $5.08 \%$ & False \\
\hline$\$ 150,000$ to $\$ 199,999$ & $6.18 \%$ & $5.88 \%$ & False \\
\hline$\$ 200,000$ or more & $7.72 \%$ & $7.22 \%$ & False \\
\hline
\end{tabular}

From the current levels of inequity calculated above, we estimate the influence of primary PM emission reductions at each location (Figure 16). The sensitivities are reported as a percent reduction to the current levels of $\mathrm{PM}_{2.5}$ health burden inequity for a 1 tonne/year reduction of primary PM emissions. 
Percent Reduction in $\mathrm{PM}_{2.5}$ Health Burden Inequity from Primary PM Emissions
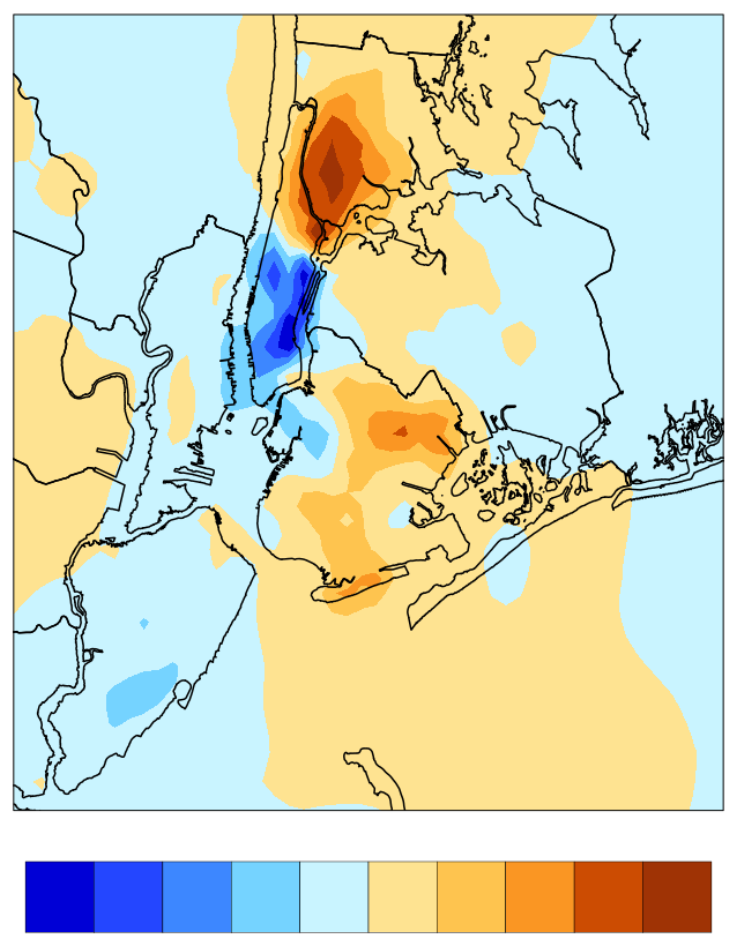

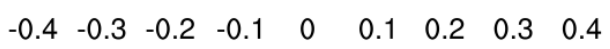

$\%$ reduction in inequity/(tonne/year)

Figure 16. Percent reduction in environmental inequity of $\mathrm{PM}_{2.5}$ health burden for a 1 tonne/year reduction in primary PM emissions.

In Figure 16, positive sensitivities occur at locations where a reduction in emissions leads to a reduction in overall inequity. The single largest positive influence originates from the Bronx, reaching an overall $0.55 \%$ cumulative reduction in inequity for each tonne of primary PM source reductions. Since low-income populations share a higher burden of the health burden, reducing emissions in predominantly low-income neighbourhoods will make the region more equitable. 
Negative sensitivities occur at locations where reducing emissions leads to a higher level of overall inequity. The single largest negative influence originates from primary PM emission reductions in Lower Manhattan, reaching an overall $0.51 \%$ increase in inequity. Generally, the largest negative influences are associated with locations that have a higher proportion of higher-income households, where emission reductions aggravate the disparities already seen across the region.

While Figure 16 shows the change in environmental equity that can be expected from reducing primary PM emissions, the monetized results in Figure 17 show the minimum amount of money that would need to be given to low-income households to have an equivalent impact on environmental equity. 


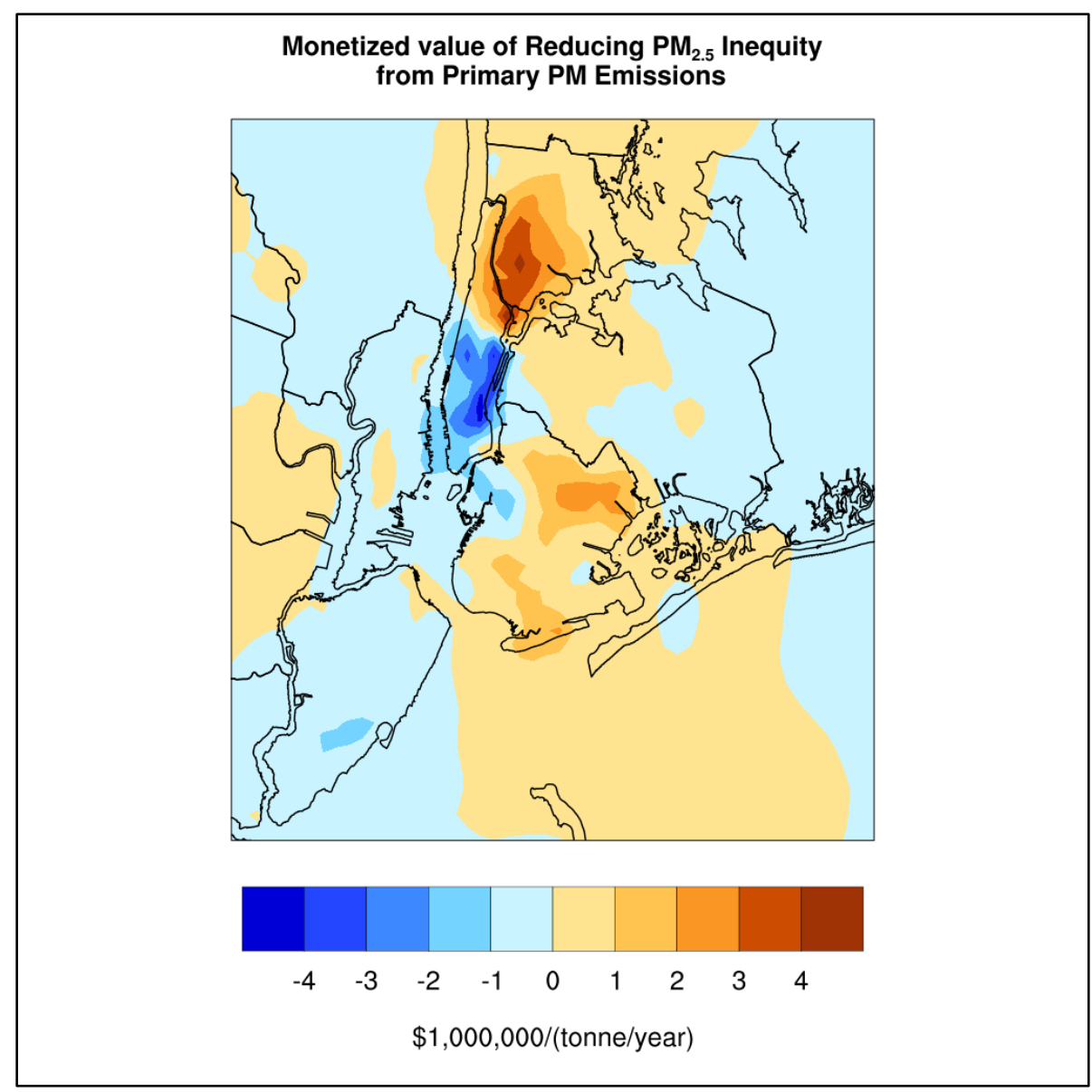

Figure 17. Monetary equivalent of change in $\mathrm{PM}_{2.5}$ health burden inequity achieved by reducing 1 tonne/year primary PM emissions.

The abatement costs of primary PM emissions are typically far smaller than the cost of improving equity through other means, as illustrated by this monetization. When considering the aligned benefits of reduced mortality and reduced inequity, these results present a compelling case for substantial monetary investments in the abatement of primary PM emissions in NYC.

Furthermore, the monetized equity improvements have magnitudes comparable to the monetized health benefits (Figure 14) at most locations. This indicates that, while 
improvements in public health continue to be the most important driver in developing air quality management policies, the importance of environmental equity should not be overlooked. These results indicate that equity considerations should be included in choosing emission reductions targets, as a secondary consideration to public health benefits. The following section explores how this coordination might occur.

\subsubsection{Coordinating Emission Reductions across Policy Endpoints}

Air quality management policies traditionally focus on achieving a single endpoint as effectively as possible (Levy et al., 2007; Yitzhaki, 2003). Environmental justice advocates have raised concerns that these policies can unintentionally aggravate disparities of pollution levels across SES (Brajer \& Hall, 2005; Burtraw \& Mansur, 1999; Corburn, 2001; Solomon \& Lee, 2000). As such, there is renewed interest in providing a complementary environmental justice analysis in tandem with proposed air quality management strategies (Levy et al., 2006; Levy, Greco, et al., 2009).

Toward this end, source-specific estimates of the influence of emission reductions on achieving both endpoints provide practical information. Combined, an analysis of multiple sensitivities can provide information on synergistic impacts of emission reductions in improving multiple policy endpoints. Figure 18 shows the impact of primary PM emission reductions on both health and equity at each location. Each point represents a grid cell from the modelling domain, and the sensitivity to reduced 
mortality from $\mathrm{PM}_{2.5}$ exposure (taken from Figure 14 ) is plotted against the sensitivity to reduced inequity in $\mathrm{PM}_{2.5}$ health burden (taken from Figure 17).

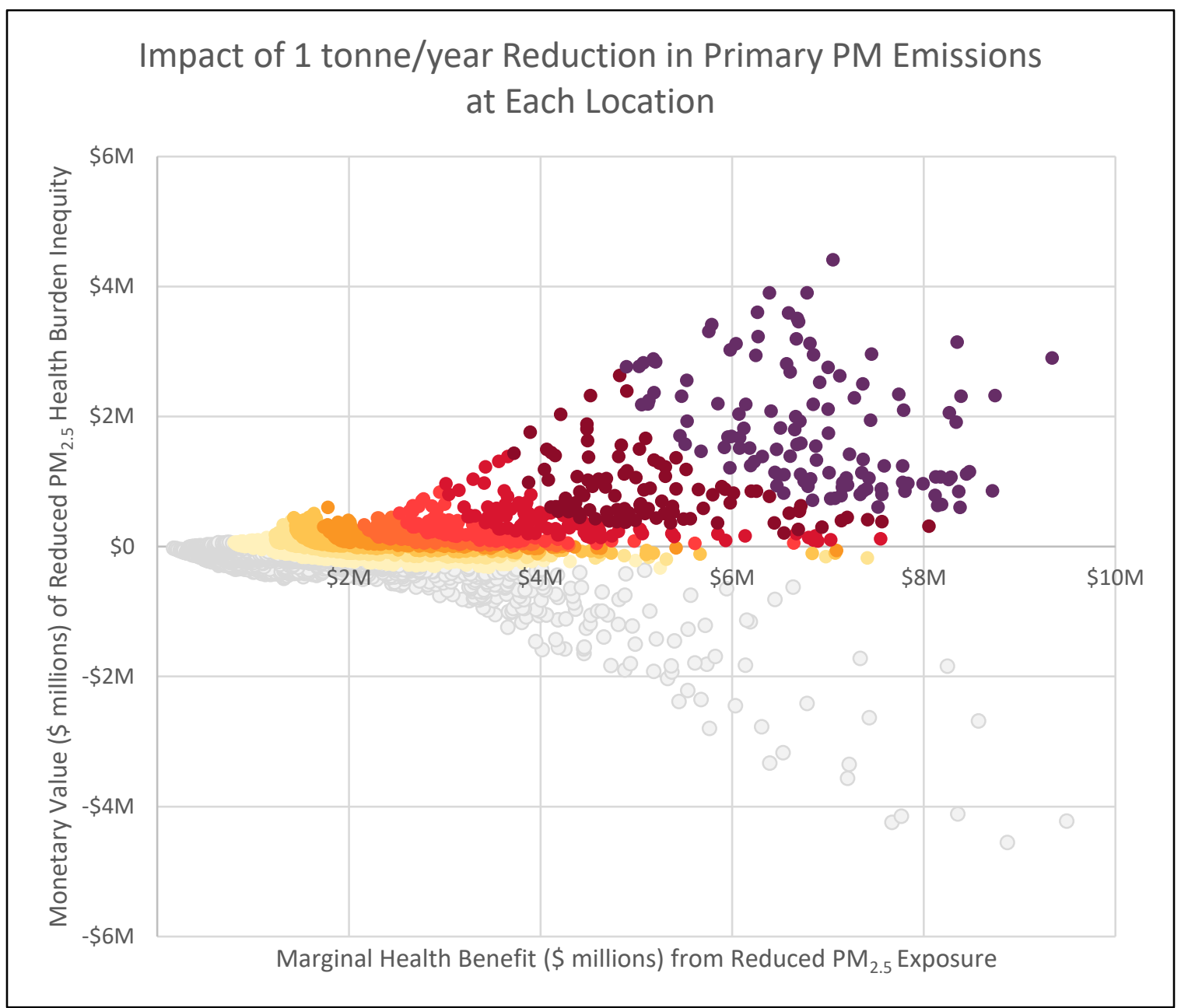

Figure 18. Scatter plot showing the impact of reducing 1 tonne/year of primary PM emissions at each location in the modelling domain. Each point represents one grid cell, where its sensitivity to health impacts is plotted against its sensitivity to reduced inequity.

Emission reductions always have positive impacts on human health, but can have positive or negative impacts on environmental equity. There are many locations in 
which emission reductions result in significant positive impacts to both health and environmental equity, corresponding to the top right corner of Figure 18.

In order to visualize the locations of synergistic emission reductions, we score each grid cell based on the percentile rank of the sensitivities in both datasets:

Score $=\left(P_{m}\right)\left(P_{e}\right)$

where $P_{m}$ is the percentile rank of that location's sensitivity to health impacts, and $P_{e}$ is the percentile rank of the same location's sensitivity to environmental inequity. The score is normalized from 0 to 1 , where lower scores occur in locations that carry low (or negative) influence to one or both policy endpoints, and higher scores occur in locations where emission reductions carry large positive influences on health and equity.

Figure 19 visualizes the scores calculated from Equation 5-4 on the modelling domain. Low scores are mostly found in locations around the edges of the domain that carry small influences on both health and equity endpoints. There is also a low score in Manhattan (excluding Harlem). While emission reductions have a large positive influence on public health, the demographics of Manhattan cause this health benefit to be biased toward high-income households, aggravating the disparity across income groups. 
The highest scores for synergistic emission reductions are found in Brooklyn, Harlem, and the Bronx, where emission reductions have positive effects on both health and equity endpoints. This can be attributed to the higher proportion of low-income households living in these areas, where emission reductions are most influential on the region's environmental equity.

Synergistic Primary PM Emission Reductions

on $\mathrm{PM}_{2.5}$ Mortality and Health Burden Inequity
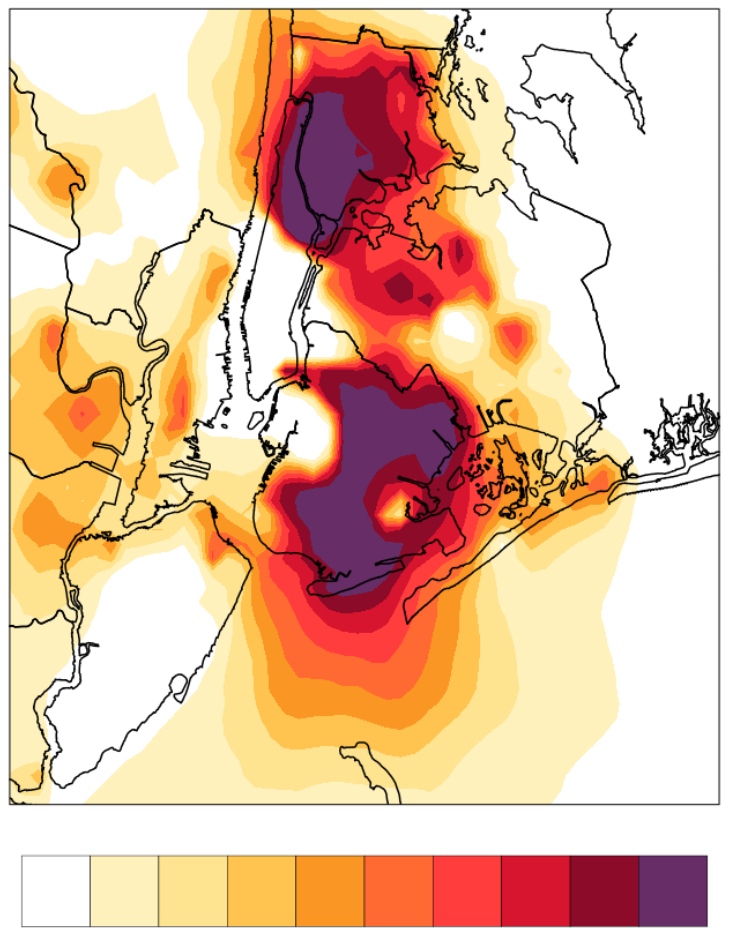

$\begin{array}{lllllllll}0.1 & 0.2 & 0.3 & 0.4 & 0.5 & 0.6 & 0.7 & 0.8 & 0.9\end{array}$

Score

Figure 19. Ranking of effectiveness of primary PM emission reductions on health and equity endpoints. Reducing emissions in a location with a higher score will carry larger benefits to both health and equity considerations. Conversely, reducing emissions in a location with a low score will either carry small benefits to both endpoints, or will have positive impacts on one endpoint and negative impacts on the other. 
Alternatively, both policy endpoints can be assessed by adding the marginal health benefits (Figure 14) to the monetized value of reduced inequity (Figure 17). Figure 20 shows the monetary benefit of reducing primary PM emissions with regards to the combined effects of health and equity endpoints.

\section{Monetized Value of Combined Reduction of $\mathrm{PM}_{2.5}$} Inequity and Mortality from Primary PM Emissions
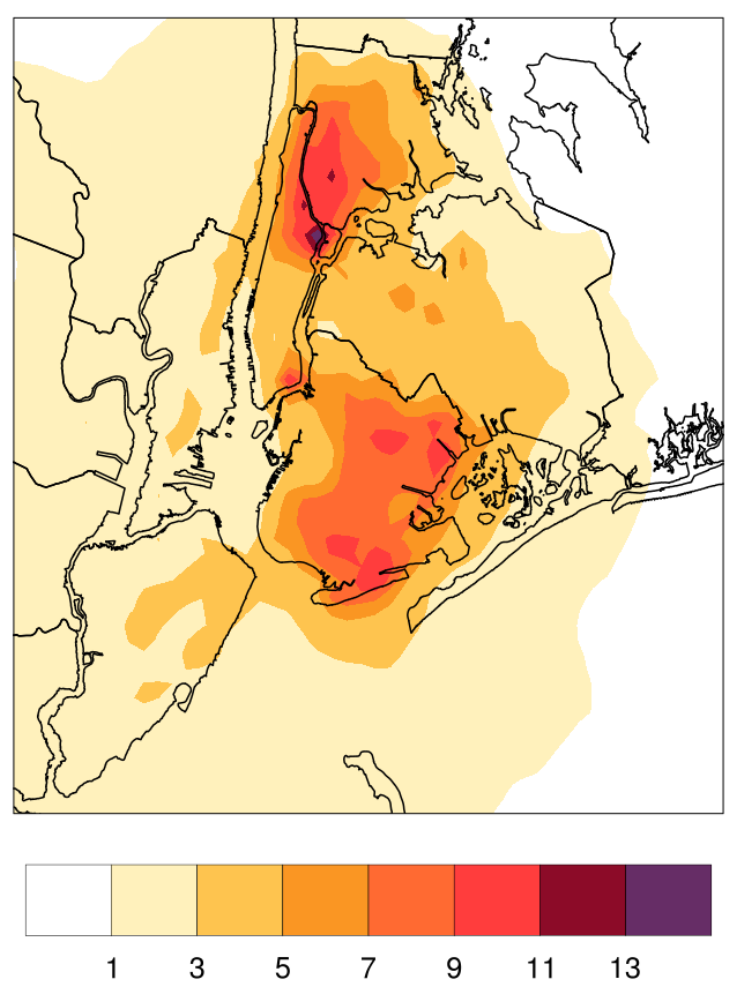

$\$ 1,000,000 /$ (tonne/year)

Figure 20. Monetized benefit of reducing 1 tonne/year primary PM emissions, when considering combined benefits of reduced $\mathrm{PM}_{2.5}$ mortality, as well as improved equity of $\mathrm{PM}_{2.5}$ health burden across income groups

Figure 20 shows only positive values, indicating that the benefits from improved health outweigh any location with disbenefits from increased disparity. In Figure 20, the largest 
overall influence occurs for emissions originating in Harlem, reaching a combined benefit of $\$ 15,000,000$ for a primary PM emission reduction of 1 tonne/year.

To illustrate the impact of this synergistic approach, we consider a case study for a $5 \%$ emission reduction target in NYC. The location of emission reductions can be chosen based on ranked sensitivities of the chosen policy metric. Toward this end, we consider 4 different ranking methods for emission reduction strategies. The first strategy maximizes public health benefits by considering the sensitivities to $\mathrm{PM}_{2.5}$ mortality alone. The second strategy maximizes environmental equity, and considers only the sensitivities to $\mathrm{PM}_{2.5}$ health burden inequity. The third strategy is based on the combined percentile scores from Figure 19, and the fourth is based on the combined monetized benefits from Figure 20. The third and fourth cases represent policy scenarios that consider multiple goals in reducing emissions.

In each case, we reduce $30 \%$ of the emissions in the most influential grid cells until the overall $5 \%$ domain-wide emission reduction target is reached. Depending on the policy priority, emission reductions are prioritized starting from the locations with maximum sensitivities or scores. Each scenario's resulting overall health and equity benefits are shown in Table 6 below. 
Table 6. Case Study Results, prioritizing different policy endpoints

\begin{tabular}{|l|c|c|c|}
\hline Scenario & $\begin{array}{c}\text { Health Benefits } \\
\text { (\$ billion USD) }\end{array}$ & $\begin{array}{c}\text { Equity Benefits } \\
\text { (\$ billion USD) }\end{array}$ & $\begin{array}{c}\text { Equity Benefits } \\
\text { (\% Reduction in } \\
\text { Inequity) }\end{array}$ \\
\hline \#1: Prioritize Health & $\$ 4.01$ & $\$ 0.15$ & $13.9 \%$ \\
\hline \#2: Prioritize Equity & $\$ 3.48$ & $\$ 1.02$ & $95.1 \%$ \\
\hline \#3: Percentile Scores & $\$ 3.65$ & $\$ 0.98$ & $91.4 \%$ \\
\hline \#4: Combined Monetization & $\$ 3.71$ & $\$ 0.95$ & $88.3 \%$ \\
\hline
\end{tabular}

Maximizing public health benefits (Scenario 1 ) leads to just over \$4 billion USD in reduced mortality from chronic $\mathrm{PM}_{2.5}$ exposure. However, since these emissions reductions occur mostly in Manhattan, environmental inequity only decreases by $14 \%$, with a monetized value of $\$ 0.15$ billion USD. Maximizing equity benefits (Scenario 2 ) leads to a $95 \%$ reduction in inequity with a monetized value of $\$ 1.02$ billion USD, however this comes with a trade-off on the public health benefits, reaching only $\$ 3.5$ billion USD in averted mortality. Scenario 3 and Scenario 4 represent the middle ground, where the emission reduction strategies address both public health and inequity metrics simultaneously. Both scenarios carry positive public health and positive equity benefits, although there are trade-offs that reduce the benefits compared to a single priority scenario.

The implications of these results are very important to future air quality management strategy development. Our findings suggest that health benefits from reduced mortality are greatest when emission reductions target areas with the largest populations. 
Meanwhile, environmental equity improves when emission reductions occur in areas with a high proportion of lower-income households. If equity is not considered, emission reduction targets can unintentionally aggravate disparities between lowincome and high-income populations.

Sensitivity analysis is one possible tool to prioritize emission reductions that satisfy multiple policy endpoints. These combined strategies can achieve significant benefits, with only minimal trade-offs. Mapping synergistic emissions sensitivities across the domain can provide a policy-relevant framework to better coordinate strategies for air quality management that will improve public health in a manner that is both efficient and equitable. 


\subsection{Conclusion}

This thesis has contributed original research to the field of air quality modelling and its application in support of evidence-based policy development, by considering the impacts of air pollution on health effects and environmental equity. It has examined these topics through a variety of analysis, considering several guiding research questions (summarized from Chapter 1):

1. What are the current levels of environmental inequity in a metropolitan area, as measured by chemical transport models?

2. How do measures of inequity compare across multiple inequality indices and air quality datasets?

3. What are the patterns of influential emission reductions when considering their impacts on human health and environmental equity?

4. How can air quality management strategies be better designed to synergistically benefit multiple policy endpoints?

In examining the case study of NYC, Chapter 4 quantifies the current levels of environmental inequality and inequity. Environmental justice was analyzed by considering the health risk of increased mortality from $\mathrm{PM}_{2.5}$ exposure, through multiple air pollution datasets, and several environmental justice metrics. Environmental justice metrics were divided between those that measure environmental equality across the entire population, and environmental equity across different income groups. It was 
found that, in NYC, low-income populations are more at risk than their higher-income counterparts. These results demonstrated that a complete environmental justice analysis must include both types of analysis, since inequity can persist even as equality improves overall.

Temporal results from the LUR dataset suggest that $\mathrm{PM}_{2.5}$ concentrations on average have dropped over 8 years. Environmental equality and equity have not always improved with dropping $\mathrm{PM}_{2.5}$ concentrations. Particularly, environmental inequity has persisted even as equality has improved, since low-income populations continue to be disproportionately impacted by $\mathrm{PM}_{2.5}$ air pollution.

When comparing LUR and AQM results, Chapter 4 found that CMAQ slightly underestimated the levels of inequality seen in the LUR model, but provided estimates that were within the same order of magnitude in all scenarios. Thus, Chapter 4 concluded that AQMs such as CMAQ are appropriate for modelling environmental justice in a metropolitan area.

In Chapter 5, the impacts of emission reductions are considered on multiple policy endpoints. In all cases, adjoint sensitivity analysis is used to trace the influences of emissions at all locations and all times, and the research shows that these influences vary significantly across the domain, both spatially and temporally. When considering 
health impacts, a reduction of emissions can cause significant health benefits. The influence of those reductions is largely driven by the population that experiences the impacts of that air pollution.

When considering environmental inequity, a reduction in emissions can cause an increase or a decrease in inequity, depending on the location of emission reductions. Reducing emissions in populated areas that have a high proportion of low-income individuals will greatly reduce current levels of inequity. However, reducing emissions in populated areas with a high proportion of high-income individuals will increase disparity across the domain, leading to a greater level of environmental inequity. This manuscript concludes that the societal impacts of environmental inequity can be as significant as health impacts. i.e., the importance of either metric should not be underestimated when developing air quality management policies.

When considering synergistic emission reductions, sensitivity analysis can provide a valuable tool for assessing the influence of emissions on multiple policy endpoints. This can be used to develop air quality management strategies that carry positive effects on both human health and air quality. This type of analysis leads to increased transparency and better decision making for policy makers and researchers. 
There are a number of limitations to the work presented here. As discussed previously, the various datasets used for analysis do not always match temporally. There have been significant emission reductions and changes in population and income compared to the CMAQ model runs for 2008. Furthermore, the CMAQ dataset is currently only modelled for a two-week period of July $1^{\text {st }}-14^{\text {th }}, 2008$. In the future, the CMAQ model should be run over different seasons and different years, to better approximate annual $\mathrm{PM}_{2.5}$ concentrations. Updating these datasets would provide a better picture of the current levels of environmental inequity, and better inform the sensitivity analysis to identify current emission reduction strategies. Finally, the adjoint model was run without considering boundary conditions. This means that only local influences from emission reductions are accounted for in the analysis. Since NYC is surrounded by other populated urban areas, it is likely that emissions from the domain would carry an impact on populations residing outside the current modelling domain.

There are a number of research topics that would complement the work presented in this thesis. In order to address some of the limitations discussed above, the current model could be nested into larger domains, in order to trace the influences of emissions in NYC on more distant downwind populations. Furthermore, the current model should be expanded temporally to model longer periods, e.g. multiple representative timeframes across seasons. This will ensure that the CMAQ model captures variations in 
air pollution that occur seasonally, and will be able to provide better sensitivity information on the temporal influence of various emission reductions.

Beyond addressing the limitations previously identified, there are other possible research areas that are related to this work. While Chapter 4 addressed multiple metrics for inequality and inequity analysis, Chapter 5 focussed on one metric for adjoint sensitivity analysis. Completing additional adjoint sensitivity studies using other inequality and inequity metrics (such as the Atkinson Index) would provide a more complete picture of the influence of various emission sources on environmental justice. Similarly, this work would be well complemented by studies that consider other forms of SES, such as race or education. Beyond household income, it would be valuable to understand how air pollution affects New Yorkers of varying SES, and which emissions impact the levels of environmental inequity seen when considering different SES metrics. Finally, similar research should be carried out in other metropolitan areas. By expanding these research topics beyond NYC, there is an opportunity to influence policies so that human health and environmental justice are prioritized, ensuring that all people can enjoy the benefits of improved air quality. 


\section{Bibliography}

Abel, T. D. (2008). Skewed riskscapes and environmental injustice: A case study of metropolitan St. Louis. Environmental Management, 42(2), 232-248. https://doi.org/10.1007/s00267-008-9126-2

Abel, T. D., \& White, J. (2011). Skewed riskscapes and gentrified inequities: Environmental exposure disparities in Seattle, Washington. American Journal of Public Health, 101(SUPPL. 1), 246-255. https://doi.org/10.2105/AJPH.2011.300174

Adams, M. D., DeLuca, P. F., Corr, D., \& Kanaroglou, P. S. (2012). Mobile Air Monitoring: Measuring Change in Air Quality in the City of Hamilton, 2005-2010. Social Indicators Research, 108(2), 351-364. https://doi.org/10.1007/s11205-012-0061-5

Agyeman, J., Schlosberg, D., Craven, L., \& Matthews, C. (2016). Trends and Directions in Environmental Justice : From Inequity to Everyday Life, Community, and Just Sustainabilities. Annual Review of Environment and Resources, 41, 321-340. https://doi.org/10.1146/annurev-environ-110615-090052

Anderson, S. J., Gardner, B. W., Moll, B. J., Tribble, G. L., Webster, T. F., Wilson, K. R., \& Zyda, M. J. (1978). Socio-Economic Factors in Los Angeles County. Atmospheric Environment, 12(1968), 1531-1535.

Apelberg, B. J., Buckley, T. J., \& White, R. H. (2005). Socioeconomic and racial disparities in cancer risk from air toxics in Maryland. Environmental Health Perspectives, 113(6), 693-699. https://doi.org/10.1289/ehp.7609

Arnold, B. C. (2005). Inequality measures for multivariate distributions. International 
Journal of Statistics, LXIII(September), 317-327. Retrieved from

https://www.google.at/\%5Cnpapers3://publication/uuid/9499C5CE-2EB2-4615-

B376-3783D56622E0

Arokiasamy, P., \& Pradhan, J. (2011). Measuring wealth-based health inequality among Indian children: The importance of equity vs efficiency. Health Policy and Planning, 26(5), 429-440. https://doi.org/10.1093/heapol/czq075

Ash, M., \& Boyce, J. K. (2011). Measuring corporate environmental justice performance. Corporate Social Responsibility and Environmental Management, 18(2), 61-79. https://doi.org/10.1002/csr.238

Ash, M., \& Fetter, T. R. (2004). Who Lives on the Wrong Side of the Environmental Tracks ? Evidence from the EPA's Risk-Screening Environmental Indicators Model. Social Science Quarterly, 85(2), 441-462.

Atkinson, A. B. (1975). The Economics of Inequality. Oxford: Clarendon Press.

Bell, M. L., \& Ebisu, K. (2012). Environmental inequality in exposures to airborne particulate matter components in the United States. Environmental Health Perspectives, 120(12), 1699-1704. https://doi.org/10.1289/ehp.1205201

Boyce, J. K., Zwickl, K., \& Ash, M. (2015). Three Measures of Environmental Inequality. Brainard, J. S., Jones, A. P., Bateman, I. J., Lovett, A. A., \& Fallon, P. J. (2002). Modelling environmental equity: Access to air quality in Birmingham, England. Environment and Planning A, 34(4), 695-716. https://doi.org/10.1068/a34184

Brajer, V., \& Hall, J. V. (2005). Changes in the distribution of air pollution exposure in the 
Los Angeles Basin from 1990 to 1999. Contemporary Economic Policy, 23(1), 50-58. https://doi.org/10.1093/cep/byi005

Brajer, V., Mead, R. W., \& Xiao, F. (2010). Adjusting Chinese income inequality for environmental equity. Environment and Development Economics, 15(15), 341-362. https://doi.org/10.1017/\$1355770X10000057

Branis, M., \& Linhartova, M. (2012). Association between unemployment, income, education level, population size and air pollution in Czech cities: Evidence for environmental inequality? A pilot national scale analysis. Health and Place, 18(5), 1110-1114. https://doi.org/10.1016/j.healthplace.2012.04.011

Briggs, D., Abellan, J. J., \& Fecht, D. (2008). Environmental inequity in England: Small area associations between socio-economic status and environmental pollution. Social Science and Medicine, 67(10), 1612-1629. https://doi.org/10.1016/j.socscimed.2008.06.040

Brunt, H., Barnes, J., Jones, S. J., Longhurst, J. W. S., Scally, G., \& Hayes, E. (2016). Air pollution, deprivation and health: understanding relationships to add value to local air quality management policy and practice in Wales, UK. Journal of Public Health, 39(3), 485-497. https://doi.org/10.1093/pubmed/fdw084

Bullard, R. (1993). Confronting Environmental Racism: Voices from the Grassroots. South End Press.

Bullard, R., Mohai, P., Saha, R., \& Wright, B. (2008). Toxic Wastes and Race at Twenty: why race still matters after all of these years. Environmental Law, 38:371, 371-411. 
Burtraw, D., \& Mansur, E. (1999). Environmental effects of SO2 trading and banking. Environmental Science and Technology, 33(20), 3489-3494. https://doi.org/10.1021/es9902726

Buzzelli, M., \& Jerrett, M. (2003). Comparing proximity measures of exposure to geostatistical estimates in environmental justice research. Environmental Hazards, 5(1-2), 13-21. https://doi.org/10.1016/j.hazards.2003.11.001

Buzzelli, M., \& Jerrett, M. (2004). Racial gradients of ambient air pollution exposure in Hamilton, Canada. Environment and Planning A, 36(10), 1855-1876. https://doi.org/10.1068/a36151

Buzzelli, M., \& Jerrett, M. (2007). Geographies of susceptibility and exposure in the city: environmental inequity of traffic-related air pollution in Toronto. Canadian Journal of Regional Science, 30(2), 195-210.

Byun, D., \& Schere, K. L. (2006). Review of the Governing Equations, Computational Algorithms, and Other Components of the Models-3 Community Multiscale Air Quality (CMAQ) Modeling System. Applied Mechanics Review, 59(2), 51-77. Carrier, M., Apparicio, P., Kestens, Y., Séguin, A.-M., Pham, H., Crouse, D. L., \& Siemiatycki, J. (2016). Application of a Global Environmental Equity Index in Montreal: Diagnostic and Further Implications Application of a Global Environmental Equity Index in Montreal: Diagnostic and Further Implications. Annals of the American Association of Geographers, 1066(January 2017), 12681285. https://doi.org/10.1080/24694452.2016.1197766 
Carrier, M., Apparicio, P., Séguin, A.-M., \& Crouse, D. L. (2014a). Ambient air pollution concentration in Montreal and environmental equity: Are children at risk at school? Case Studies on Transport Policy, 2(2), 61-69.

https://doi.org/10.1016/j.cstp.2014.06.003

Carrier, M., Apparicio, P., Séguin, A.-M., \& Crouse, D. L. (2014b). The application of three methods to measure the statistical association between different social groups and the concentration of air pollutants in Montreal: A case of environmental equity. Transportation Research Part D: Transport and Environment, 30, 38-52. https://doi.org/10.1016/j.trd.2014.05.001

Carrier, M., Apparicio, P., Séguin, A.-M., \& Crouse, D. L. (2016). The cumulative effect of nuisances from road transportation in residential sectors on the Island of Montreal - Identification of the most exposed groups and areas. Transportation Research Part D: Transport and Environment, 46, 11-25. https://doi.org/10.1016/j.trd.2016.03.005

Castillo-Salgado, C., Schneider, C., Loyola, E., Mujica, O., Roca, A., \& Yerg, T. (2001). Measuring Health Inequalities: Gini Coefficient and Concentration Index. Epidemiological Bulletin, 22(1), 3-4. Retrieved from http://www1.paho.org/english/sha/be_v22n1-Gini.htm

Chaix, B., Gustafsson, S., Jerrett, M., Kristersson, H., Boalt, Å., Merlo, J., ... Merlo, J. (2017). Children's exposure to nitrogen dioxide in Sweden: investigating environmental injustice in an egalitarian country. Journal of Epidemiology and 
Community Health, 60(3), 234-241.

Chakraborty, J. (2009). Automobiles, air toxics, and adverse health risks: Environmental inequities in tampa bay, Florida. Annals of the Association of American Geographers, 99(4), 674-697. https://doi.org/10.1080/00045600903066490

Chakraborty, J. (2012). Cancer risk from exposure to hazardous air pollutants: Spatial and social inequities in Tampa Bay, Florida. International Journal of Environmental Health Research, 22(2), 165-183. https://doi.org/10.1080/09603123.2011.628643

Chakraborty, J., Collins, T. W., Grineski, S. E., Montgomery, M. C., \& Hernandez, M. (2014). Comparing Disproportionate Exposure to Acute and Chronic Pollution Risks: A Case Study in Houston, Texas. Risk Analysis, 34(11), 2005-2020. https://doi.org/10.1111/risa.12224

Chakraborty, J., \& Zandbergen, P. A. (2007). Children at risk : measuring racial / ethnic disparities in potential exposure to air pollution at school and home. Journal of Epidemiology and Community Health, 61(12), 1074-1079.

Charafeddine, R., \& Boden, L. I. (2008). Does income inequality modify the association between air pollution and health? Environmental Research, 106(1), 81-88. https://doi.org/10.1016/j.envres.2007.09.005

Clark, L. P., Millet, D. B., \& Marshall, J. D. (2014). National patterns in environmental injustice and inequality: outdoor NO2 air pollution in the United States. PloS One, 9(4), e94431. https://doi.org/10.1371/journal.pone.0094431

Clark, L. P., Millet, D. B., \& Marshall, J. D. (2017). Changes in Transportation-Related Air 
Pollution Exposures by Race-Ethnicity and Socioeconomic Status: Outdoor Nitrogen Dioxide in the United States in 2000 and 2010. Environmental Health Perspectives, 125(9), 097012. https://doi.org/10.1289/EHP959

Clougherty, J. E., Levy, J. I., Kubzansky, L. D., Ryan, P. B., Suglia, S. F., Canner, M. J., \& Wright, R. J. (2007). Synergistic effects of traffic-related air pollution and exposure to violence on urban asthma etiology. Environmental Health Perspectives, 115(8), 1140-1146. https://doi.org/10.1289/ehp.9863

Cohan, A., Wu, J., \& Dabdub, D. (2011). High-resolution pollutant transport in the San Pedro Bay of California. Atmospheric Pollution Research, 2(3), 237-246. https://doi.org/10.5094/APR.2011.030

Collins, T. W., Grineski, S. E., \& Chakraborty, J. (2015). Household-level disparities in cancer risks from vehicular air pollution in Miami. Environmental Research Letters, 10(9). https://doi.org/10.1088/1748-9326/10/9/095008

Collins, T. W., Grineski, S. E., Chakraborty, J., \& McDonald, Y. J. (2011). Understanding environmental health inequalities through comparative intracategorical analysis: Racial/ethnic disparities in cancer risks from air toxics in El Paso County, Texas. Health and Place, 17(1), 335-344.

https://doi.org/10.1016/j.healthplace.2010.11.011

Collins, T. W., Grineski, S. E., \& Morales, D. X. (2017). Environmental injustice and sexual minority health disparities: A national study of inequitable health risks from air pollution among same-sex partners. Social Science and Medicine, 191, 38-47. 
https://doi.org/10.1016/j.socscimed.2017.08.040

Community Modeling and Analysis System. (2018). SMOKE. Retrieved March 24, 2018, from https://www.cmascenter.org/smoke/

Conley, J. F. (2011). Estimation of exposure to toxic releases using spatial interaction modeling. International Journal of Health Geographics, 10(1), 20. https://doi.org/10.1186/1476-072X-10-20

Corburn, J. (2001). Emissions trading and environmental justice: distributive fairness and the USA's Acid Rain Programme. Environmental Conservation, 28(4), 323-332. https://doi.org/10.1017/S0376892901000352

Costa Font, J., Hernandez-Quevedo, C., \& McGuire, A. (2011). Persistence despite action? Measuring the patterns of health inequality in England (1997-2007). Health Policy, 103(2-3), 149-159. https://doi.org/10.1016/j.healthpol.2011.07.002 Council on Environmental Quality. (1971). Environmental quality: the second annual report on the council on environmental quality. Washington, D.C.

Crouse, D. L., Ross, N. A., \& Goldberg, M. S. (2009). Double burden of deprivation and high concentrations of ambient air pollution at the neighbourhood scale in Montreal, Canada. Social Science and Medicine, 69(6), 971-981. https://doi.org/10.1016/j.socscimed.2009.07.010

De Maio, F. G. (2007). Income inequality measures. Journal of Epidemiology and Community Health, 61(10), 849-852. https://doi.org/10.1136/jech.2006.052969 Dominici, F., Peng, R. D., Zeger, S. L., White, R. H., \& Samet, J. M. (2007). Particulate air 
pollution and mortality in the United States: Did the risks change from 1987 to 2000? American Journal of Epidemiology, 166(8), 880-888.

https://doi.org/10.1093/aje/kwm222

Donaldson, D., \& Weymark, J. A. (1980). A single-parameter generalization of the Gini indices of inequality. Journal of Economic Theory, 22(1), 67-86.

https://doi.org/10.1016/0022-0531(80)90065-4

Downey, L., Dubois, S., Hawkins, B., \& Walker, M. (2008). Environmental Inequality in Metropolitan America. Organization \& Environment, 21(3), 270-294.

https://doi.org/10.1177/1086026608321327

Downey, L., \& Hawkins, B. (2008). Single-mother families and air pollution: A national study. Social Science Quarterly, 89(2), 523-536. https://doi.org/10.1111/j.1540$6237.2008 .00545 . x$

Duro, J. A., \& Teixidó-Figueras, J. (2013). Ecological footprint inequality across countries: The role of environment intensity, income and interaction effects. Ecological Economics, 93, 34-41. https://doi.org/10.1016/j.ecolecon.2013.04.011

Fan, X., Lam, K. che, \& Yu, Q. (2012). Differential exposure of the urban population to vehicular air pollution in Hong Kong. Science of the Total Environment, 426, 211219. https://doi.org/10.1016/j.scitotenv.2012.03.057

Fann, N., Roman, H. A., Fulcher, C. M., Gentile, M. A., Hubbell, B. J., Wesson, K., \& Levy, J. I. (2011). Maximizing Health Benefits and Minimizing Inequality: Incorporating Local-Scale Data in the Design and Evaluation of Air Quality Policies. Risk Analysis, 
31(6), 908-922. https://doi.org/10.1111/j.1539-6924.2011.01629.x

Fernández-Somoano, A., Hoek, G., \& Tardon, A. (2013). Relationship between area-level socioeconomic characteristics and outdoor NO2 concentrations in rural and urban areas of northern Spain. BMC Public Health, 13(1), 71.

https://doi.org/10.1186/1471-2458-13-71

Fisher, J. B., Kelly, M., \& Romm, J. (2006). Scales of environmental justice: Combining GIS and spatial analysis for air toxics in West Oakland, California. Health and Place, 12(4), 701-714. https://doi.org/10.1016/j.healthplace.2005.09.005

Forouzanfar, M. H., Afshin, A., Alexander, L. T., Biryukov, S., Brauer, M., Cercy, K., ... Zhu, J. (2016). Global, regional, and national comparative risk assessment of 79 behavioural, environmental and occupational, and metabolic risks or clusters of risks, 1990-2015: a systematic analysis for the Global Burden of Disease Study 2015. The Lancet, 388(10053), 1659-1724. https://doi.org/10.1016/S01406736(16)31679-8

Gastwirth, J. L. (1972). The Estimation of the Lorenz Curve and Gini Index. The Review of Economics and Statistics, 54(3), 306-316.

Gilbert, A., \& Chakraborty, J. (2011). Using geographically weighted regression for environmental justice analysis: Cumulative cancer risks from air toxics in Florida. Social Science Research, 40(1), 273-286. https://doi.org/10.1016/j.ssresearch.2010.08.006

Goodkind, A. L., Coggins, J. S., \& Marshall, J. D. (2014). A Spatial Model of Air Pollution: 
The Impact of the Concentration-Response Function. Journal of the Association of Environmental and Resource Economists, 1(4), 451-479. https://doi.org/10.1086/678985

Goodman, A., Wilkinson, P., Stafford, M., \& Tonne, C. (2011). Characterising socioeconomic inequalities in exposure to air pollution: A comparison of socio-economic markers and scales of measurement. Health and Place, 17(3), 767-774. https://doi.org/10.1016/j.healthplace.2011.02.002

Grant, D., Trautner, M. N., Downey, L., \& Thiebaud, L. (2010). Bringing the Polluters Back In: Environmental Inequality and the Organization of Chemical Production. American Sociological Review, 75(4), 479-504. https://doi.org/10.1177/0003122410374822

Grineski, S. E., Bolin, B., \& Boone, C. (2007). Criteria air pollution and marginalized populations: Environmental inequity in metropolitan phoenix, Arizona. Social Science Quarterly, 88(2), 535-554. https://doi.org/10.1111/j.1540$6237.2007 .00470 . x$

Grineski, S. E., \& Collins, T. W. (2008). Exploring patterns of environmental injustice in the Global South: Maquiladoras in Ciudad Juárez, Mexico. Population and Environment, 29(6), 247-270. https://doi.org/10.1007/s11111-008-0071-z Grineski, S. E., \& Collins, T. W. (2010). Environmental injustices in transnational context: Urbanization and industrial hazards in El Paso/Ciudad juárez. Environment and Planning A, 42(6), 1308-1327. https://doi.org/10.1068/a42392 
Grineski, S. E., Collins, T. W., Aguilar, M. de L. R., \& Aldouri, R. (2010). No Safe Place: Environmental Hazards and Injustice along Mexico's Northern Border. Social Forces, 88(5), 2241-2266. https://doi.org/10.3868/s050-004-015-0003-8

Grineski, S. E., Collins, T. W., \& Chakraborty, J. (2013). Hispanic heterogeneity and environmental injustice: Intra-ethnic patterns of exposure to cancer risks from traffic-related air pollution in Miami. Population and Environment, 35(1), 26-44. https://doi.org/10.1007/s11111-012-0184-2

Grineski, S. E., Collins, T. W., Chakraborty, J., \& McDonald, Y. J. (2013). Environmental Health Injustice: Exposure to Air Toxics and Children's Respiratory Hospital Admissions in El Paso, Texas. Professional Geographer, 65(1), 31-46. https://doi.org/10.1080/00330124.2011.639625

Grineski, S. E., Collins, T. W., Chakraborty, J., \& Montgomery, M. C. (2014). Hazardous air pollutants and flooding: a comparative interurban study of environmental injustice. GeoJournal, 80(1), 145-158. https://doi.org/10.1007/s10708-014-9542-1

Grineski, S. E., Collins, T. W., Chakraborty, J., \& Montgomery, M. C. (2017). Hazard Characteristics and Patterns of Environmental Injustice: Household-Level Determinants of Environmental Risk in Miami, Florida. Risk Analysis, 37(7), 14191434. https://doi.org/10.1111/risa.12706

Grineski, S. E., \& McDonald, Y. J. (2011). Mapping the uninsured using secondary data: An environmental justice application in Dallas. Population and Environment, 32(4), 376-387. https://doi.org/10.1007/s11111-010-0129-6 
Hackbarth, A. D., Romley, J. A., \& Goldman, D. P. (2011). Racial and ethnic disparities in hospital care resulting from air pollution in excess of federal standards. Social Science and Medicine, 73(8), 1163-1168. https://doi.org/10.1016/j.socscimed.2011.08.008

Hakami, A., Henze, D. K., Seinfeld, J. H., Chai, T., Tang, Y., Carmichael, G. R., \& Sandu, A. (2005). Adjoint inverse modeling of black carbon during the Asian Pacific Regional Aerosol Characterization Experiment. Journal of Geophysical Research D: Atmospheres, 110(14), 1-17. https://doi.org/10.1029/2004JD005671

Hakami, A., Henze, D. K., Seinfeld, J. H., Singh, K., Sandu, A., Kim, S., ... Li, Q. (2007). The adjoint of CMAQ. Environmental Science and Technology, 41(22), 7807-7817. https://doi.org/10.1021/es070944p

Hakami, A., Seinfeld, J. H., Chai, T., Tang, Y., Carmichael, G. R., \& Sandu, A. (2006). Adjoint Sensitivity Analysis of Ozone Non- attainment over the Continental United States, 40(626), 1-27.

Havard, S., Deguen, S., Zmirou-Navier, D., Schillinger, C., \& Bard, D. (2009). TrafficRelated Air Pollution and Socioeconomic Status. Epidemiology, 20(2), 223-230. https://doi.org/10.1097/EDE.0b013e31819464e1

Henze, D. K., Hakami, A., \& Seinfeld, J. H. (2007). Development of the adjoint of GEOSChem. Atmospheric Chemistry and Physics, 7(9), 2413-2433. https://doi.org/10.5194/acp-7-2413-2007 Jacob, D. J. (2007). Chapter 1: The Continuity Equation. In Models of Atmospheric 
Transport and Chemistry. Retrieved from

http://acmg.seas.harvard.edu/education/jacob_lectures_ctms_chap1.pdf

James, W., Jia, C., \& Kedia, S. (2012). Uneven magnitude of disparities in cancer risks from air toxics. International Journal of Environmental Research and Public Health, 9(12), 4365-4385. https://doi.org/10.3390/ijerph9124365

Jerrett, M., Arain, M. A., Kanaroglou, P., Beckerman, B., Crouse, D. L., Gilbert, N. L., ... Finkelstein, M. M. (2007). Modelling the Intra-Urban Variability of Ambient Traffic Pollution in Toronto, Canada. Journal of Toxicology and Environmental Health, Part A, 70(3-4), 200-212.

Kakwani, N., Wagstaff, A., \& van Doorslaer, E. (1997). Socioeconomic inequalities in health: Measurement, computation, and statistical inference. Journal of Econometrics, 77, 87-103.

Kawachi, I., \& Kennedy, B. P. (1997). The relationship of income inequality to mortality: Does the choice of indicator matter? Social Science and Medicine, 45(7), 11211127. https://doi.org/10.1016/S0277-9536(97)00044-0

Kheirbek, I., Haney, J., Douglas, S., Ito, K., Caputo, S., \& Matte, T. (2014). The Public Health Bene fi ts of Reducing Fine Particulate Matter through Conversion to Cleaner Heating Fuels in New York City. Environmental Science \& Technology, 48, 13573-13582. https://doi.org/10.1021/es503587p

Kheirbek, I., Haney, J., Douglas, S., Ito, K., \& Matte, T. (2016). The contribution of motor vehicle emissions to ambient fine particulate matter public health impacts in New 
York City: a health burden assessment. Environmental Health, 15(1), 89.

https://doi.org/10.1186/s12940-016-0172-6

Koolman, X., \& van Doorslaer, E. (2004). On the interpretation of a concentration index of inequality. Health Economics, 13(7), 649-656. https://doi.org/10.1002/hec.884

Krewski, D., Jerrett, M., Burnett, R. T., Ma, R., Hughes, E., Shi, Y., ... Thun, M. J. (2009).

Extended follow-up and spatial analysis of the American Cancer Society study linking particulate air pollution and mortality. Research Report Health Effects Institute, (June 2009), 5-114.

Laurian, L. (2008). Environmental injustice in France. Journal of Environmental Planning and Management, 51(1), 55-79. https://doi.org/10.1080/09640560701712267

Lee, W. (1997). Characterizing Exposure - Disease Association in Human Populations Using the Lorenz Curve and Gini Index. Statistics in Medicine, 16(February 1996), 729-739.

Levy, J. I., Baxter, L. K., \& Schwartz, J. (2009). Uncertainty and variability in healthrelated damages from coal-fired power plants in the United States. Risk Analysis, 29(7), 1000-1014. https://doi.org/10.1111/j.1539-6924.2009.01227.x

Levy, J. I., Chemerynski, S. M., \& Tuchmann, J. L. (2006). Incorporating concepts of inequality and inequity into health benefits analysis. International Journal for Equity in Health, 5, 2. https://doi.org/10.1186/1475-9276-5-2

Levy, J. I., Greco, S. L., Melly, S. J., \& Mukhi, N. (2009). Evaluating efficiency-equality tradeoffs for mobile source control strategies in an urban area. Risk Analysis, 29(1), 
34-47. https://doi.org/10.1111/j.1539-6924.2008.01119.x

Levy, J. I., Wilson, A. M., \& Zwack, L. M. (2007). Quantifying the efficiency and equity implications of power plant air pollution control strategies in the United States. Environmental Health Perspectives, 115(5), 743-750.

https://doi.org/10.1289/ehp.9712

Lim, S. S., Vos, T., Flaxman, A. D., Danaei, G., Shibuya, K., Adair-Rohani, H., ... Ezzati, M. (2012). A comparative risk assessment of burden of disease and injury attributable to 67 risk factors and risk factor clusters in 21 regions, 1990-2010: A systematic analysis for the Global Burden of Disease Study 2010. The Lancet, 380(9859), 22242260. https://doi.org/10.1016/S0140-6736(12)61766-8

Linder, S. H., Marko, D., \& Sexton, K. (2008). Policy Analysis Cumulative Cancer Risk from Air Pollution in Houston: Disparities in Risk Burden and Social Disadvantage. Environmental Science \& Technology, 42(12), 4312-4322. https://doi.org/10.1021/es072042u Lynch, J. W., Kaplan, G. A., Pamuk, E. R., Cohen, R. D., Heck, K. E., Balfour, J. L., \& Yen, I. H. (1998). Income inequality and mortality in metropolitan areas of the United States. American Journal of Public Health, 88(7), 1074-1080. https://doi.org/10.2105/AJPH.88.7.1074

Maantay, J. (2007). Asthma and air pollution in the Bronx: Methodological and data considerations in using GIS for environmental justice and health research. Health and Place, 13(1), 32-56. https://doi.org/10.1016/j.healthplace.2005.09.009 
Maguire, K., \& Sheriff, G. (2011). Comparing distributions of environmental outcomes for regulatory environmental justice analysis. International Journal of Environmental Research and Public Health, 8(5), 1707-1726. https://doi.org/10.3390/ijerph8051707

Maroko, A. R. (2012). Using air dispersion modeling and proximity analysis to assess chronic exposure to fine particulate matter and environmental justice in New York City. Applied Geography, 34(4), 533-547. https://doi.org/10.1016/j.apgeog.2012.02.005

Marshall, J. D. (2008). Environmental inequality: Air pollution exposures in California's South Coast Air Basin. Atmospheric Environment, 42(21), 5499-5503. https://doi.org/10.1016/j.atmosenv.2008.02.005

Marshall, J. D., Swor, K. R., \& Nguyen, N. P. (2014). Prioritizing environmental justice and equality: Diesel emissions in Southern California. Environmental Science and Technology, 48(7), 4063-4068. https://doi.org/10.1021/es405167f

Martenies, S. E., Milando, C. W., Williams, G. O., \& Batterman, S. A. (2017). Disease and health inequalities attributable to air pollutant exposure in Detroit, Michigan. International Journal of Environmental Research and Public Health, 14(10), 1-24. https://doi.org/10.3390/ijerph14101243

Mellor, J. M., \& Milyo, J. (2001). Reexamining the Evidence of an Ecological Association between Income Inequality and Health. Journal of Health Politics, Policy and Law, 26(3), 487-522. https://doi.org/10.1215/03616878-26-3-487 
Millimet, D. L., \& Slottje, D. (2002a). An environmental Paglin-Gini. Applied Economics Letters, 9(4), 271-274. https://doi.org/10.1080/13504850110062031

Millimet, D. L., \& Slottje, D. (2002b). Environmental compliance costs and the distribution of emissions in the U.S. Journal of Regional Science, 42(1), 87-105. https://doi.org/10.1111/1467-9787.00251

Miranda, M. L., Edwards, S. E., Keating, M. H., \& Paul, C. J. (2011). Making the environmental justice grade: the relative burden of air pollution exposure in the United States. International Journal of Environmental Research and Public Health, 8(6), 1755-1771. https://doi.org/10.3390/ijerph8061755

Mohai, P., Kweon, B.-S., Lee, S., \& Ard, K. (2011). Air Pollution Around Schools Is Linked To Poorer Student Health And Academic Performance. Health Care and Policy Health Affairs on January Health Affairs By, 40077(6), 852-862. https://doi.org/10.1377/hlthaff.2011.0077

Mohai, P., \& Saha, R. (2006). Reassessing Racial and Socioeconomic Disparities in Environmental Justice Research. Demography, 43(2), 383-399. https://doi.org/10.1353/dem.2006.0017

Mohai, P., \& Saha, R. (2015). Which came first, people or pollution? A review of theory and evidence from longitudinal environmental justice studies. Environmental Research Letters, 10(12), 125011. https://doi.org/10.1088/1748$9326 / 10 / 12 / 125011$

Molitor, J., Su, J. G., Molitor, N. T., Rubio, V. G., Richardson, S., Hastie, D., ... Jerrett, M. 
(2011). Identifying vulnerable populations through an examination of the association between multipollutant profiles and poverty. Environmental Science and Technology, 45(18), 7754-7760. https://doi.org/10.1021/es104017x Morello-Frosch, R., \& Jesdale, B. M. (2006). Separate and unequal: Residential segregation and estimated cancer risks associated with ambient air toxins in U.S. metropolitan areas. Environmental Health Perspectives, 114(3), 386-393. https://doi.org/10.1289/ehp.8500

Morello-Frosch, R., Pastor, M., \& Sadd, J. L. (2001). Environmental Justice and Southern California's "Riskscape": The Distribution of Air Toxics Exposures and Health Risks among Diverse Communities. Urban Affairs Review, 36(4), 551-578. https://doi.org/10.1177/10780870122184993 National Center for Atmospheric Research. (2018). Weather Research and Forecasting Model. Retrieved March 24, 2018, from https://www.mmm.ucar.edu/weatherresearch-and-forecasting-model New York City Department of Health and Mental Hygiene. (2018). New York City Community Air Survey. Retrieved January 16, 2018, from http://www1.nyc.gov/site/doh/data/data-publications/air-quality-nyc-communityair-survey.page

Nguyen, N. P., \& Marshall, J. D. (2018). Impact, efficiency, inequality, and injustice of urban air pollution: variability by emission location. Environmental Research Letters, 13(024002), 1-8. https://doi.org/10.1088/1748-9326/aa9cb5 
O’Neill, M. S., Jerrett, M., Kawachi, I., Levy, J. I., Cohen, A. J., Gouveia, N., ... Zanobetti, A. (2003). Health, wealth, and air pollution: Advancing theory and methods. Environmental Health Perspectives, 111(16), 1861-1870. https://doi.org/10.1289/ehp.6334

Padilla, E., \& Duro, J. A. (2013). Explanatory factors of CO2 per capita emission inequality in the European Union. Energy Policy, 62, 1320-1328. https://doi.org/10.1016/j.enpol.2013.07.018

Pappin, A. J. (2016). Air Quality Modelling for Informing Air Pollution Policy. Carleton University.

Pappin, A. J., \& Hakami, A. (2013a). Attainment vs exposure: Ozone metric responses to source-specific NO x controls using adjoint sensitivity analysis. Environmental Science and Technology, 47(23), 13519-13527. https://doi.org/10.1021/es4024145

Pappin, A. J., \& Hakami, A. (2013b). Source attribution of health benefits from air pollution abatement in Canada and the United States. Environmental Health Perspectives, In press(5), 572-579. https://doi.org/10.1289/ehp.1205561

Pappin, A. J., Hakami, A., Blagden, P., Nasari, M., Szyszkowicz, M., \& Burnett, R. T. (2016). Health benefits of reducing NOx emissions in the presence of epidemiological and atmospheric nonlinearities. Environmental Research Letters, 11(6), 1-10. https://doi.org/10.1088/1748-9326/11/6/064015

Pappin, A. J., Mesbah, S. M., Hakami, A., \& Schott, S. (2015). Diminishing Returns or Compounding Benefits of Air Pollution Control? The Case of NOx and Ozone. 
Environmental Science and Technology, 49(16), 9548-9556.

https://doi.org/10.1021/acs.est.5b00950

Parenteau, M. P., \& Sawada, M. C. (2012). The role of spatial representation in the development of a LUR model for Ottawa, Canada. Air Quality, Atmosphere and Health, 5(3), 311-323. https://doi.org/10.1007/s11869-010-0094-3

Pastor, M., Morello-Frosch, R., \& Sadd, J. L. (2005). The air is always cleaner on the other side: Race, space, and ambient air toxics exposures in California. Journal of Urban Affairs, 27(2), 127-148. https://doi.org/10.1111/j.0735-2166.2005.00228.x

Pastor, M., Morello-Frosch, R., \& Sadd, J. L. (2006). Breathless : Schools, Air Toxics , and Environmental Justice in California. The Policy Studies Journal, 34(3), 337-362.

Pastor, M., Sadd, J. L., \& Morello-Frosch, R. (2002). Who's minding the kids? Pollution, public schools, and environmental justice in Los Angeles. Soc. Sci. Q., 83(1), 263280. https://doi.org/10.1111/1540-6237.00082

Pastor, M., Sadd, J. L., \& Morello-Frosch, R. (2004a). Reading, writing, and toxics: Children's health, academic performance, and environmental justice in Los Angeles. Environment and Planning C: Government and Policy, 22(2), 271-290. https://doi.org/10.1068/c009r

Pastor, M., Sadd, J. L., \& Morello-Frosch, R. (2004b). Waiting to inhale: The demographics of toxic air release facilities in 21st-century California. Social Science Quarterly, 85(2), 420-440. https://doi.org/10.1111/j.0038-4941.2004.08502010.x Perlin, S. A., Wong, D., \& Sexton, K. (2001). Residential proximity to industrial sources of 
air pollution: Interrelationships among race, poverty, and age. Journal of the Air and Waste Management Association, 51(3), 406-421.

https://doi.org/10.1080/10473289.2001.10464271

Pinault, L., Crouse, D. L., Jerrett, M., Brauer, M., \& Tjepkema, M. (2016). Spatial associations between socioeconomic groups and NO2 air pollution exposure within three large Canadian cities. Environmental Research, 147(2), 373-382. https://doi.org/10.1016/j.envres.2016.02.033

Pinault, L., van Donkelaar, A., \& Martin, R. V. (2017). Exposure to fine particulate matter air pollution in Canada. Health Reports, 28(3), 9-16.

Poorfakhraei, A., Tayarani, M., \& Rowangould, G. M. (2017). Evaluating health outcomes from vehicle emissions exposure in the long range regional transportation planning process. Journal of Transport \& Health, 6(August 2016), 501-515.

https://doi.org/10.1016/j.jth.2017.05.177

Pope III, C. A., Burnett, R. T., Thun, M. J., Calle, E. E., Krewski, D., \& Thurston, G. D. (2002). Lung Cancer, Cardiopulmonary Mortality, and Long-term Exposure to Fine Particulate Air Pollution. The Journal of the American Medical Association, 287(9), 1132-1141. https://doi.org/10.1001/jama.287.9.1132

Pope, R., Wu, J., \& Boone, C. (2016). Spatial patterns of air pollutants and social groups : A distributive environmental justice study in the Phoenix Metropolitan Region of USA. Environmental Management, (In Press), 753-766.

https://doi.org/10.1007/s00267-016-0741-z 
Pratt, G. C., Vadali, M. L., Kvale, D. L., \& Ellickson, K. M. (2015). Traffic, air pollution, minority and socio-economic status: Addressing inequities in exposure and risk. International Journal of Environmental Research and Public Health, 12(5), 53555372. https://doi.org/10.3390/ijerph120505355

Premji, S., Bertrand, F., Smargiassi, A., \& Daniel, M. (2007). Socio-economic correlates of municipal-level pollution emissions on Montreal Island. Canadian Journal of Public Health, 98(2), 138-142.

Requia, W. J., Dalumpines, R., Adams, M. D., Arain, A., Ferguson, M., \& Koutrakis, P. (2017). Modeling spatial patterns of link-based PM2.5 emissions and subsequent human exposure in a large canadian metropolitan area. Atmospheric Environment, 158(X), 172-180. https://doi.org/10.1016/j.atmosenv.2017.03.038

Rosofsky, A., Levy, J. I., Zanobetti, A., Janulewicz, P., \& Fabian, M. P. (2018). Temporal trends in air pollution exposure inequality in Massachusetts. Environmental Research, 161(October 2017), 76-86. https://doi.org/10.1016/j.envres.2017.10.028 Sandu, A., Daescu, D. N., Carmichael, G. R., \& Chai, T. (2005). Adjoint sensitivity analysis of regional air quality models. Journal of Computational Physics, 204(1), 222-252. https://doi.org/10.1016/j.jcp.2004.10.011

Sarabia, J. M., \& Jorda, V. (2013). Modeling Bivariate Lorenz Curves with Applications to Multidimensional Inequality in Well-Being. In Fifth meeting of the Society for the Study of Economic Inequality ECINEQ. Retrieved from http://www.ecineq.org/ecineq_bari13/filesxbari13/cr2/p155.pdf 
Sauter, C., Grether, J. M., \& Mathys, N. A. (2016). Geographical spread of global emissions: Within-country inequalities are large and increasing. Energy Policy, 89, 138-149. https://doi.org/10.1016/j.enpol.2015.11.024

Sicotte, D., \& Swanson, S. (2007). Whose risk in philadelphia? Proximity to unequally hazardous industrial facilities. Social Science Quarterly, 88(2), 515-534. https://doi.org/10.1111/j.1540-6237.2007.00469.x

Solomon, B. D., \& Lee, R. (2000). Emissions trading systems and environmental justice. Environment, 42(8), 32-45. https://doi.org/10.1080/00139150009605756

Stuart, A. L., Mudhasakul, S., \& Sriwatanapongse, W. (2009). The social distribution of neighborhood-scale air pollution and monitoring protection. Journal of the Air and Waste Management Association, 59(5), 591-602. https://doi.org/10.3155/10473289.59.5.591

Su, J. G., Jerrett, M., Morello-Frosch, R., Jesdale, B. M., \& Kyle, A. D. (2012). Inequalities in cumulative environmental burdens among three urbanized counties in California. Environment International, 40(1), 79-87. https://doi.org/10.1016/j.envint.2011.11.003

Su, J. G., Larson, T., Gould, T., Cohen, M., \& Buzzelli, M. (2010). Transboundary air pollution and environmental justice: Vancouver and Seattle compared. GeoJournal, 75(6), 595-608. https://doi.org/10.1007/s10708-009-9269-6

Su, J. G., Morello-Frosch, R., Jesdale, B. M., Kyle, A. D., Shamasunder, B., \& Jerrett, M. (2009). An index for assessing demographic inequalities in cumulative 
environmental hazards with application to Los Angeles, California. Environmental Science and Technology, 43(20), 7626-7634. https://doi.org/10.1021/es901041p

Tayarani, M., Poorfakhraei, A., Nadafianshahamabadi, R., \& Rowangould, G. M. (2016). Evaluating unintended outcomes of regional smart-growth strategies:

Environmental justice and public health concerns. Transportation Research Part D: Transport and Environment, 49, 280-290.

https://doi.org/10.1016/j.trd.2016.10.011

Temam, S., Burte, E., Adam, M., Antó, J. M., Basagaña, X., Bousquet, J., ... Jacquemin, B. (2017). Socioeconomic position and outdoor nitrogen dioxide (NO2) exposure in Western Europe: A multi-city analysis. Environment International, 101(2), 117-124. https://doi.org/10.1016/j.envint.2016.12.026

Turner, M. D., Henze, D. K., Capps, S. L., Hakami, A., Zhao, S., Resler, J., ... Chai, T. (2015). Premature deaths attributed to source-specific BC emissions in six urban US regions. Environmental Research Letters, 10(11). https://doi.org/10.1088/1748$9326 / 10 / 11 / 114014$

Turner, M. D., Henze, D. K., Hakami, A., Zhao, S., Resler, J., Carmichael, G. R., ... Chai, T. (2015). Differences between magnitudes and health impacts of BC emissions across the United States using $12 \mathrm{~km}$ scale seasonal source apportionment. Environmental Science and Technology, 49(7), 4362-4371. https://doi.org/10.1021/es505968b

Turrell, G., \& Mathers, C. (2001). Socioeconomic inequalities in all-cause and specificcause mortality in Australia: 1985-1987 and 1995-1997. International Journal of 
Epidemiology, 30(2), 231-239. https://doi.org/10.1093/ije/30.2.231

U.S. Environmental Protection Agency. (2015). Criteria Air Pollutants. America's Children and the Environment. Retrieved from http://www.epa.gov/criteria-air-pollutants

U.S. Environmental Protection Agency. (2016). Health and Environmental Effects of Particulate Matter (PM). Retrieved January 11, 2018, from https://www.epa.gov/pm-pollution/health-and-environmental-effects-particulatematter-pm

U.S. Environmental Protection Agency. (2017a). Environmental Benefits Mapping and Analysis Program - Community Edition (BenMAP-CE). Retrieved February 4, 2018, from https://www.epa.gov/benmap

U.S. Environmental Protection Agency. (2017b). Environmental Justice. Retrieved December 19, 2017, from https://www.epa.gov/environmentaljustice U.S. Environmental Protection Agency. (2017c). NATA Overview. Retrieved December 23, 2017, from https://www.epa.gov/national-air-toxics-assessment/nata-overview U.S. Environmental Protection Agency. (2018a). CMAQ Models. Retrieved March 24, 2018, from https://www.epa.gov/cmaq/cmaq-models-0

U.S. Environmental Protection Agency. (2018b). Mortality Risk Valuation. Retrieved March 31, 2018, from https://www.epa.gov/environmental-economics/mortalityrisk-valuation

United Church of Christ Commission for Racial Justice. (1987). Toxic Wastes and Race in the United States: A National Report on the Racial and Socio-Economic 
Characteristics of Communities with Hazardous Waste Sites. Retrieved from

http://www.newyorker.com/news/news-desk/environmentalisms-racist-

history\%5Cnpapers3://publication/uuid/7C909FBD-515E-42EE-8E49-

B3EA92B9F6B6

United States General Accounting Office. (1983). Siting of Hazardous Waste Landfills and Their Correlation with Racial and Economic Status of Surrounding Communities. Washington, D.C.

University of Washington. (2018). Environmental Justice.

https://doi.org/http://deohs.washington.edu/environmental-justice

Van Arsdol, M. D. (1966). Metropolitan growth and environmental hazards: an illustrative case. Ekistics, 21, 48-50.

Wagstaff, A. (2002). Achievement Inequality Aversion, Health Inequalities, and Health, 21(January 2002), 627-641.

Wagstaff, A., van Doorslaer, E., \& Paci, P. (1989). Equity in the Finance and Delivery of Health Care: Some Tentative Cross-Country Comparisons. Oxford Review of Economic Policy, 5(1), 89-112.

Walker, G., Mitchell, G., Fairburn, J., \& Smith, G. (2005). Industrial pollution and social deprivation: Evidence and complexity in evaluating and responding to environmental inequality. Local Environment, 10(4), 361-377. https://doi.org/10.1080/13549830500160842

World Health Organization. (2014). 7 million premature deaths annually linked to air 
pollution. Retrieved January 12, 2017, from

http://www.who.int/mediacentre/news/releases/2014/air-pollution/en/

Yang, Y.-J., Wilkinson, J. G., \& Russell, A. G. (1997). Fast, Direct Sensitivity Analysis of Multidimensional Photochemical Models. Environmental Science and Technology, 31(10), 2859-2868.

Yitzhaki, S. (1983). On an Extension of the Gini Inequality Index. International Economic Review, 24(3), 617-628. https://doi.org/10.2307/2648789

Yitzhaki, S. (2003). Cost-benefit analysis and the distributional consequences of government projects. National Tax Journal, 56(2), 319-336.

Young, G. S., Fox, M. A., Trush, M., Kanarek, N., Glass, T. A., \& Curriero, F. C. (2012). Differential exposure to hazardous air pollution in the United States: A multilevel analysis of urbanization and neighborhood socioeconomic deprivation. International Journal of Environmental Research and Public Health, 9(6), 22042225. https://doi.org/10.3390/ijerph9062204

Zanobetti, A., \& Schwartz, J. (2008). Mortality displacement in the association of ozone with mortality: An analysis of 48 cities in the United States. American Journal of Respiratory and Critical Care Medicine, 177(2), 184-189.

https://doi.org/10.1164/rccm.200706-8230C

Zwickl, K., Ash, M., \& Boyce, J. K. (2014). Regional variation in environmental inequality: Industrial air toxics exposure in U.S. cities. Ecological Economics, 107, 494-509. https://doi.org/10.1016/j.ecolecon.2014.09.013 


\section{Appendix 1: Lorenz Curves for 8-Year LUR Dataset}

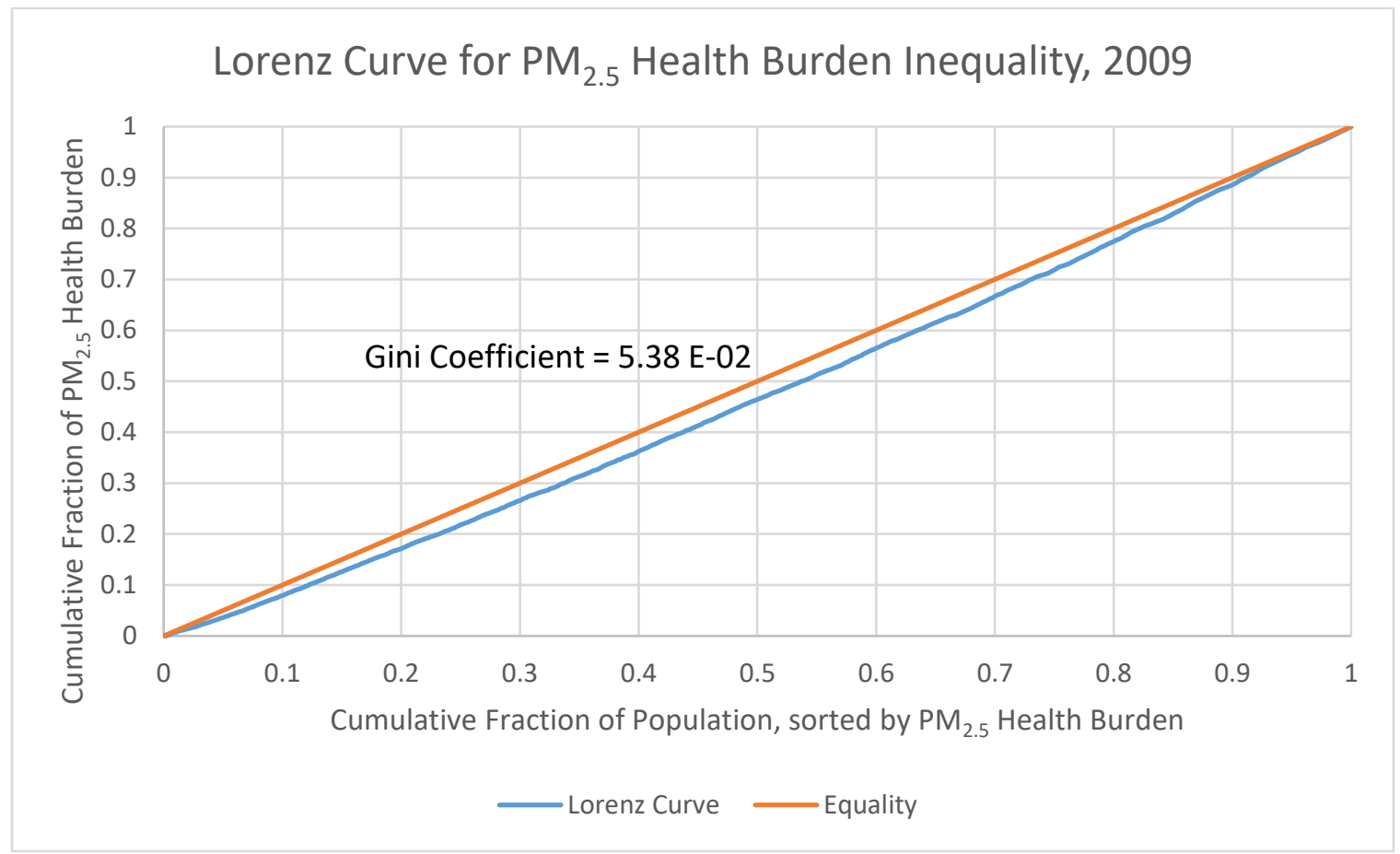

Figure 21. Lorenz Curve for Land-Use Regression Data for 2009

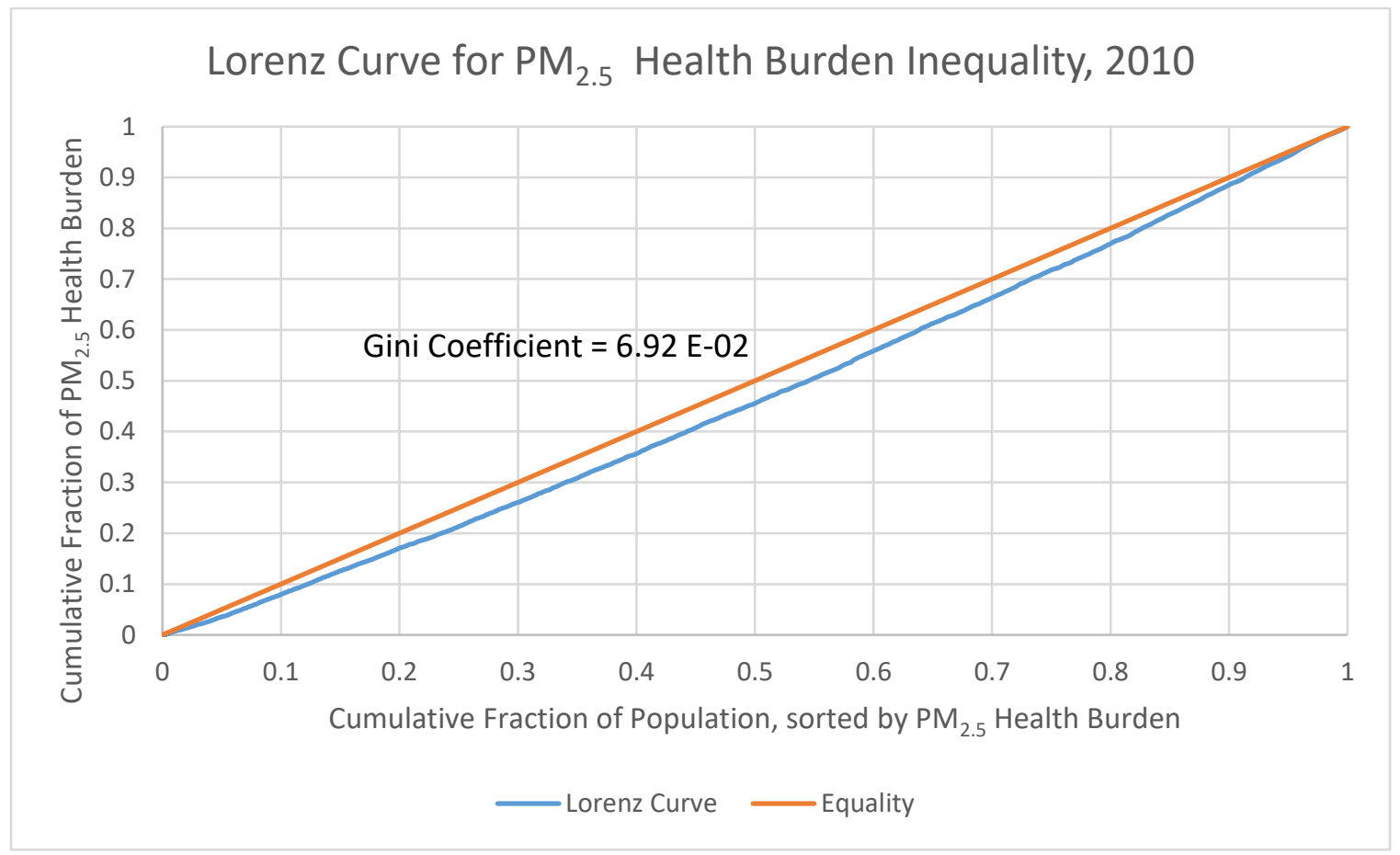

Figure 22. Lorenz Curve for Land-Use Regression Data for 2010 


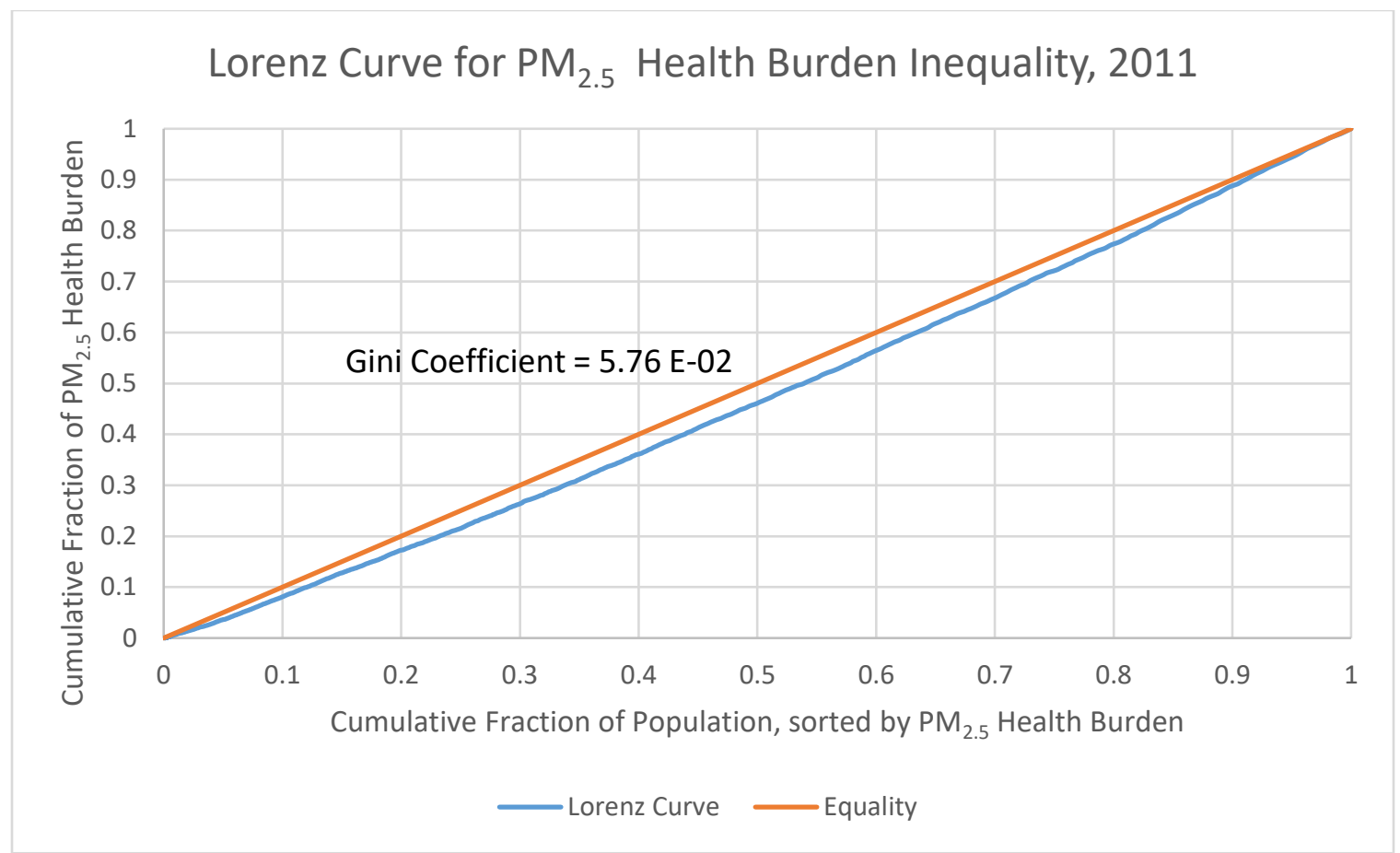

Figure 23. Lorenz Curve for Land-Use Regression Data for 2011

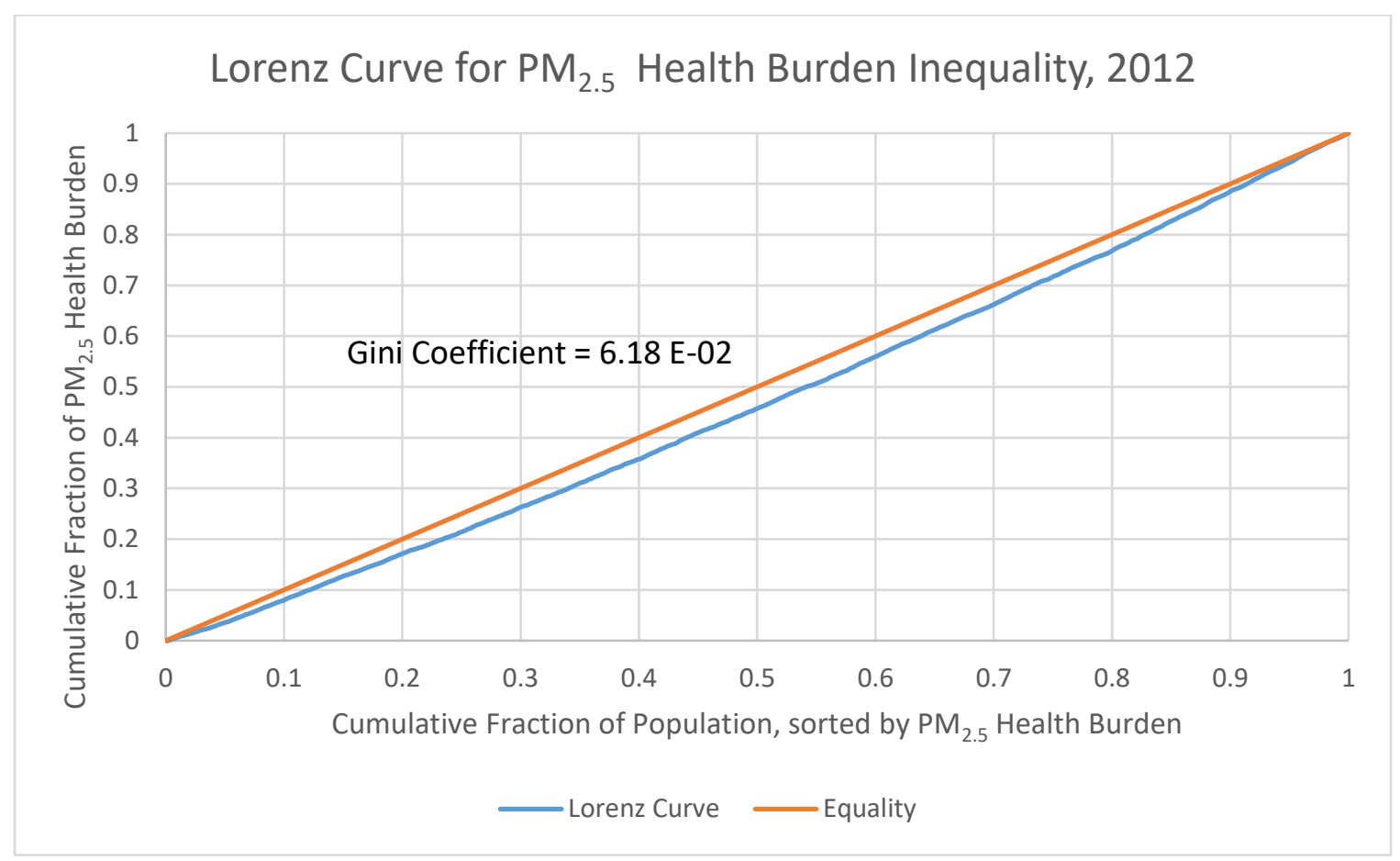

Figure 24. Lorenz Curve for Land-Use Regression Data for 2012 


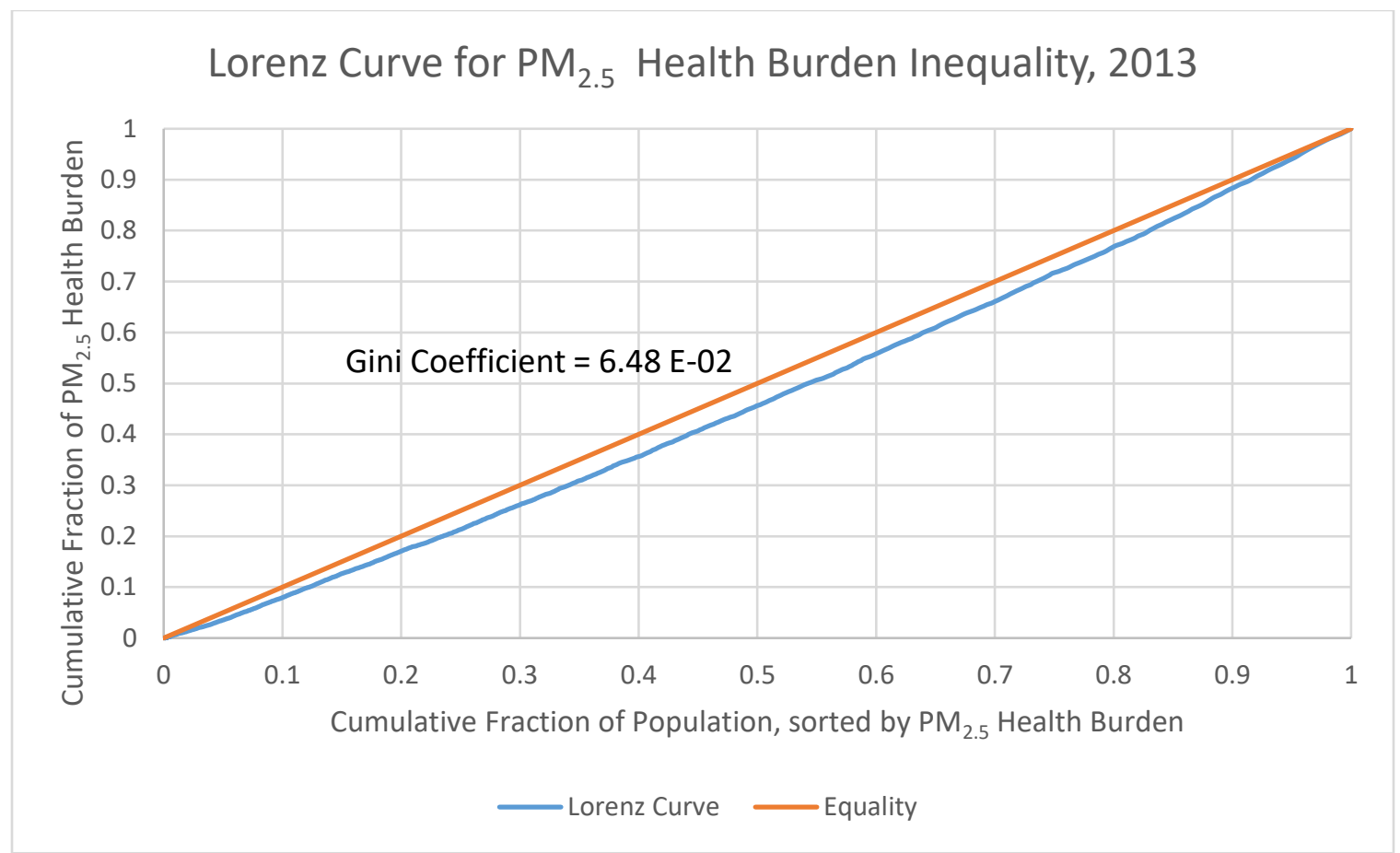

Figure 25. Lorenz Curve for Land-Use Regression Data for 2013

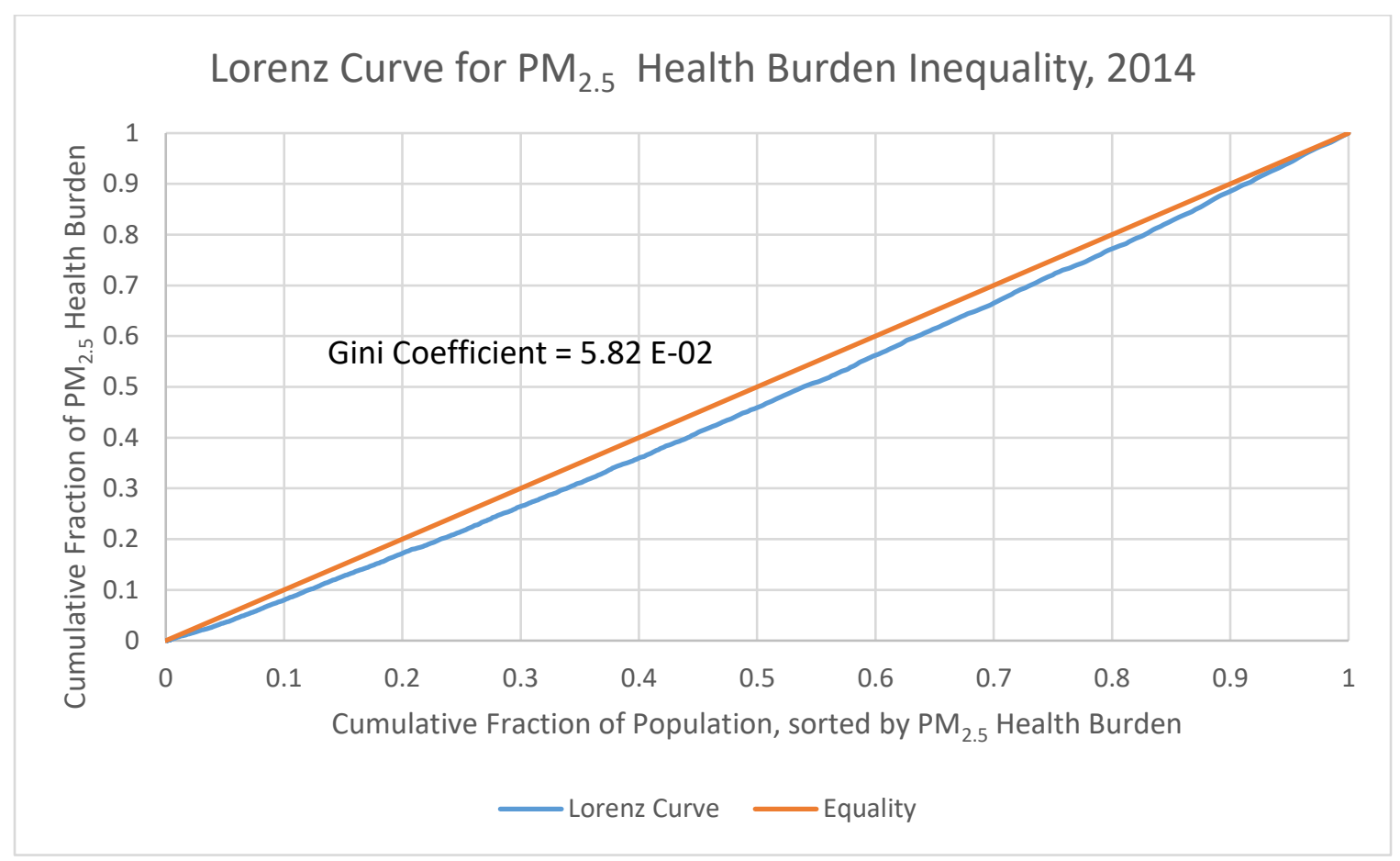

Figure 26. Lorenz Curve for Land-Use Regression Data for 2014 


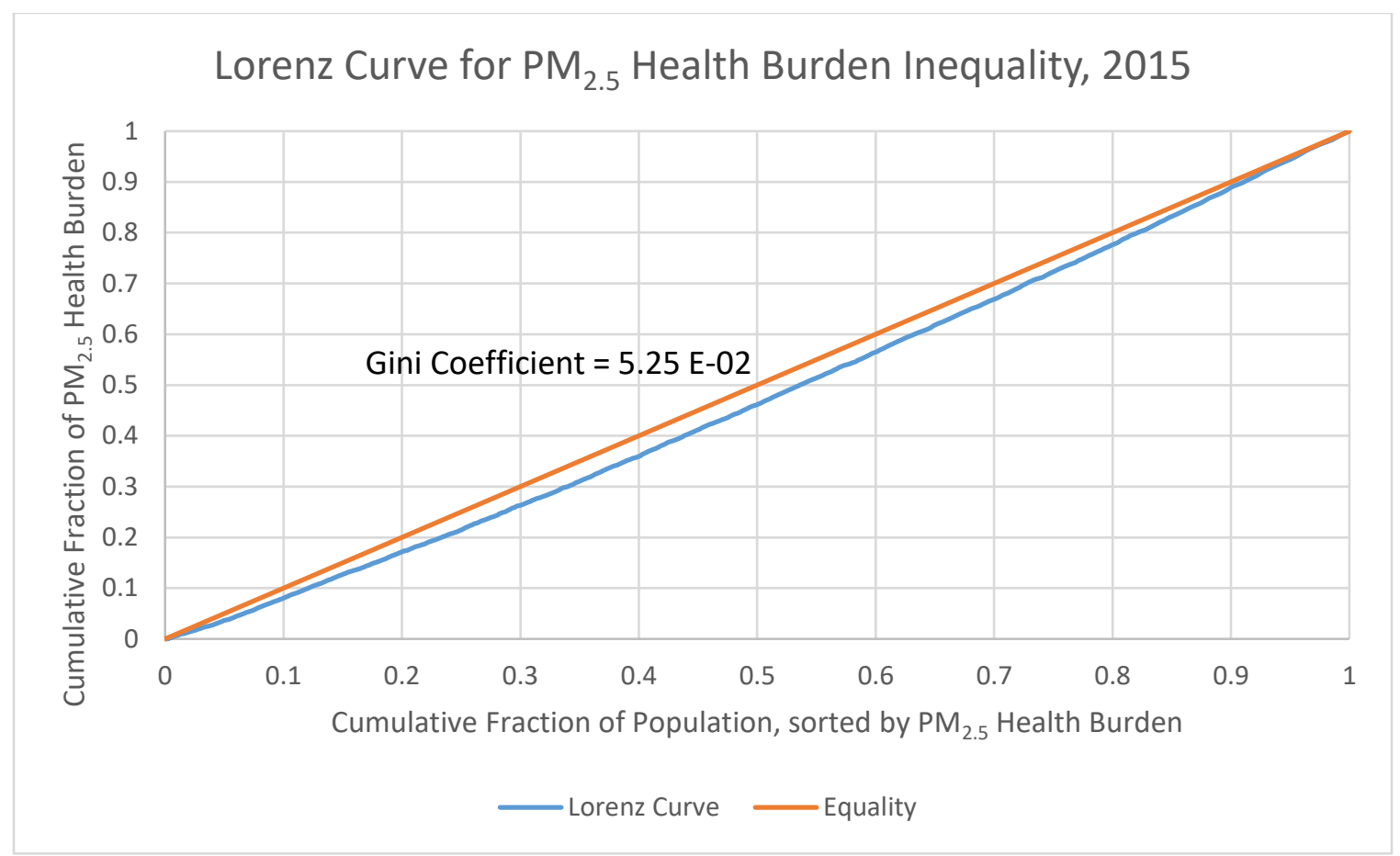

Figure 27. Lorenz Curve for Land-Use Regression Data for 2015

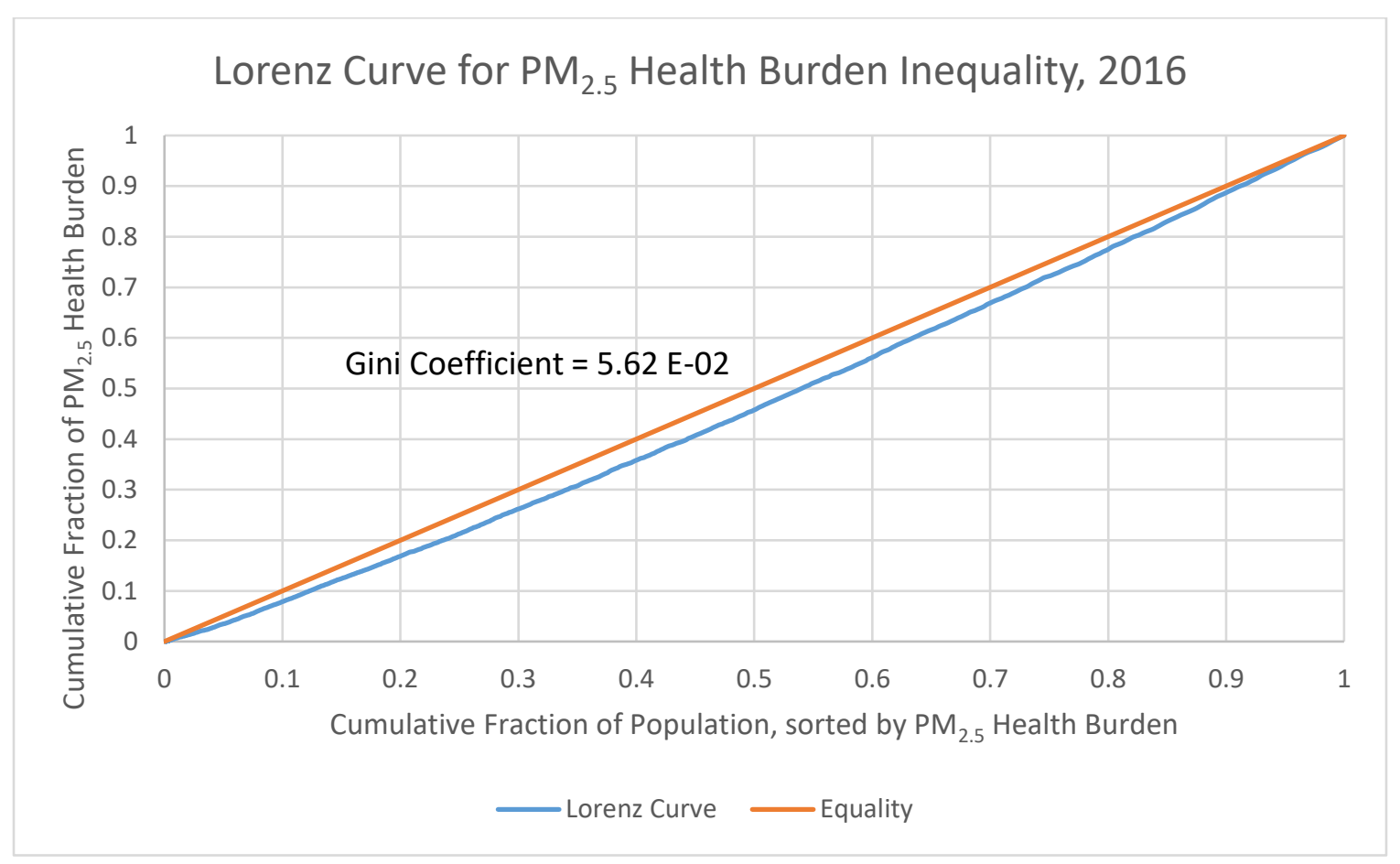

Figure 28. Lorenz Curve for Land-Use Regression Data for 2016 


\section{Appendix 2: Concentration Curves for 8-Year LUR Dataset}

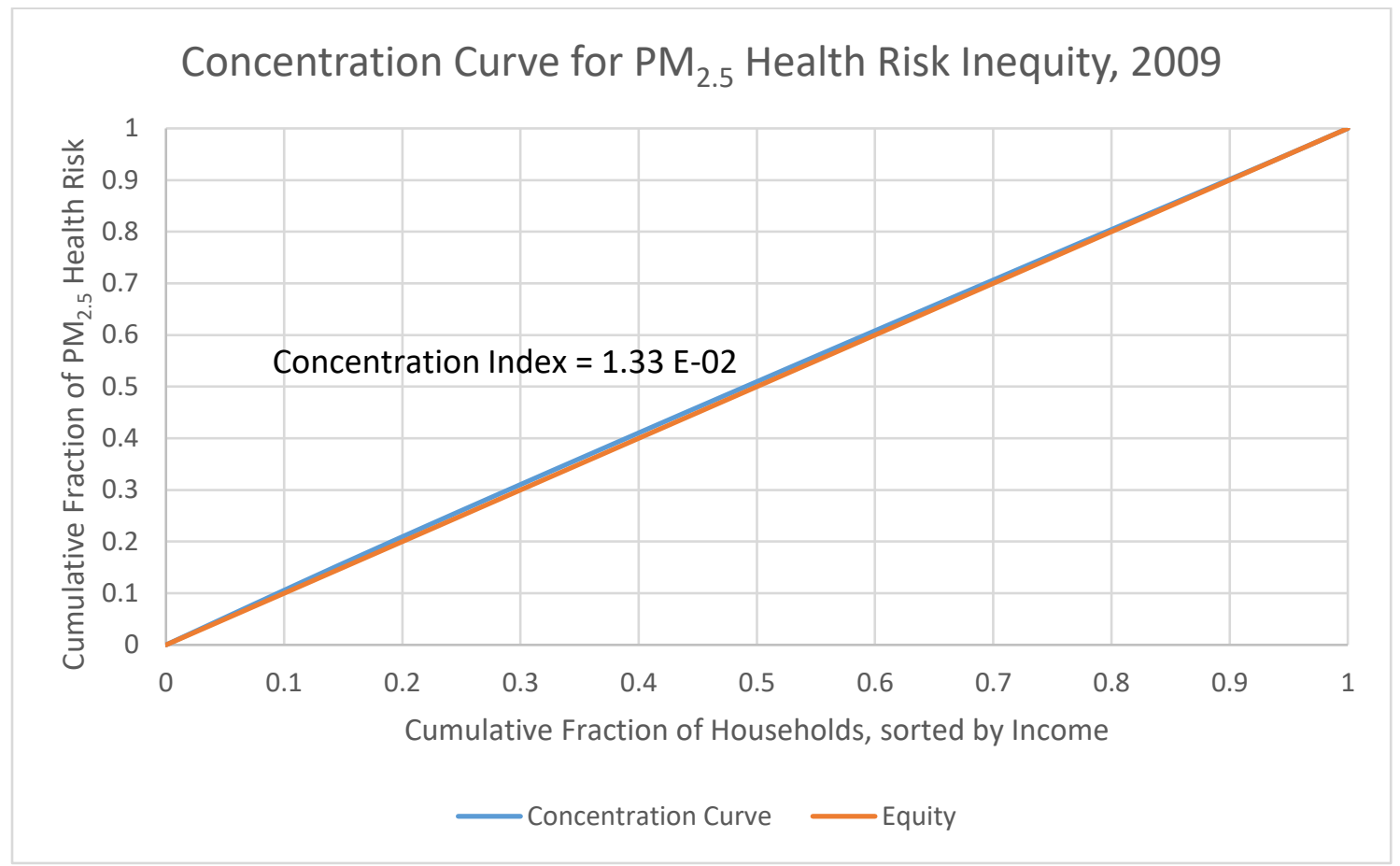

Figure 29. Concentration Curve for Land Use Regression Data for 2009

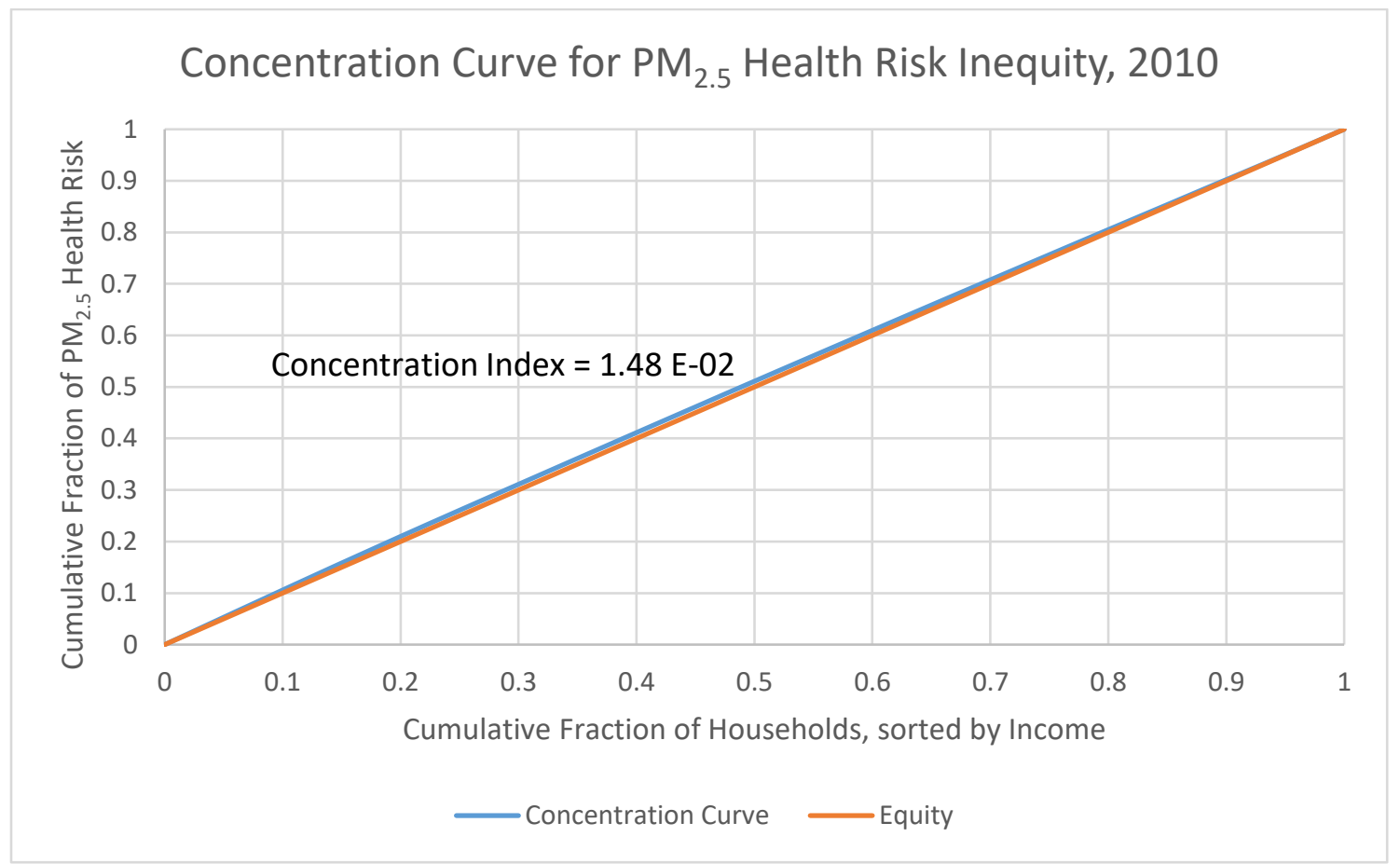

Figure 30. Concentration Curve for Land Use Regression Data for 2010 


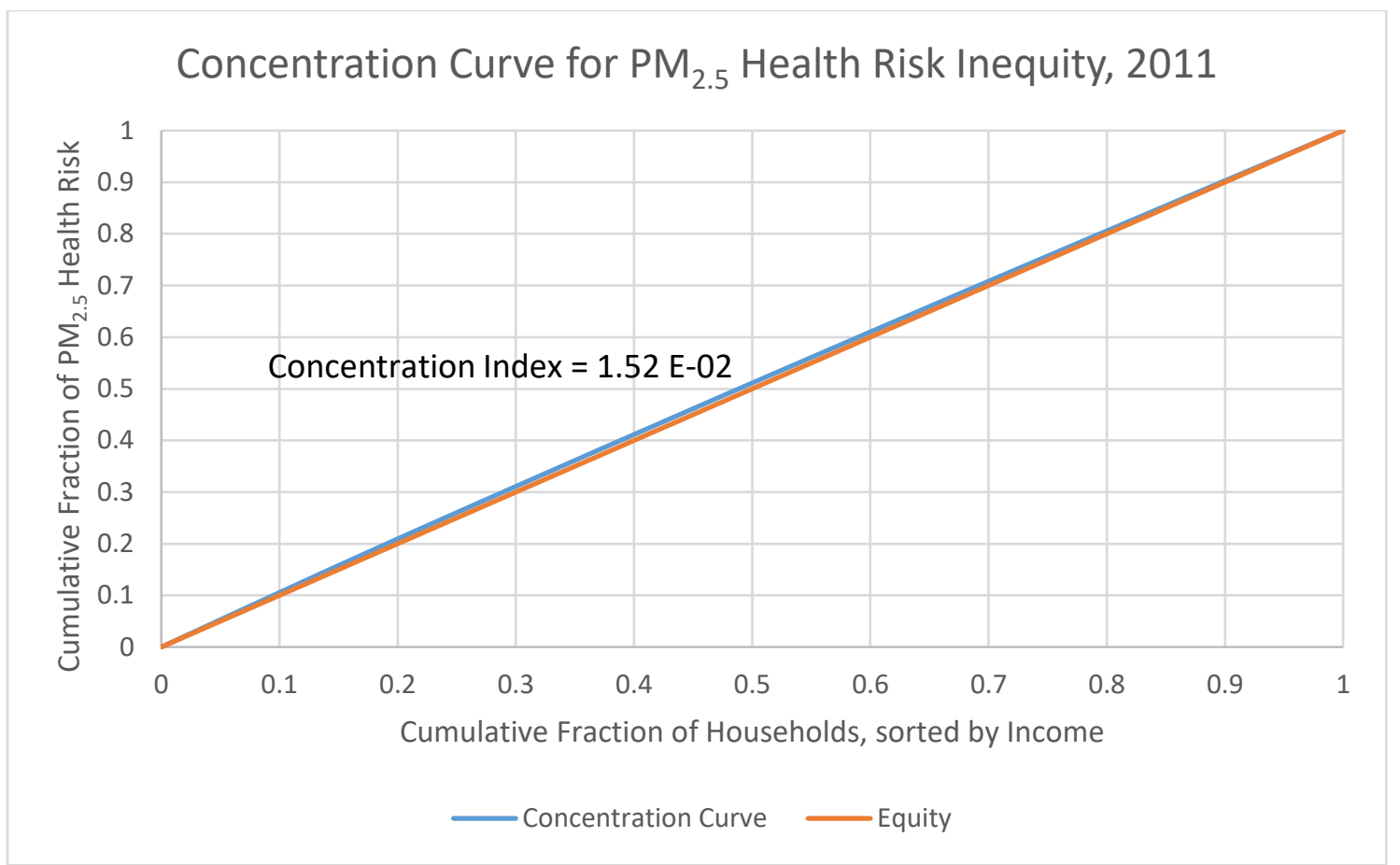

Figure 31. Concentration Curve for Land Use Regression Data for 2011

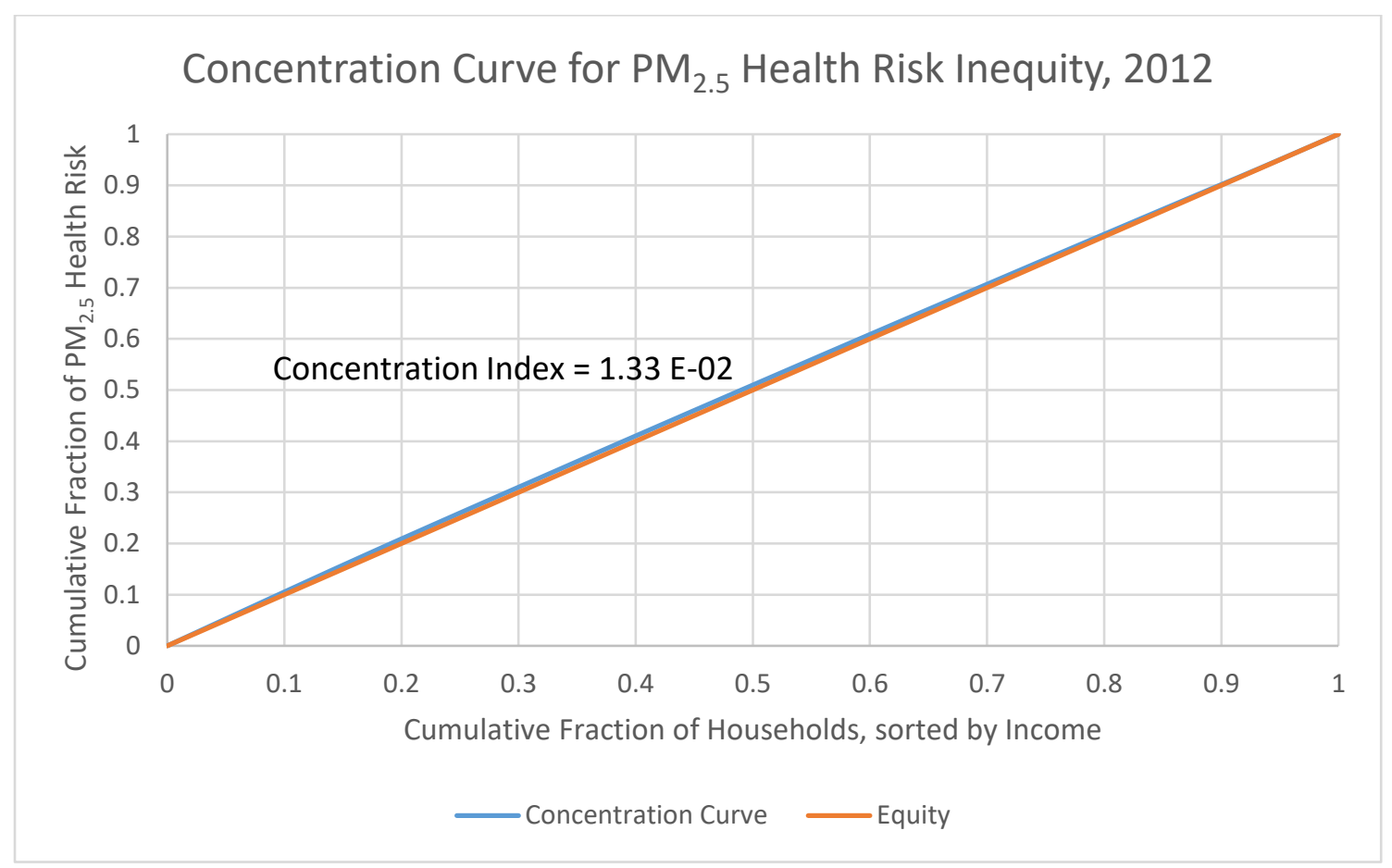

Figure 32. Concentration Curve for Land Use Regression Data for 2012 


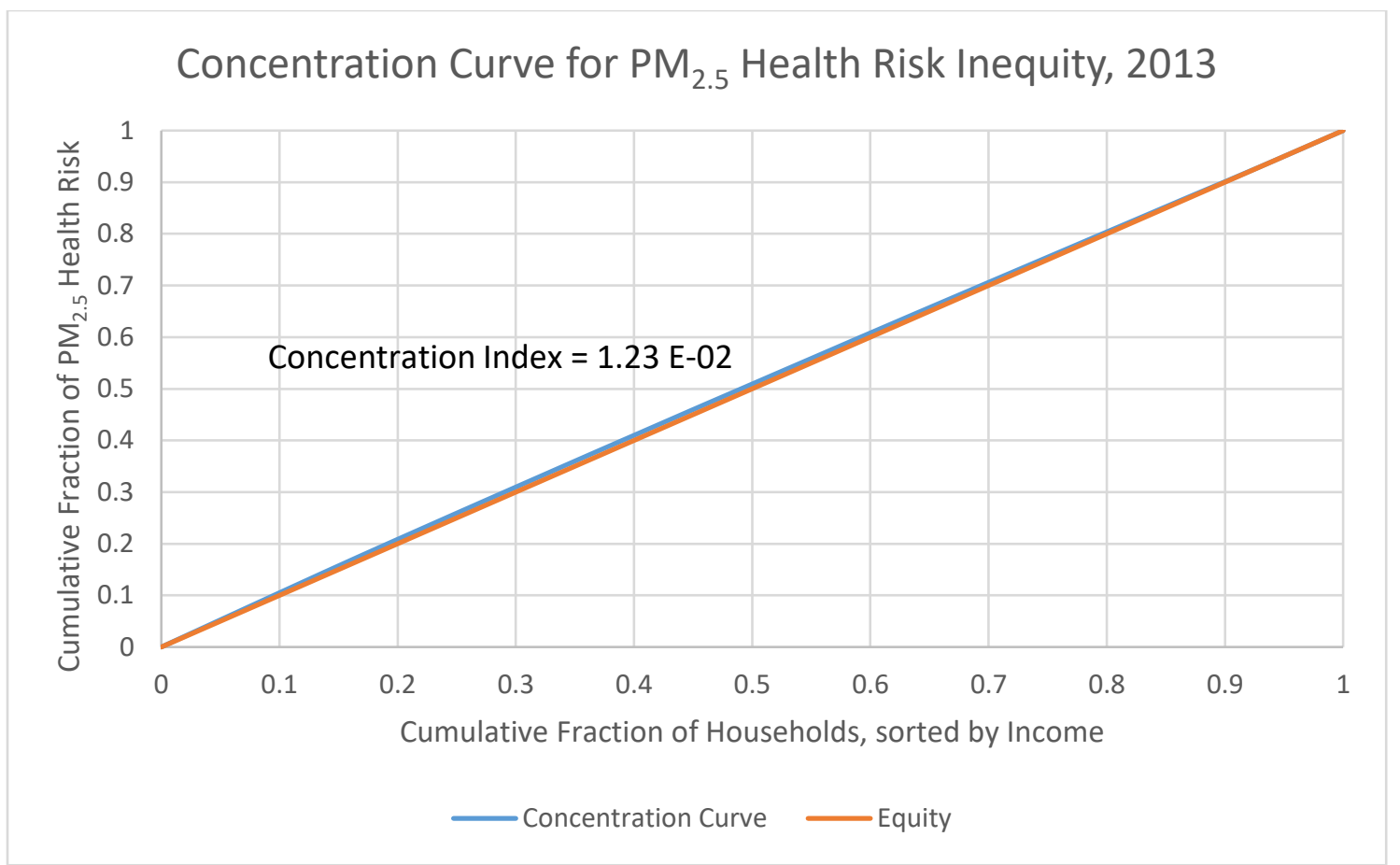

Figure 33. Concentration Curve for Land Use Regression Data for 2013

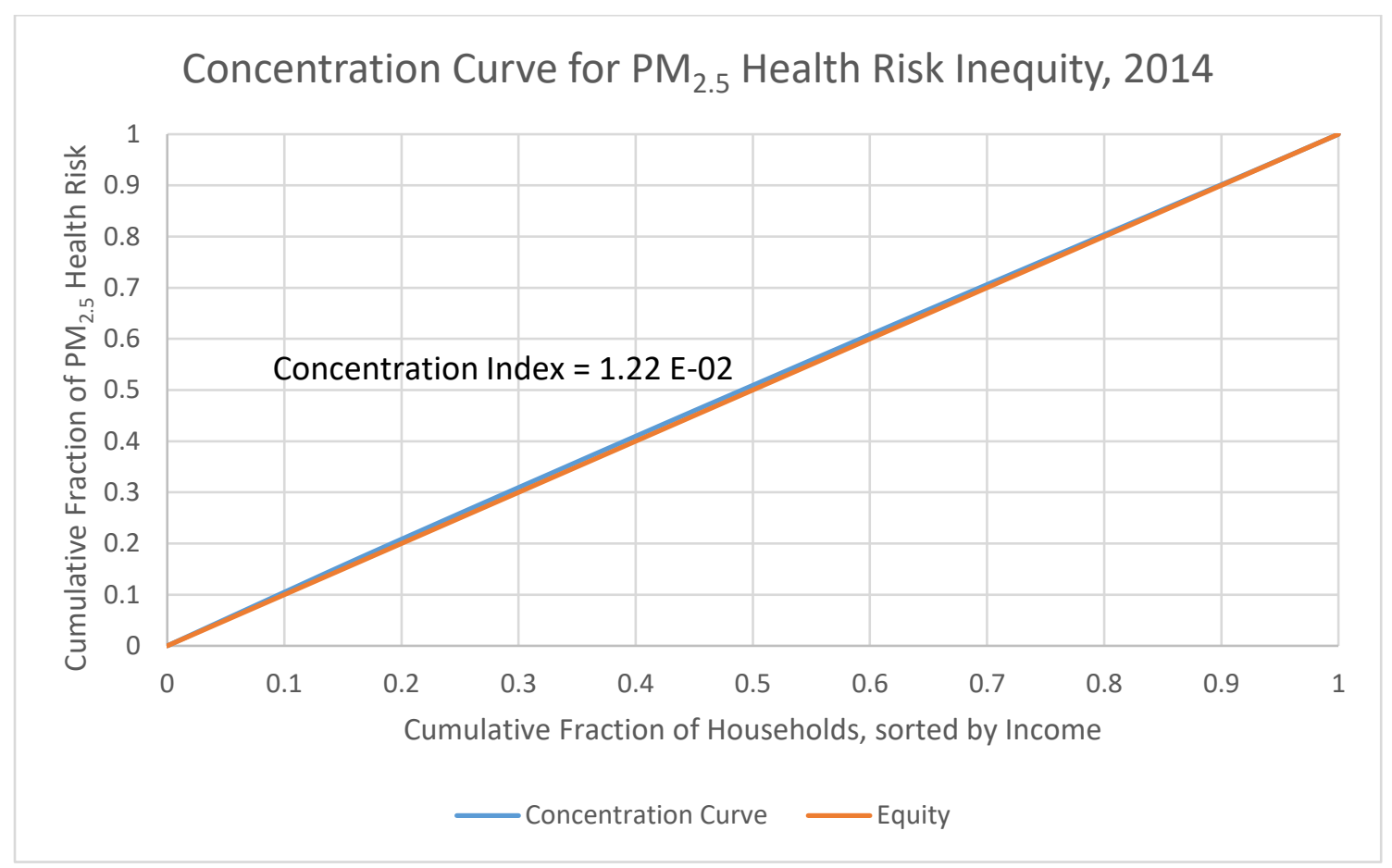

Figure 34. Concentration Curve for Land Use Regression Data for 2014 


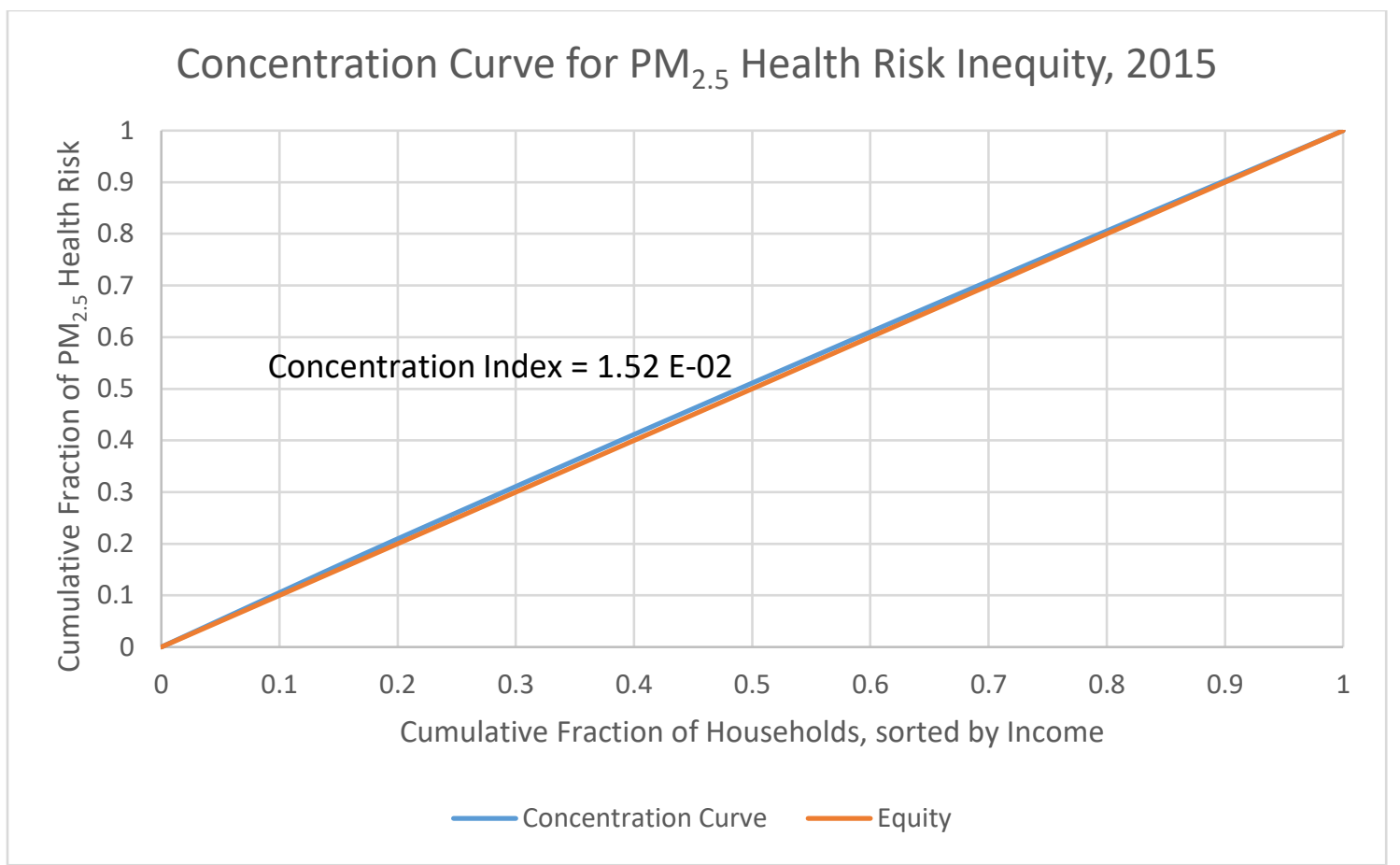

Figure 35. Concentration Curve for Land Use Regression Data for 2015

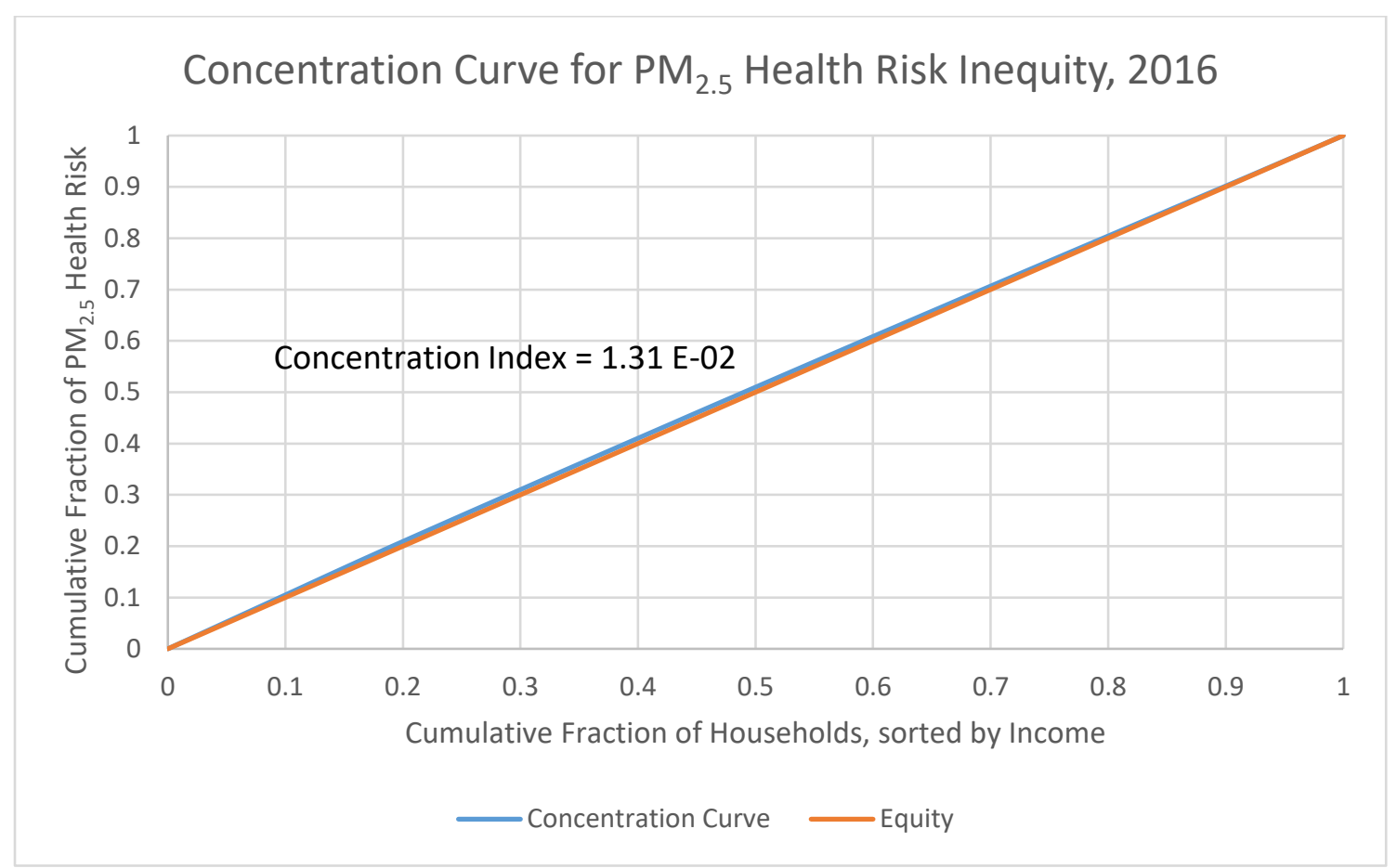

Figure 36. Concentration Curve for Land Use Regression Data for 2016 
Appendix 3: Summary Tables for LUR Environmental Equity

Table 7. Share of Total Income and Total PM2.5 Health Burden, for LUR Year 2010

\begin{tabular}{|c|c|c|c|}
\hline $\begin{array}{l}\text { 12-month Household } \\
\text { Income range }\end{array}$ & $\begin{array}{c}\text { Share of total } \\
\text { income (\%) }\end{array}$ & $\begin{array}{c}\text { Share of total } \mathrm{PM}_{2.5} \\
\text { health burden (\%) }\end{array}$ & $\begin{array}{c}\text { Health burden share } \\
\text { > income share }\end{array}$ \\
\hline Less than $\$ 10,000$ & $10.82 \%$ & $11.45 \%$ & TRUE \\
\hline$\$ 10,000$ to $\$ 14,999$ & $6.19 \%$ & $6.45 \%$ & TRUE \\
\hline$\$ 15,000$ to $\$ 19,999$ & $5.40 \%$ & $5.54 \%$ & TRUE \\
\hline$\$ 20,000$ to $\$ 24,999$ & $5.13 \%$ & $5.19 \%$ & TRUE \\
\hline$\$ 25,000$ to $\$ 29,999$ & $4.79 \%$ & $4.82 \%$ & TRUE \\
\hline$\$ 30,000$ to $\$ 34,999$ & $4.84 \%$ & $4.86 \%$ & TRUE \\
\hline$\$ 35,000$ to $\$ 39,999$ & $4.33 \%$ & $4.34 \%$ & TRUE \\
\hline$\$ 40,000$ to $\$ 44,999$ & $4.34 \%$ & $4.33 \%$ & FALSE \\
\hline$\$ 45,000$ to $\$ 49,999$ & $3.80 \%$ & $3.78 \%$ & FALSE \\
\hline$\$ 50,000$ to $\$ 59,999$ & $7.36 \%$ & $7.26 \%$ & FALSE \\
\hline$\$ 60,000$ to $\$ 74,999$ & $9.12 \%$ & $8.96 \%$ & FALSE \\
\hline$\$ 75,000$ to $\$ 99,999$ & $11.03 \%$ & $10.77 \%$ & FALSE \\
\hline$\$ 100,000$ to $\$ 124,999$ & $7.40 \%$ & $7.17 \%$ & FALSE \\
\hline$\$ 125,000$ to $\$ 149,999$ & $4.43 \%$ & $4.31 \%$ & FALSE \\
\hline$\$ 150,000$ to $\$ 199,999$ & $4.87 \%$ & $4.70 \%$ & FALSE \\
\hline$\$ 200,000$ or more & $6.15 \%$ & $6.06 \%$ & FALSE \\
\hline
\end{tabular}


Table 8. Share of Total Income and Total PM2.5 Health Burden, for LUR Year 2011

\begin{tabular}{|c|c|c|c|}
\hline $\begin{array}{l}\text { 12-month Household } \\
\text { Income range }\end{array}$ & $\begin{array}{l}\text { Share of total } \\
\text { income (\%) }\end{array}$ & $\begin{array}{c}\text { Share of total } \mathrm{PM}_{2.5} \\
\text { health burden (\%) }\end{array}$ & $\begin{array}{c}\text { Health burden share } \\
>\text { income share }\end{array}$ \\
\hline Less than $\$ 10,000$ & $10.56 \%$ & $11.15 \%$ & TRUE \\
\hline$\$ 10,000$ to $\$ 14,999$ & $6.10 \%$ & $6.36 \%$ & TRUE \\
\hline$\$ 15,000$ to $\$ 19,999$ & $5.42 \%$ & $5.56 \%$ & TRUE \\
\hline$\$ 20,000$ to $\$ 24,999$ & $5.12 \%$ & $5.19 \%$ & TRUE \\
\hline$\$ 25,000$ to $\$ 29,999$ & $4.77 \%$ & $4.82 \%$ & TRUE \\
\hline$\$ 30,000$ to $\$ 34,999$ & $4.71 \%$ & $4.74 \%$ & TRUE \\
\hline$\$ 35,000$ to $\$ 39,999$ & $4.21 \%$ & $4.21 \%$ & TRUE \\
\hline$\$ 40,000$ to $\$ 44,999$ & $4.30 \%$ & $4.29 \%$ & FALSE \\
\hline$\$ 45,000$ to $\$ 49,999$ & $3.64 \%$ & $3.64 \%$ & FALSE \\
\hline$\$ 50,000$ to $\$ 59,999$ & $7.27 \%$ & $7.19 \%$ & FALSE \\
\hline$\$ 60,000$ to $\$ 74,999$ & $8.93 \%$ & $8.80 \%$ & FALSE \\
\hline$\$ 75,000$ to $\$ 99,999$ & $10.99 \%$ & $10.74 \%$ & FALSE \\
\hline$\$ 100,000$ to $\$ 124,999$ & $7.39 \%$ & $7.19 \%$ & FALSE \\
\hline$\$ 125,000$ to $\$ 149,999$ & $4.78 \%$ & $4.64 \%$ & FALSE \\
\hline$\$ 150,000$ to $\$ 199,999$ & $5.20 \%$ & $5.04 \%$ & FALSE \\
\hline$\$ 200,000$ or more & $6.61 \%$ & $6.44 \%$ & FALSE \\
\hline
\end{tabular}


Table 9. Share of Total Income and Total PM2.5 Health Burden, for LUR Year 2012

\begin{tabular}{|c|c|c|c|}
\hline $\begin{array}{l}\text { 12-month Household } \\
\text { Income range }\end{array}$ & $\begin{array}{l}\text { Share of total } \\
\text { income (\%) }\end{array}$ & $\begin{array}{l}\text { Share of total } \mathrm{PM}_{2.5} \\
\text { health burden (\%) }\end{array}$ & $\begin{array}{c}\text { Health burden share } \\
>\text { income share }\end{array}$ \\
\hline Less than $\$ 10,000$ & $10.49 \%$ & $11.05 \%$ & TRUE \\
\hline$\$ 10,000$ to $\$ 14,999$ & $6.11 \%$ & $6.37 \%$ & TRUE \\
\hline$\$ 15,000$ to $\$ 19,999$ & $5.44 \%$ & $5.56 \%$ & TRUE \\
\hline$\$ 20,000$ to $\$ 24,999$ & $5.17 \%$ & $5.23 \%$ & TRUE \\
\hline$\$ 25,000$ to $\$ 29,999$ & $4.76 \%$ & $4.78 \%$ & TRUE \\
\hline$\$ 30,000$ to $\$ 34,999$ & $4.62 \%$ & $4.63 \%$ & TRUE \\
\hline$\$ 35,000$ to $\$ 39,999$ & $4.09 \%$ & $4.08 \%$ & FALSE \\
\hline$\$ 40,000$ to $\$ 44,999$ & $4.30 \%$ & $4.28 \%$ & FALSE \\
\hline$\$ 45,000$ to $\$ 49,999$ & $3.54 \%$ & $3.51 \%$ & FALSE \\
\hline$\$ 50,000$ to $\$ 59,999$ & $7.12 \%$ & $7.05 \%$ & FALSE \\
\hline$\$ 60,000$ to $\$ 74,999$ & $8.90 \%$ & $8.77 \%$ & FALSE \\
\hline$\$ 75,000$ to $\$ 99,999$ & $10.85 \%$ & $10.62 \%$ & FALSE \\
\hline$\$ 100,000$ to $\$ 124,999$ & $7.60 \%$ & $7.41 \%$ & FALSE \\
\hline$\$ 125,000$ to $\$ 149,999$ & $4.83 \%$ & $4.69 \%$ & FALSE \\
\hline$\$ 150,000$ to $\$ 199,999$ & $5.39 \%$ & $5.24 \%$ & FALSE \\
\hline$\$ 200,000$ or more & $6.80 \%$ & $6.72 \%$ & FALSE \\
\hline
\end{tabular}


Table 10. Share of Total Income and Total PM 2.5 Health Burden, for LUR Year 2013

\begin{tabular}{|c|c|c|c|}
\hline $\begin{array}{l}\text { 12-month Household } \\
\text { Income range }\end{array}$ & $\begin{array}{l}\text { Share of total } \\
\text { income (\%) }\end{array}$ & $\begin{array}{l}\text { Share of total } \mathrm{PM}_{2.5} \\
\text { health burden (\%) }\end{array}$ & $\begin{array}{c}\text { Health burden share } \\
>\text { income share }\end{array}$ \\
\hline Less than $\$ 10,000$ & $10.40 \%$ & $10.93 \%$ & TRUE \\
\hline$\$ 10,000$ to $\$ 14,999$ & $6.11 \%$ & $6.36 \%$ & TRUE \\
\hline$\$ 15,000$ to $\$ 19,999$ & $5.51 \%$ & $5.62 \%$ & TRUE \\
\hline$\$ 20,000$ to $\$ 24,999$ & $5.19 \%$ & $5.26 \%$ & TRUE \\
\hline$\$ 25,000$ to $\$ 29,999$ & $4.62 \%$ & $4.65 \%$ & TRUE \\
\hline$\$ 30,000$ to $\$ 34,999$ & $4.63 \%$ & $4.66 \%$ & TRUE \\
\hline$\$ 35,000$ to $\$ 39,999$ & $3.98 \%$ & $3.97 \%$ & FALSE \\
\hline$\$ 40,000$ to $\$ 44,999$ & $4.21 \%$ & $4.20 \%$ & FALSE \\
\hline$\$ 45,000$ to $\$ 49,999$ & $3.53 \%$ & $3.50 \%$ & FALSE \\
\hline$\$ 50,000$ to $\$ 59,999$ & $6.97 \%$ & $6.90 \%$ & FALSE \\
\hline$\$ 60,000$ to $\$ 74,999$ & $8.74 \%$ & $8.61 \%$ & FALSE \\
\hline$\$ 75,000$ to $\$ 99,999$ & $10.93 \%$ & $10.67 \%$ & FALSE \\
\hline$\$ 100,000$ to $\$ 124,999$ & $7.71 \%$ & $7.52 \%$ & FALSE \\
\hline$\$ 125,000$ to $\$ 149,999$ & $4.88 \%$ & $4.77 \%$ & FALSE \\
\hline$\$ 150,000$ to $\$ 199,999$ & $5.55 \%$ & $5.38 \%$ & FALSE \\
\hline$\$ 200,000$ or more & $7.04 \%$ & $7.02 \%$ & FALSE \\
\hline
\end{tabular}


Table 11. Share of Total Income and Total PM2.5 Health Burden, for LUR Year 2014

\begin{tabular}{|c|c|c|c|}
\hline $\begin{array}{l}\text { 12-month Household } \\
\text { Income range }\end{array}$ & $\begin{array}{l}\text { Share of total } \\
\text { income (\%) }\end{array}$ & $\begin{array}{c}\text { Share of total } \mathrm{PM}_{2.5} \\
\text { health burden (\%) }\end{array}$ & $\begin{array}{c}\text { Health burden share } \\
>\text { income share }\end{array}$ \\
\hline Less than $\$ 10,000$ & $10.28 \%$ & $10.79 \%$ & TRUE \\
\hline$\$ 10,000$ to $\$ 14,999$ & $6.20 \%$ & $6.46 \%$ & TRUE \\
\hline$\$ 15,000$ to $\$ 19,999$ & $5.53 \%$ & $5.62 \%$ & TRUE \\
\hline$\$ 20,000$ to $\$ 24,999$ & $5.11 \%$ & $5.18 \%$ & TRUE \\
\hline$\$ 25,000$ to $\$ 29,999$ & $4.56 \%$ & $4.58 \%$ & TRUE \\
\hline$\$ 30,000$ to $\$ 34,999$ & $4.47 \%$ & $4.49 \%$ & TRUE \\
\hline$\$ 35,000$ to $\$ 39,999$ & $4.04 \%$ & $4.04 \%$ & TRUE \\
\hline$\$ 40,000$ to $\$ 44,999$ & $4.14 \%$ & $4.13 \%$ & FALSE \\
\hline$\$ 45,000$ to $\$ 49,999$ & $3.42 \%$ & $3.40 \%$ & FALSE \\
\hline$\$ 50,000$ to $\$ 59,999$ & $6.82 \%$ & $6.75 \%$ & FALSE \\
\hline$\$ 60,000$ to $\$ 74,999$ & $8.67 \%$ & $8.55 \%$ & FALSE \\
\hline$\$ 75,000$ to $\$ 99,999$ & $11.00 \%$ & $10.76 \%$ & FALSE \\
\hline$\$ 100,000$ to $\$ 124,999$ & $7.71 \%$ & $7.52 \%$ & FALSE \\
\hline$\$ 125,000$ to $\$ 149,999$ & $4.98 \%$ & $4.87 \%$ & FALSE \\
\hline$\$ 150,000$ to $\$ 199,999$ & $5.74 \%$ & $5.59 \%$ & FALSE \\
\hline$\$ 200,000$ or more & $7.33 \%$ & $7.26 \%$ & FALSE \\
\hline
\end{tabular}


Table 12. Share of Total Income and Total PM2.5 Health Burden, for LUR Year 2015

\begin{tabular}{|c|c|c|c|}
\hline $\begin{array}{l}\text { 12-month Household } \\
\text { Income range }\end{array}$ & $\begin{array}{l}\text { Share of total } \\
\text { income (\%) }\end{array}$ & $\begin{array}{l}\text { Share of total } \mathrm{PM}_{2.5} \\
\text { health burden (\%) }\end{array}$ & $\begin{array}{c}\text { Health burden share } \\
>\text { income share }\end{array}$ \\
\hline Less than $\$ 10,000$ & $10.36 \%$ & $10.92 \%$ & TRUE \\
\hline$\$ 10,000$ to $\$ 14,999$ & $6.08 \%$ & $6.38 \%$ & TRUE \\
\hline$\$ 15,000$ to $\$ 19,999$ & $5.47 \%$ & $5.60 \%$ & TRUE \\
\hline$\$ 20,000$ to $\$ 24,999$ & $5.06 \%$ & $5.12 \%$ & TRUE \\
\hline$\$ 25,000$ to $\$ 29,999$ & $4.44 \%$ & $4.49 \%$ & TRUE \\
\hline$\$ 30,000$ to $\$ 34,999$ & $4.42 \%$ & $4.45 \%$ & TRUE \\
\hline$\$ 35,000$ to $\$ 39,999$ & $4.04 \%$ & $4.06 \%$ & TRUE \\
\hline$\$ 40,000$ to $\$ 44,999$ & $4.00 \%$ & $4.01 \%$ & TRUE \\
\hline$\$ 45,000$ to $\$ 49,999$ & $3.37 \%$ & $3.36 \%$ & FALSE \\
\hline$\$ 50,000$ to $\$ 59,999$ & $6.70 \%$ & $6.65 \%$ & FALSE \\
\hline$\$ 60,000$ to $\$ 74,999$ & $8.79 \%$ & $8.69 \%$ & FALSE \\
\hline$\$ 75,000$ to $\$ 99,999$ & $10.89 \%$ & $10.65 \%$ & FALSE \\
\hline$\$ 100,000$ to $\$ 124,999$ & $7.83 \%$ & $7.62 \%$ & FALSE \\
\hline$\$ 125,000$ to $\$ 149,999$ & $4.98 \%$ & $4.85 \%$ & FALSE \\
\hline$\$ 150,000$ to $\$ 199,999$ & $5.86 \%$ & $5.67 \%$ & FALSE \\
\hline$\$ 200,000$ or more & $7.69 \%$ & $7.49 \%$ & FALSE \\
\hline
\end{tabular}


Table 13. Share of Total Income and Total PM2.5 Health Burden, for LUR Year 2016

\begin{tabular}{|c|c|c|c|}
\hline $\begin{array}{l}\text { 12-month Household } \\
\text { Income range }\end{array}$ & $\begin{array}{l}\text { Share of total } \\
\text { income (\%) }\end{array}$ & $\begin{array}{c}\text { Share of total } \mathrm{PM}_{2.5} \\
\text { health burden (\%) }\end{array}$ & $\begin{array}{c}\text { Health burden share } \\
>\text { income share }\end{array}$ \\
\hline Less than $\$ 10,000$ & $10.14 \%$ & $10.65 \%$ & TRUE \\
\hline$\$ 10,000$ to $\$ 14,999$ & $5.95 \%$ & $6.25 \%$ & TRUE \\
\hline$\$ 15,000$ to $\$ 19,999$ & $5.34 \%$ & $5.46 \%$ & TRUE \\
\hline$\$ 20,000$ to $\$ 24,999$ & $4.82 \%$ & $4.87 \%$ & TRUE \\
\hline$\$ 25,000$ to $\$ 29,999$ & $4.37 \%$ & $4.39 \%$ & TRUE \\
\hline$\$ 30,000$ to $\$ 34,999$ & $4.37 \%$ & $4.38 \%$ & TRUE \\
\hline$\$ 35,000$ to $\$ 39,999$ & $3.98 \%$ & $3.97 \%$ & FALSE \\
\hline$\$ 40,000$ to $\$ 44,999$ & $3.91 \%$ & $3.90 \%$ & FALSE \\
\hline$\$ 45,000$ to $\$ 49,999$ & $3.24 \%$ & $3.23 \%$ & FALSE \\
\hline$\$ 50,000$ to $\$ 59,999$ & $6.62 \%$ & $6.56 \%$ & FALSE \\
\hline$\$ 60,000$ to $\$ 74,999$ & $8.74 \%$ & $8.63 \%$ & FALSE \\
\hline$\$ 75,000$ to $\$ 99,999$ & $10.99 \%$ & $10.77 \%$ & FALSE \\
\hline$\$ 100,000$ to $\$ 124,999$ & $8.01 \%$ & $7.81 \%$ & FALSE \\
\hline$\$ 125,000$ to $\$ 149,999$ & $5.18 \%$ & $5.06 \%$ & FALSE \\
\hline$\$ 150,000$ to $\$ 199,999$ & $6.13 \%$ & $5.96 \%$ & FALSE \\
\hline$\$ 200,000$ or more & $8.21 \%$ & $8.10 \%$ & FALSE \\
\hline
\end{tabular}




\section{Appendix 4: Marginal Health Benefits for Secondary PM 2.5 Concentrations}

Results are shown for the impact of $\mathrm{SO}_{2}$ emissions on the formation of secondary $\mathrm{PM}_{2.5}$. The marginal health benefits from $\mathrm{SO}_{2}$ emission reductions at each location are shown in Figure 37. The marginal health benefits are reported in $\$ 1,000$ 's for a reduction of $\mathrm{SO}_{2}$ emissions by 1 tonne/year, and represent the annual health benefits from reduced mortality from chronic $\mathrm{PM}_{2.5}$ exposure experienced across the domain.

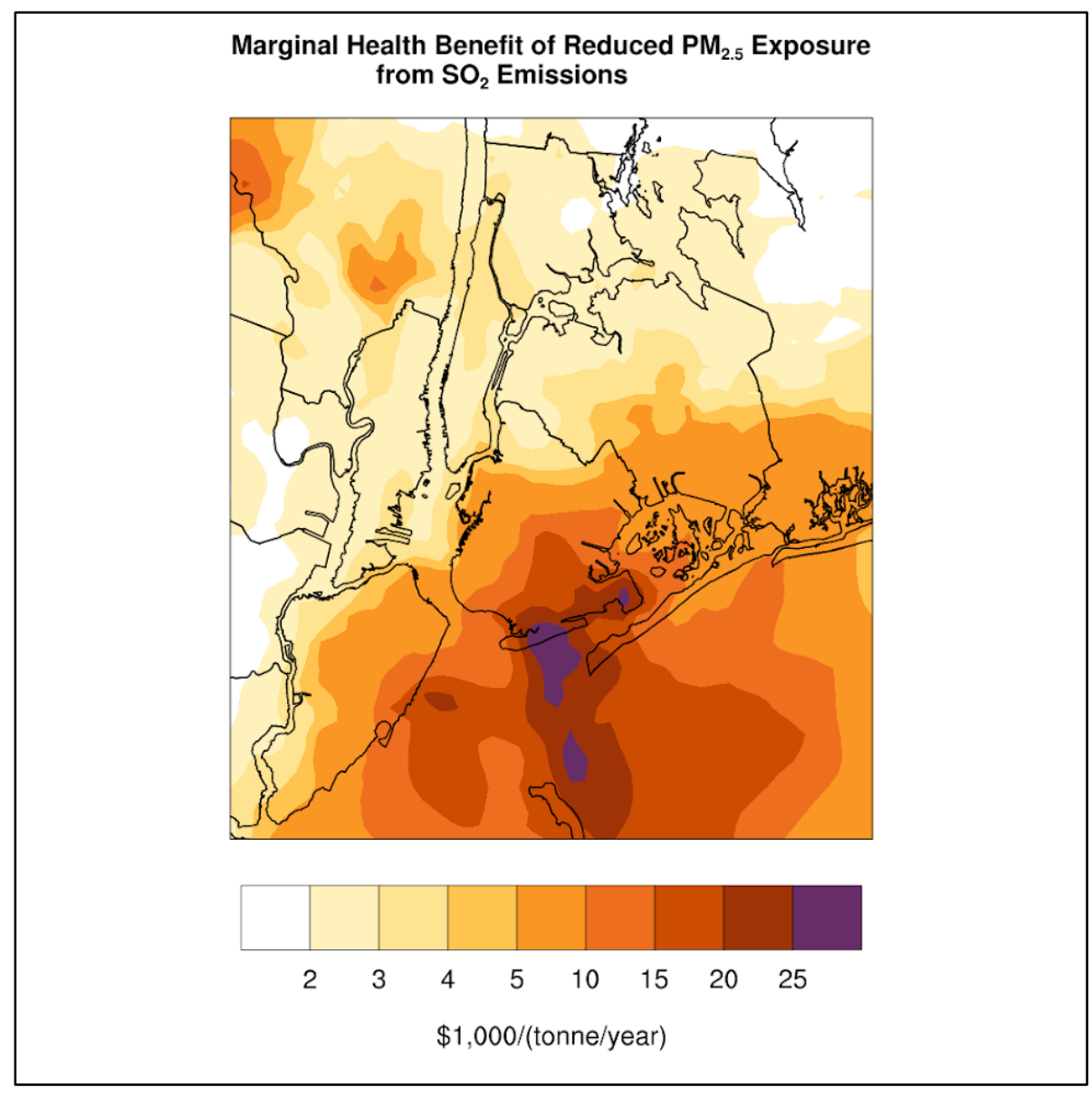

Figure 37. Marginal Health Benefits from individual locations for a 1 tonne/year reduction in $\mathrm{SO} 2$ emissions. 